\title{
External knowledge transfer deployment inside a simple double agent Viterbi algorithm
}

\author{
Zied Baklouti*†
}

August 2021

\begin{abstract}
We consider in this paper deploying external knowledge transfer inside a simple double agent Viterbi algorithm which is an algorithm firstly introduced by the author in his preprint "Hidden Markov Based Mathematical Model dedicated to Extract Ingredients from Recipe Text" Baklouti 2019, September 4). The key challenge of this work lies in discovering the reason why our old model does have bad performances when it is confronted with estimating ingredient state for unknown words and see if deploying external knowledge transfer directly on calculating state matrix could be the solution instead of deploying it only on back propagating step.
\end{abstract}

\section{Introduction}

Extracting ingredients from a recipe text is a very common activity especially for data scientists and developers who want to study recipes or want to make statistical representations about nutritive values of cuisine recipes. Ingredients is not the only useful information we want to extract, the quantity used for each ingredient and how they are prepared are also interesting informations that we can extract by the same method presented in this work. Hidden Markov Models are the first idea that came in my mind because there are previous successful works that used this method for information extraction ( $($ Freitag \& McCallum, 2000),(Freitag \& McCallum, 1999), (Seymore, McCallum, Rosenfeld, et al. , 1999),(Bikel, Miller, Schwartz, \& Weischedel, 1998),(Leek, 1997)), and also because modeling sequences of words where we have to estimate the hidden state is typically a hidden Markov procedure. In this work we are concentrating on the external knowledge part deployed in what we called a simple double agent Viterbi algorithm.

\footnotetext{
${ }^{*}$ Corresponding author: ziedbaklouti.ing.math@gmail.com

${ }^{\dagger} \mathrm{MSc}$ computer science and mathematics, Paris University
} 


\section{Previous work}

We used Named Entity recognition as a subtask of information extraction to extract ingredients, HMM are widely used to perform named entity recognition (Morwal, Jahan, \& Chopra, 2012) but in its basic technology , HMM is not able to incorporate external knowledge, this is why we developed on this work an advanced Viterbi algorithm to consider POS tags as an external knowledge playing an active role in calculating the state matrix. The major modification made are explained in (Baklouti, 2019, September 4) . Extracting ingredients help developers creating recipe recommendation systems, but not only ingredients are targeted in a text recipe, quantities deployed inside a recipes and cooking techniques are useful information to construct a hybrid recommendation system (Shah, Gaudani, \& Balani, 2016) (Ueda, Asanuma, Miyawaki, \& Nakajima, 2014 and incorporating POS tags as an external knowledge will help definitely creating more performant hybrid recommendation systems.

Methodologies for transfer learning varies according to the model's task, for example for image classification layers in a neural network may be involved in recognizing specific features and by knowledge transfer we don't have to retrain those layers in medical images to relearn those specific features (Zhu et al. 2011). Our bigger part of our methodology is explained in (Baklouti, 2019, September 4), in this paper we are going to make some modification in iteration step to take maximum advantage of already estimated knowledge, in our case already estimated knowledge are POS tags.

\section{Methodology}

When observing the equations calculating the elements of the state matrix for a second order mono-agent Viterbi algorithm and compare it with the algorithm used in an ingredient extractor (Baklouti, 2019, September 4), we found an interesting property that kept the second order mono-layered Viterbi more precise in the context of unknown words, in other words when the probability $b_{i j}\left(v_{k}\right)=P\left(V_{r}=v_{k} / \Gamma_{r}=\gamma_{j}, T_{r}=\tau_{i}\right)$ is losing its efficiency behind an unknown word, the algorithm used for an ingredient extractor couldn't rely on the other probabilities inside the equations that determines a state matrix. In order to discover the property in second order Viterbi HMM, we created a table of cases constituted with the list of tokens constituting a sentence and we fill it with the parameters inside the lexical probability and the contextual probability for the most probable cases inside a state matrix $\delta$. For example, for the sentence 'زيت زيتون من النوعية الجيدة ', we want to create its situations table for the token الجيدة, we search first for the most probable cases revealed by the higher values of the state matrix $\delta$, the segment of the matrix $\delta_{6}$ reveals 3 most probables cases : first case the token الجيدة is not an ingredient, second case the token الجيدة is an ingredient and it is extracted alone, the third case the token الجيدة is a part of an ingredient composed with two words and the word is the second word of that ingredient. In order to calculate one element 
of a matrix state $\delta_{i}$ for a mono-layered Viterbi algorithm, the algorithm choose one element of the precedent segment $\delta_{i-1}$ of the state matrix and add it with the corresponding lexical probability and transitional probability. We dressed a 3 situations tables for the most probable situations revealed by the higher elements of the state matrix filled with the parameters of those specific probabilities. After dressing the situations tables, we can distinguish between two kind of probabilities:

- A sane probability: showing an existing case, for example the probability $P\left(\Gamma_{r}=0 / \Gamma_{r-1}=0, \Gamma_{r-2}=0\right)$ used in Table 1 calculating $\delta_{6}(1,1)$ in equation 2 one of the highest elements of matrix 1 is a sane probability because we are supposing that the token in position $r-1$ is not an ingredient $\left(\Gamma_{r-1}=0\right)$ and the estimation obtained from the backtracking step for the token in position $\mathrm{r}$ is true $\left(\Gamma_{r}=0\right)$, and the estimation of the ingredient state for the token in position $r-2$ obtained from the mathematical expression $\max _{1 \leq i \leq 4}\left(\delta_{5}(i, 2)+\log \left(P\left(\Gamma_{r}=0 / \Gamma_{r-1}=1, \Gamma_{r-2}=\gamma_{i}\right)\right)\right.$ in equation 2 is true $\left(\bar{\Gamma}_{r-2}=0\right)$.

- An insane or a parasite probability: showing a non existing case, for example the probability $P\left(\Gamma_{r}=0 / \Gamma_{r-1}=2, \Gamma_{r-2}=1\right)$ in Table 3 used in calculating $\delta_{6}(1,3)$ in equation 4 is a parasite probability because we are supposing that the token in position $r-1$ is the second word of an ingredient $\left(\Gamma_{r-1}=2\right)$ and the estimation obtained from the backtracking step for the token in position $\mathrm{r}$ is the real value of the token in position $r\left(\Gamma_{r}=0\right)$, and the estimation of the ingredient state for the token in position $r-2$ obtained from the mathematical expression $\max _{1 \leq i \leq 4}\left(\delta_{5}(i, 3)+\log \left(P\left(\Gamma_{r}=0 / \Gamma_{r-1}=2, \Gamma_{r-2}=\gamma_{i}\right)\right)\right.$ in equation 4 is the real value of the token in position $r-2\left(\Gamma_{r-2}=1\right)$, the first word of an ingredient.

We are supposing that a "good" algorithm is an algorithm were there is the least possible parasite probabilities in its most probable state matrix calculations and we are going to try to ameliorate our ingredient extractor in that way and see if this hypothesis is a valid hypothesis by experimentation. 
Estimating an ingredient state using a second order HMM model:

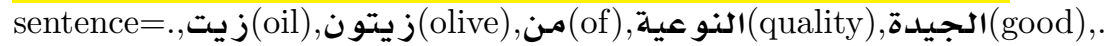
ingredient state $=[0,1,2,0,0,0,0]$

زيت زيتون=ingredient to be extracted

$$
\begin{aligned}
& \delta_{6}(i, j)=\left[\begin{array}{cccc}
-41.8209 & -46.5677 & -53.3321 & -54.4383 \\
-41.0199 & -53.0687 & -47.9396 & -54.175 \\
-41.6138 & -53.0402 & -53.4034 & -51.8439 \\
-55.8817 & -56.4674 & -56.1374 & -55.9642
\end{array}\right] \\
& \delta_{6}(1,1)=\max _{1 \leq i \leq 4}\left(\delta_{5}(i, 1)+\log \left(a_{i 11}\right)\right)+\log \left(b_{11}(" . .)\right) \\
& =\max _{1 \leq i \leq 4}\left(\delta_{5}(i, 1)+\log \left(P\left(\Gamma_{r}=0 / \Gamma_{r-1}=0, \Gamma_{r-2}=\gamma_{i}\right)\right)\right) \\
& +\log \left(P\left(V_{r}=" . " / \Gamma_{r}=0, \Gamma_{r-1}=0\right)\right) \\
& =\underbrace{\delta_{5}(1,1)}_{-38.13}+\underbrace{\log \left(P\left(\Gamma_{r}=0 / \Gamma_{r-1}=0, \Gamma_{r-2}=0\right)\right)}_{-0.832} \\
& +\underbrace{\log \left(P\left(V_{r}=" . " / \Gamma_{r}=0, \Gamma_{r-1}=0\right)\right)}_{-2.85} \\
& =-41.82
\end{aligned}
$$

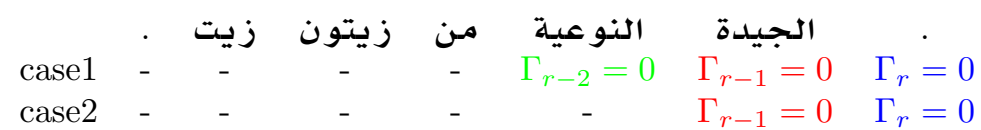

Table 1: situations table for $\delta_{6}(1,1)$ for a second order HMM estimation with all the words are known. The probabilities $P\left(\Gamma_{r}=0 / \Gamma_{r-1}=0, \Gamma_{r-2}=0\right)$ and $P\left(V_{r}=" . " / \Gamma_{r}=0, \Gamma_{r-1}=0\right)$ are describing existing cases from the tagged sentence, they are not parasite probabilities.

$$
\begin{aligned}
\delta_{6}(2,1) & =\max _{1 \leq i \leq 4}\left(\delta_{5}(i, 2)+\log \left(a_{i 21}\right)\right)+\log \left(b_{21}(" . ")\right) \\
& =\max _{1 \leq i \leq 4}\left(\delta_{5}(i, 2)+\log \left(P\left(\Gamma_{r}=0 / \Gamma_{r-1}=1, \Gamma_{r-2}=\gamma_{i}\right)\right)\right. \\
& +\log \left(P\left(V_{r}=" . " / \Gamma_{r}=0, \Gamma_{r-1}=1\right)\right) \\
& =\underbrace{\delta_{5}(1,2)}_{-38.43}+\underbrace{\log \left(P\left(\Gamma_{r}=0 / \Gamma_{r-1}=1, \Gamma_{r-2}=0\right)\right)}_{-0.351} \\
& +\underbrace{\log \left(P\left(V_{r}=" . " / \Gamma_{r}=0, \Gamma_{r-1}=1\right)\right)}_{-2.238} \\
& =-41.0199
\end{aligned}
$$




\begin{tabular}{|c|c|c|c|c|c|}
\hline & زيت & زيتون & من & النو عيـة & الجيدة \\
\hline case & - & - & 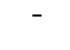 & $\Gamma_{r-2}=0$ & $\Gamma_{r-1}=1$ \\
\hline & - & - & - & - & $\Gamma_{r-1}=1$ \\
\hline
\end{tabular}

Table 2: Situations table for $\delta_{6}(1,2)$ for a second order HMM estimation. The probabilities $P\left(\Gamma_{r}=0 / \Gamma_{r-1}=1, \Gamma_{r-2}=0\right)$ and $P\left(V_{r}=" . " / \Gamma_{r}=0, \Gamma_{r-1}=1\right)$ are describing existing cases from the tagged sentence, supposing that the word is an ingredient. These probabilities are not parasite probabilities.

$$
\begin{aligned}
& \delta_{6}(3,1)=\max _{1 \leq i \leq 4}\left(\delta_{5}(i, 3)+\log \left(a_{i 31}\right)\right)+\log \left(b_{31}(" . ")\right) \\
& =\max _{1 \leq i \leq 4}\left(\delta_{5}(i, 3)+\log \left(P\left(\Gamma_{r}=0 / \Gamma_{r-1}=2, \Gamma_{r-2}=\gamma_{i}\right)\right)\right. \\
& +\log \left(P\left(V_{r}=" . " / \Gamma_{r}=0, \Gamma_{r-1}=2\right)\right) \\
& =\underbrace{\delta_{5}(2,3)}_{-38.7}+\underbrace{\log \left(P\left(\Gamma_{r}=0 / \Gamma_{r-1}=2, \Gamma_{r-2}=1\right)\right)}_{-0.043} \\
& +\underbrace{\log \left(P\left(V_{r}=" . " / \Gamma_{r}=0, \Gamma_{r-1}=2\right)\right)}_{-2.866} \\
& =-41,61
\end{aligned}
$$

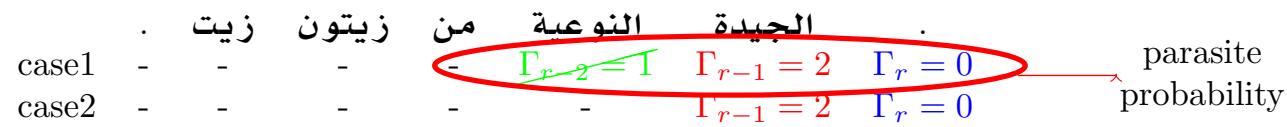

Table 3: Situations table for $\delta_{6}(3,1)$ for a second order HMM estimation. The probability $P\left(\Gamma_{r}=0 / \Gamma_{r-1}=2, \Gamma_{r-2}=1\right)$ is a parasite probability because $\Gamma_{r-2}=1$ is not the real state of the word النوعية and $P\left(V_{r}=\right.$ $\left." . " \Gamma_{r}=0, \Gamma_{r-1}=1\right)$ is not a parasite probability because it is describing an existing case from the tagged sentence after considering the word الجيدة as the second word of an ingredient.

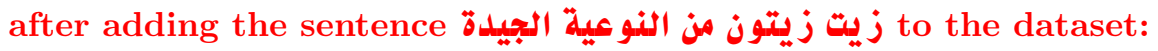

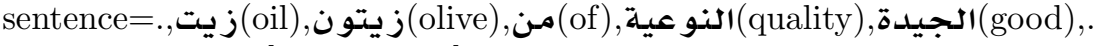
ingredient state $=[0,1,2,0,0,0,0]$

زيت زيتون=ئingredient to be extracted

$$
\delta_{6}(i, j)=\left[\begin{array}{llll}
-41.0035 & -45.7531 & -53.3305 & -53.6236 \\
-40.6117 & -52.6603 & -47.5296 & -53.7664 \\
-41.6097 & -53.0374 & -53.4007 & -51.8409 \\
-55.7362 & -56.3216 & -55.9917 & -55.8183
\end{array}\right]
$$




$$
\begin{aligned}
& \delta_{6}(1,1)=\max _{1 \leq i \leq 4}\left(\delta_{5}(i, 1)+\log \left(a_{i 11}\right)\right)+\log \left(b_{11}(" . ")\right) \\
& =\max _{1 \leq i \leq 4}\left(\delta_{5}(i, 1)+\log \left(P\left(\Gamma_{r}=0 / \Gamma_{r-1}=0, \Gamma_{r-2}=\gamma_{i}\right)\right)\right) \\
& +\log \left(P\left(V_{r}=" . " / \Gamma_{r}=0, \Gamma_{r-1}=0\right)\right) \\
& =\underbrace{\delta_{5}(1,1)}_{-37.314}+\underbrace{\log \left(P\left(\Gamma_{r}=0 / \Gamma_{r-1}=0, \Gamma_{r-2}=0\right)\right)}_{-0.831} \\
& +\underbrace{\log \left(P\left(V_{r}=" . " \Gamma_{r}=0, \Gamma_{r-1}=0\right)\right)}_{-2.8567} \\
& =-41.003 \\
& \begin{array}{cccccccc} 
& . & \text { النيدة } & & \\
\text { case1 } & - & - & - & - & \Gamma_{r-2}=0 & \Gamma_{r-1}=0 & \Gamma_{r}=0 \\
\text { case2 } & - & - & - & - & - & \Gamma_{r-1}=0 & \Gamma_{r}=0
\end{array}
\end{aligned}
$$

Table 4: situations table for $\delta_{6}(1,1)$ for a second order HMM estimation with زيت زيتون من النوعية الت الت الجيدة to the dataset. The probabilities $P\left(\Gamma_{r}=0 / \Gamma_{r-1}=0, \Gamma_{r-2}=0\right)$ and $P\left(\dot{V}_{r}=" . " \Gamma_{r}=0, \Gamma_{r-1}=0\right)$ are describing existing cases from the tagged sentence, they are not parasite probabilities.

$$
\begin{aligned}
\delta_{6}(2,1) & =\max _{1 \leq i \leq 4}\left(\delta_{5}(i, 2)+\log \left(a_{i 21}\right)\right)+\log \left(b_{21}(" . ")\right) \\
& =\max _{1 \leq i \leq 4}\left(\delta_{5}(i, 2)+\log \left(P\left(\Gamma_{r}=0 / \Gamma_{r-1}=1, \Gamma_{r-2}=\gamma_{i}\right)\right)\right. \\
& +\log \left(P\left(V_{r}=" . " / \Gamma_{r}=0, \Gamma_{r-1}=1\right)\right) \\
& =\underbrace{\delta_{5}(1,2)}_{-38.021}+\underbrace{\log \left(P\left(\Gamma_{r}=0 / \Gamma_{r-1}=1, \Gamma_{r-2}=0\right)\right)}_{-0.3517} \\
& +\underbrace{\log \left(P\left(V_{r}=" . " / \Gamma_{r}=0, \Gamma_{r-1}=1\right)\right)}_{-2.238} \\
& =-40.61 \\
\delta_{6}(3,1) & =\max _{1 \leq i \leq 4}\left(\delta_{5}(i, 3)+\log \left(a_{i 31}\right)\right)+\log \left(b_{31}(" . ")\right) \\
& =\max _{1 \leq i \leq 4}\left(\delta_{5}(i, 3)+\log \left(P\left(\Gamma_{r}=0 / \Gamma_{r-1}=2, \Gamma_{r-2}=\gamma_{i}\right)\right)\right. \\
& +\underbrace{\log \left(P\left(V_{r}=" . " \Gamma_{r}=0, \Gamma_{r-1}=2\right)\right)}_{-38.69} \\
& =\underbrace{\log \left(P\left(V_{r}=" . " / \Gamma_{r}=0, \Gamma_{r-1}=2\right)\right)}_{-0.0437} \\
& =-41.609
\end{aligned}
$$




\begin{tabular}{|c|c|c|c|c|c|}
\hline & زيت & زيتون & من & النو عيـة & الجيدة \\
\hline case & - & - & 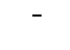 & $\Gamma_{r-2}=0$ & $\Gamma_{r-1}=1$ \\
\hline & - & - & - & - & $\Gamma_{r-1}=1$ \\
\hline
\end{tabular}

Table 5: Situations table for $\delta_{6}(2,1)$ for a second order HMM estimation with زيت زيتون من النوعية الت الت الجيدة to the dataset. The probabilities $P\left(\Gamma_{r}=0 / \Gamma_{r-1}=1, \Gamma_{r-2}=0\right)$ and $P\left(V_{r}=" . " \Gamma_{r}=0, \Gamma_{r-1}=1\right)$ are describing existing cases from the tagged sentence, supposing that the word الجيدة is an ingredient. These probabilities are not parasite probabilities.

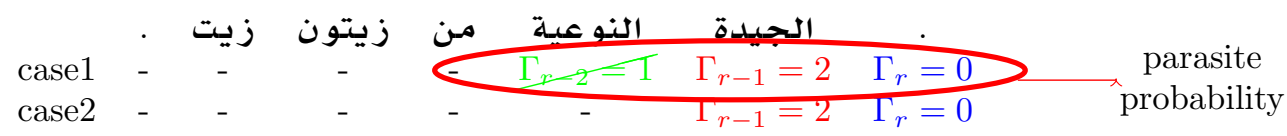

Table 6: Situations table for $\delta_{6}(3,1)$ for a second order HMM estimation with زيت زيتون من النوعية jentence the words are known after adding the senten to the dataset. The probability $P\left(\Gamma_{r}=0 / \Gamma_{r-1}=2, \Gamma_{r-2}=1\right)$ is a parasite probability because $\Gamma_{r-2}=1$ is not the real state of the word النوعيد and $P\left(V_{r}=" . " \Gamma_{r}=0, \Gamma_{r-1}=1\right)$ is not a parasite probability because it is describing an existing case from the tagged sentence after considering the word الجيدة as the second word of an ingredient.

after adding the sentence كعبة طماطم من الحجم الكبير to the dataset:

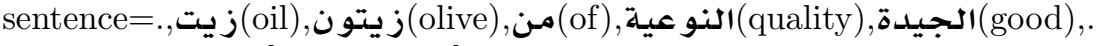
ingredient state $=[0,1,2,0,0,0,0]$

زيت زيتون=ي

$$
\begin{aligned}
& \delta_{6}(i, j)=\left[\begin{array}{llll}
-41.8278 & -46.5781 & -53.3457 & -54.4495 \\
-41.0313 & -53.0804 & -47.9504 & -54.1875 \\
-41.6249 & -53.0533 & -53.4171 & -51.8577 \\
-55.8946 & -56.4807 & -56.1513 & -55.9783
\end{array}\right] \\
\delta_{6}(1,1) & =\max _{1 \leq i \leq 4}\left(\delta_{5}(i, 1)+\log \left(a_{i 11}\right)\right)+\log \left(b_{11}(" . ")\right) \\
& =\max _{1 \leq i \leq 4}\left(\delta_{5}(i, 1)+\log \left(P\left(\Gamma_{r}=0 / \Gamma_{r-1}=0, \Gamma_{r-2}=\gamma_{i}\right)\right)\right) \\
& +\log \left(P\left(V_{r}=" . " / \Gamma_{r}=0, \Gamma_{r-1}=0\right)\right) \\
& =\underbrace{\delta_{5}(1,1)}_{-38.138}+\underbrace{\log \left(P\left(\Gamma_{r}=0 / \Gamma_{r-1}=0, \Gamma_{r-2}=0\right)\right)}_{-0.831} \\
& +\underbrace{\log \left(P\left(V_{r}=" . " / \Gamma_{r}=0, \Gamma_{r-1}=0\right)\right)}_{-2.857} \\
& =-41.827
\end{aligned}
$$




$\begin{array}{cccccccc} & . & \text { الجيدة } & & \\ \text { case1 } & - & - & - & - & \Gamma_{r-2}=0 & \Gamma_{r-1}=0 & \Gamma_{r}=0 \\ \text { case2 } & - & - & - & - & - & \Gamma_{r-1}=0 & \Gamma_{r}=0\end{array}$

Table 7: situations table for $\delta_{6}(1,1)$ for a second order HMM estimation with all the words are known after adding the sentence كعبة طماطهم من الحجه الكبير to the dataset. The probabilities $P\left(\Gamma_{r}=0 / \Gamma_{r-1}=0, \Gamma_{r-2}=0\right)$ and $P\left(V_{r}=\right.$ $\left." . " \Gamma_{r}=0, \Gamma_{r-1}=0\right)$ are describing existing cases from the tagged sentence, they are not parasite probabilities.

$$
\begin{aligned}
\delta_{6}(2,1) & =\max _{1 \leq i \leq 4}\left(\delta_{5}(i, 2)+\log \left(a_{i 21}\right)\right)+\log \left(b_{21}(" . ")\right) \\
& =\max _{1 \leq i \leq 4}\left(\delta_{5}(i, 2)+\log \left(P\left(\Gamma_{r}=0 / \Gamma_{r-1}=1, \Gamma_{r-2}=\gamma_{i}\right)\right)\right. \\
& +\log \left(P\left(V_{r}=" . " / \Gamma_{r}=0, \Gamma_{r-1}=1\right)\right) \\
& =\underbrace{\delta_{5}(1,2)}_{-38.44}+\underbrace{\log \left(P\left(\Gamma_{r}=0 / \Gamma_{r-1}=1, \Gamma_{r-2}=0\right)\right)}_{-0.3517} \\
& +\underbrace{\log \left(P\left(V_{r}=" . " \Gamma_{r}=0, \Gamma_{r-1}=1\right)\right)}_{-2.239} \\
& =-41.0312
\end{aligned}
$$

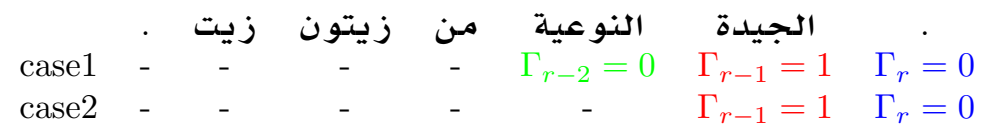

Table 8: Situations table for $\delta_{6}(2,1)$ for a second order HMM estimation with all the words are known after adding the sentence كعبة طماطم من الحجم الكبير to the dataset. The probabilities $P\left(\Gamma_{r}=0 / \Gamma_{r-1}=1, \Gamma_{r-2}=0\right)$ and $P\left(V_{r}=\right.$ $\left." . " \Gamma_{r}=0, \Gamma_{r-1}=1\right)$ are describing existing cases from the tagged sentence, supposing that the word الجيدة is an ingredient . These probabilities are not parasite probabilities.

$$
\begin{aligned}
\delta_{6}(3,1) & =\max _{1 \leq i \leq 4}\left(\delta_{5}(i, 3)+\log \left(a_{i 31}\right)\right)+\log \left(b_{31}(" . ")\right) \\
& =\max _{1 \leq i \leq 4}\left(\delta_{5}(i, 3)+\log \left(P\left(\Gamma_{r}=0 / \Gamma_{r-1}=2, \Gamma_{r-2}=\gamma_{i}\right)\right)\right. \\
& +\log \left(P\left(V_{r}=" . " / \Gamma_{r}=0, \Gamma_{r-1}=2\right)\right) \\
& =\underbrace{\delta_{5}(2,3)}_{-38.713}+\underbrace{\log \left(P\left(\Gamma_{r}=0 / \Gamma_{r-1}=2, \Gamma_{r-2}=1\right)\right)}_{-0.0437} \\
& +\underbrace{\log \left(P\left(V_{r}=" . " \Gamma_{r}=0, \Gamma_{r-1}=2\right)\right)}_{-2.867} \\
& =-41.6249
\end{aligned}
$$




\begin{tabular}{|c|c|c|c|c|c|c|c|c|}
\hline & - & زيت & زيتون & مـن & النو عيـة & الحجيلة & & \\
\hline case & - & - & - & $<$ & $\Gamma_{x-2}=I$ & $\Gamma_{r-1}=2$ & $\Gamma_{r}=0$ & parasite \\
\hline ase2 & - & - & - & - & & $T_{r-1}=2$ & $\Gamma_{r}=0$ & $\mathrm{pr}$ \\
\hline
\end{tabular}

Table 9: Situations table for $\delta_{6}(3,1)$ for a second order HMM estimation with all the words are known after adding the sentence كعبة طماطه من الحجه الكبير to the dataset. The probability $P\left(\Gamma_{r}=0 / \Gamma_{r-1}=2, \Gamma_{r-2}=1\right)$ is a parasite probability because $\Gamma_{r-2}=1$ is not the real state of the word النوعية and $P\left(V_{r}=" . " / \Gamma_{r}=0, \Gamma_{r-1}=2\right)$ is not a parasite probability because it is describing an existing case from the tagged sentence after considering the word الجيدة as the second word of an ingredient.

For a simple double agent Viterbi algorithm without external knowledge transfer, the parasite probabilities can easily infiltrate the most probable cases inside the equations of a state matrix . For example, for the sentence ' الجيدة الجيدة الجيدة shows three parasite probabilities, $P\left(\Gamma_{r}=0 / \Gamma_{r-1}=0, T_{r-1}=\right.$ "نع") in table 10 and $P\left(\Gamma_{r}=1 / \Gamma_{r-1}=0, T_{r-1}="\right.$ "نs $)$ in table 11 and $P\left(\Gamma_{r}=2 / \Gamma_{r-1}=\right.$ $3, T_{r-1}=$ " assume that the token الجيدة in position $r$ is considered as respectively a non ingredient $\Gamma_{r}=0$ or as an ingredient $\Gamma_{r}=1$ or a second word of an ingredient $\Gamma_{r}=2$ because the token in position $r-1$ haven't a POS tag of type نعت. In order to avoid the creation of parasite probability, we decided to use the information obtained in the first layer in calculating the elements of the state matrix, this operation is called external knowledge transfer. 
Estimating an ingredient state using a simple double agent Viterbi algorithm without unknown words consideration without external knowledge transfer:

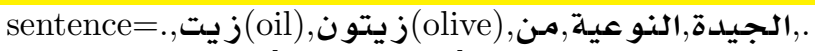

ingredient state $=[0,1,2,0,0,0,0]$

POS tags $=[., \mathrm{C}, \mathrm{D}, \mathrm{G}, \mathrm{E}, \mathrm{F},$.$] coded as [4,2,3,9,6,7,4]$

ingredient to be extracted=زيت زيتون

$$
\psi_{6}(i, j)=\left[\begin{array}{cccc}
0 & 0 & 1 & 1 \\
3 & 3 & 1 & 3 \\
2 & 0 & 3 & 3 \\
0 & 0 & 1 & 1 \\
0 & 0 & 0 & 0 \\
0 & 3 & 1 & 3 \\
0 & 0 & 0 & 0 \\
3 & 3 & 3 & 3 \\
3 & 3 & 3 & 3 \\
3 & 3 & 3 & 3 \\
3 & 3 & 3 & 3 \\
1 & 3 & 3 & 3 \\
3 & 3 & 3 & 3 \\
3 & 3 & 3 & 3
\end{array}\right]
$$

$$
\psi_{6}(7,1)=\operatorname{argmax}_{1 \leq i \leq 4}\left(\delta_{5}(7, i)+\log \left(a_{7 i 1}\right)\right)
$$

$$
\begin{aligned}
& \delta_{5}(7,1)+\log \left(a_{711}\right)=\max _{1 \leq i \leq 4}\left(\delta_{4}(7, i)+\log \left(a_{7 i 1}\right)\right)+\lambda_{\max } \log \left(b_{71}(" \text { "الجيدة" })\right)+\log \left(a_{711}\right) \\
& =\underbrace{\delta_{4}(7,1)}_{-134.9168}+\underbrace{\log \left(P\left(\Gamma_{r}=0 / \Gamma_{r-1}=0, T_{r-1}=" ن "\right)\right)}_{-2.717} \\
& +\underbrace{\lambda_{\max } \log \left(P\left(V_{r}=" \text { "الجيدة" } " \Gamma_{r}=0, T_{r}="\right)\right.}_{-36.629}
\end{aligned}
$$

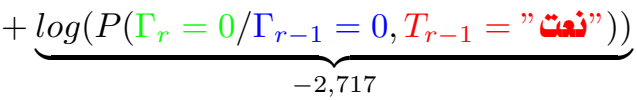

$$
\begin{aligned}
& =-176.982
\end{aligned}
$$




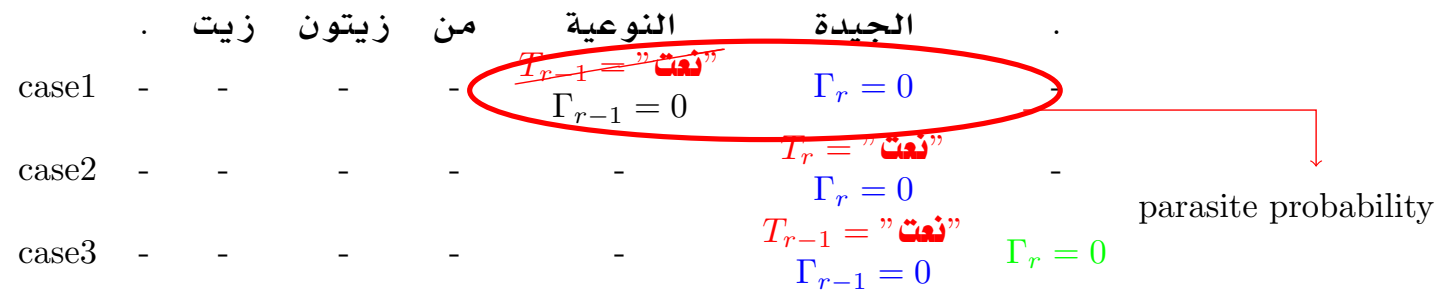

Table 10: situations table for $\delta_{5}(7,1)+\log \left(a_{711}\right)$ for a second order HMM estimation, the probability $P\left(\Gamma_{r}=0 / \Gamma_{r-1}=0, T_{r-1}=\right.$ "نعت because the POS tag of the word منعوت is النوعية and not نعت

$$
\begin{aligned}
& \delta_{5}(7,2)+\log \left(a_{721}\right)=\max _{1 \leq i \leq 4}\left(\delta_{4}(7, i)+\log \left(a_{7 i 2}\right)\right)+\lambda_{\max } \log \left(b_{72}(" \text { "الجيدة") })+\log \left(a_{721}\right)\right. \\
& =\underbrace{\delta_{4}(7,1)}_{-134.916}+\underbrace{\log \left(P\left(\Gamma_{r}=1 / \Gamma_{r-1}=0, T_{r-1}=" \dot{ن} "\right)\right)}_{-3.487} \\
& +\underbrace{\lambda_{\max } \log \left(P\left(V_{r}=" \text { الجيلةة" } " \Gamma_{r}=1, T_{r}="\right)\right.}_{-38.016} \\
& +\underbrace{\log \left(P\left(\Gamma_{r}=0 / \Gamma_{r-1}=1, T_{r-1}=" \text { "ن" }\right)\right)}_{-6.583} \\
& =-183
\end{aligned}
$$

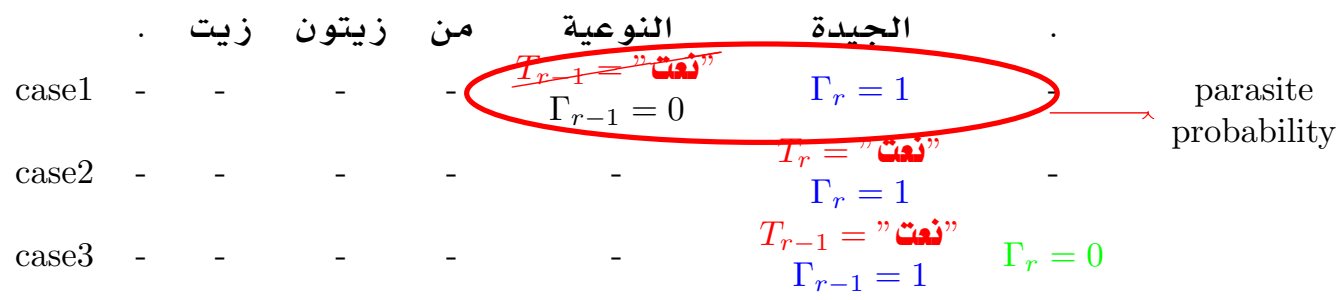

Table 11: situations table for $\delta_{5}(7,2)+\log \left(a_{721}\right)$ for a second order HMM estima-

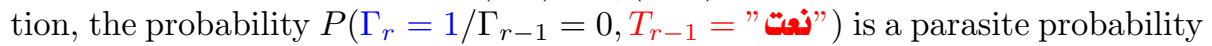
because the POS tag of the word منعوت is النو عية and not نعت 


$$
\begin{aligned}
& \delta_{5}(7,3)+\log \left(a_{731}\right)=\max _{1 \leq i \leq 4}\left(\delta_{4}(7, i)+\log \left(a_{7 i 3}\right)\right)+\lambda_{\max } \log \left(b_{73}(" \text { "الجيل ") })\right)+\log \left(a_{731}\right) \\
& =\underbrace{\delta_{4}(7,3)}_{-137.789}+\underbrace{\log \left(P\left(\Gamma_{r}=2 / \Gamma_{r-1}=3, T_{r-1}=" ن "\right)\right)}_{-4.077} \\
& +\underbrace{\lambda_{\max } \log \left(P\left(V_{r}=" \text { الجيدة" } " \Gamma_{r}=2, T_{r}=" ن\right)\right.}_{-37.541} \\
& +\underbrace{\log \left(P\left(\Gamma_{r}=0 / \Gamma_{r-1}=2, T_{r-1}=" \dot{*} "\right)\right)}_{-0.851} \\
& =-180.259
\end{aligned}
$$

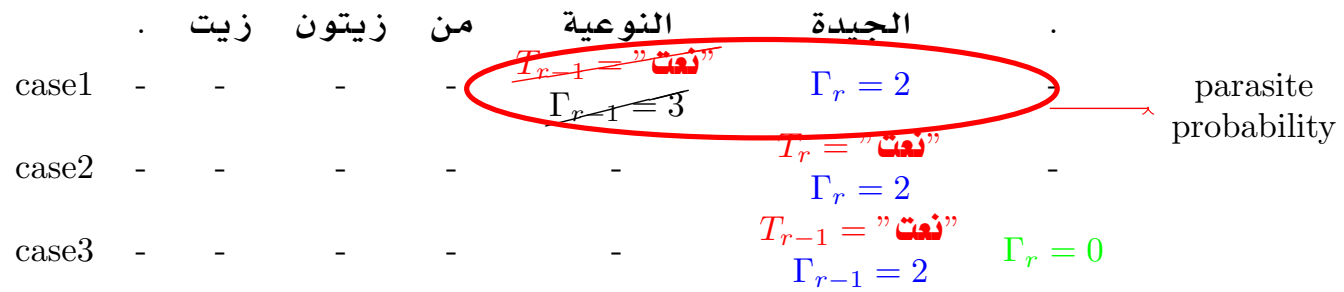

Table 12: situations table for $\delta_{5}(7,3)+\log \left(a_{731}\right)$ for a second order HMM estimation, the probability $P\left(\Gamma_{r}=2 / \Gamma_{r-1}=3, T_{r-1}=\right.$ "نعتص because the POS tag of the word منعوت is and not نعت النو عية 
after adding the sentence زيت زيتون من النوعية الجيلة to the dataset:

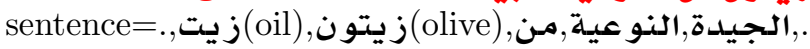

ingredient state $=[0,1,2,0,0,0,0]$

POS tags $=[., \mathrm{C}, \mathrm{D}, \mathrm{G}, \mathrm{E}, \mathrm{F},$.$] coded as [4,2,3,9,6,7,4]$

ingredient to be extracted=زيت زيتون

$$
\psi_{6}(i, j)=\left[\begin{array}{cccc}
0 & 0 & 1 & 1 \\
3 & 3 & 1 & 3 \\
2 & 0 & 3 & 3 \\
0 & 0 & 1 & 1 \\
0 & 0 & 0 & 0 \\
0 & 3 & 1 & 3 \\
0 & 0 & 0 & 0 \\
3 & 3 & 3 & 3 \\
3 & 3 & 3 & 3 \\
3 & 3 & 3 & 3 \\
3 & 3 & 3 & 3 \\
1 & 3 & 3 & 3 \\
3 & 3 & 3 & 3 \\
3 & 3 & 3 & 3
\end{array}\right]
$$

$$
\begin{aligned}
& \psi_{6}(7,1)=\operatorname{argmax}_{1 \leq i \leq 4}\left(\delta_{5}(7, i)+\log \left(a_{7 i 1}\right)\right) \\
& \delta_{5}(7,1)+\log \left(a_{711}\right)=\max _{1 \leq i \leq 4}\left(\delta_{4}(7, i)+\log \left(a_{7 i 1}\right)\right)+\lambda_{\max } \log \left(b_{71}(" \text { "الجيدة" })\right)+\log \left(a_{711}\right) \\
& =\underbrace{\delta_{4}(7,1)}_{-134.9174}+\underbrace{\log \left(P\left(\Gamma_{r}=0 / \Gamma_{r-1}=0, T_{r-1}=" ن "\right)\right)}_{-2.7157} \\
& +\underbrace{\lambda_{\max } \log \left(P\left(V_{r}=" \text { "الجيدة" } / \Gamma_{r}=0, T_{r}="\right)\right.}_{-550086} \\
& +\underbrace{\log \left(P\left(\Gamma_{r}=0 / \Gamma_{r-1}=0, T_{r-1}=" ن ق ي "\right)\right)}_{-2.7157} \\
& =-175.357
\end{aligned}
$$




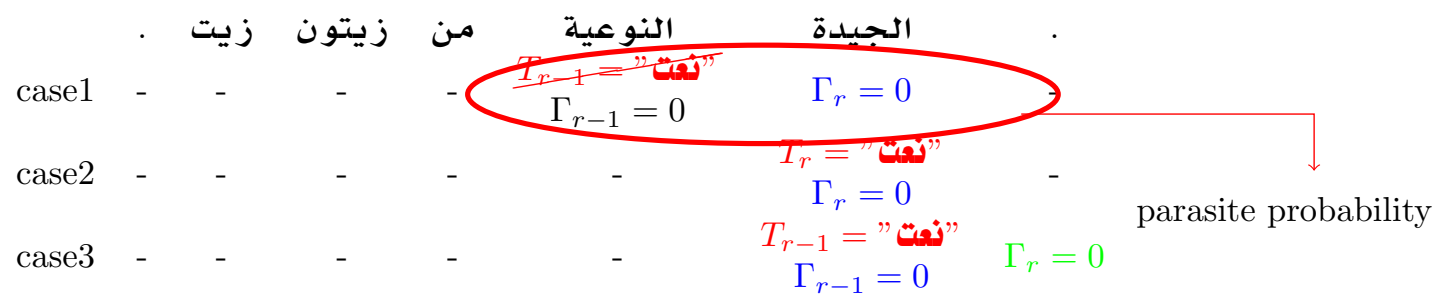

Table 13: situations table for $\delta_{5}(7,1)+\log \left(a_{711}\right)$ for a second order HMM estimation after adding the sentence زيت زيتون من النوعية الجيدة to the dataset

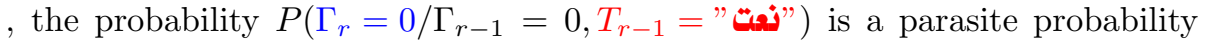
because the POS tag of the word منعوت is النوعية and not نعت

$$
\begin{aligned}
& \delta_{5}(7,2)+\log \left(a_{721}\right)=\max _{1 \leq i \leq 4}\left(\delta_{4}(7, i)+\log \left(a_{7 i 2}\right)\right)+\lambda_{\max } \log \left(b_{72}(" \text { "الجيدة") })+\log \left(a_{721}\right)\right. \\
& =\underbrace{\delta_{4}(7,1)}_{-134.917}+\underbrace{\log \left(P\left(\Gamma_{r}=1 / \Gamma_{r-1}=0, T_{r-1}=" \dot{*} "\right)\right)}_{-3.488} \\
& +\underbrace{\lambda_{\max } \log \left(P\left(V_{r}=" / \Gamma_{r}=1, T_{r}=" ن\right)\right.}_{-38.0165}
\end{aligned}
$$

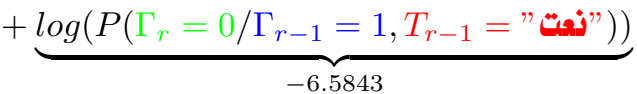

$$
\begin{aligned}
& =-183.006
\end{aligned}
$$

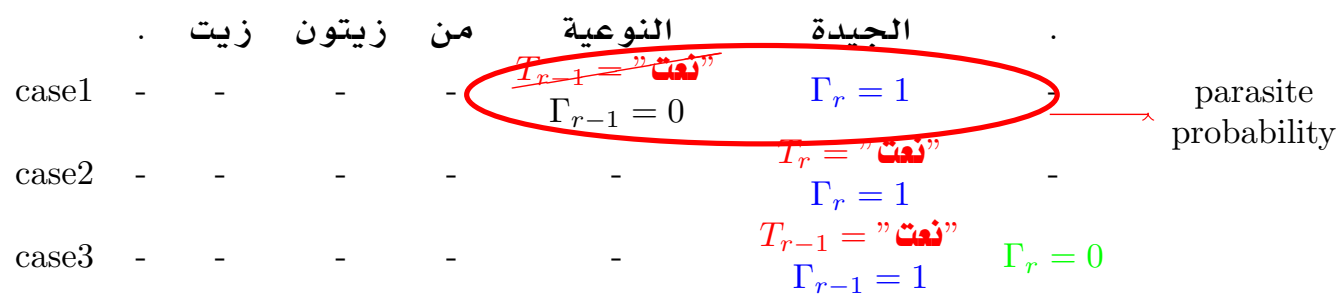

Table 14: situations table for $\delta_{5}(7,2)+\log \left(a_{721}\right)$ for a second order HMM estimation after adding the sentence زيت زيتون من النوعية الجيدة) to the dataset, the

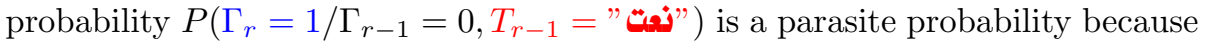
the POS tag of the word منعوت is النو عية and not نعت 


$$
\begin{aligned}
& \delta_{5}(7,3)+\log \left(a_{731}\right)=\max _{1 \leq i \leq 4}\left(\delta_{4}(7, i)+\log \left(a_{7 i 3}\right)\right)+\lambda_{\max } \log \left(b_{73}(" \text { "الجيل } ")\right)+\log \left(a_{731}\right) \\
& =\underbrace{\delta_{4}(7,3)}_{-137.7902}+\underbrace{\log \left(P\left(\Gamma_{r}=2 / \Gamma_{r-1}=3, T_{r-1}=" ن "\right)\right)}_{-4.0775} \\
& +\underbrace{\lambda_{\max } \log \left(P\left(V_{r}=" \text { "الجيلدة" } / \Gamma_{r}=2, T_{r}=" ن\right)\right.}_{-37.5415} \\
& +\underbrace{\log \left(P\left(\Gamma_{r}=0 / \Gamma_{r-1}=2, T_{r-1}=" \text { "ن" }\right)\right)}_{-0.8527} \\
& =-180.262
\end{aligned}
$$

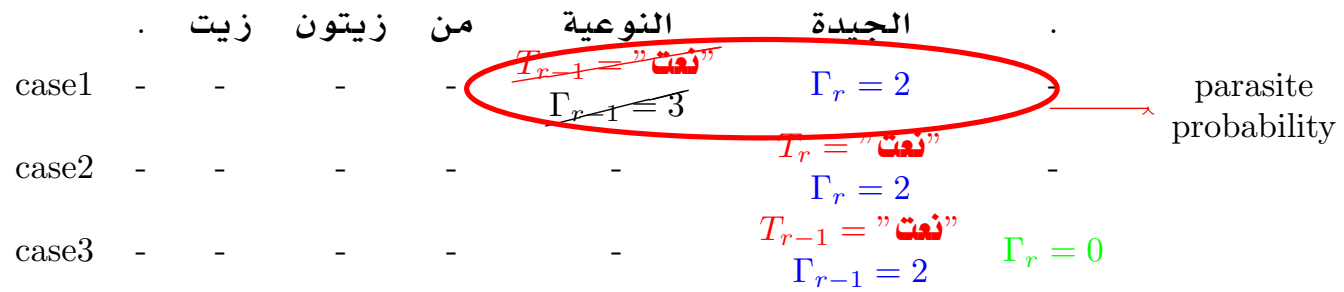

Table 15: situations table for $\delta_{5}(7,3)+\log \left(a_{731}\right)$ for a second order HMM estimation after adding the sentence زيت زيتون من النو عية الجيدة to the dataset,

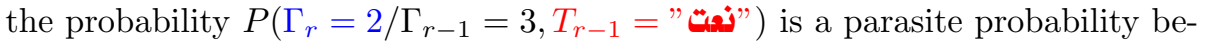
cause the POS tag of the word منعوت is النو عية and not نعت and the ingredient state of the word النوعية is $\Gamma_{r}=0$ and not $\Gamma_{r}=3$ 
after adding the sentence كمبة طماطم من الحجم الكبير to the dataset:

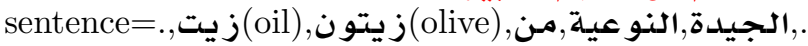

ingredient state $=[0,1,2,0,0,0,0]$

POS tags $=[., \mathrm{C}, \mathrm{D}, \mathrm{G}, \mathrm{E}, \mathrm{F},$.$] coded as [4,2,3,9,6,7,4]$

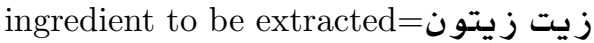

$$
\psi_{6}(i, j)=\left[\begin{array}{cccc}
0 & 0 & 1 & 1 \\
3 & 3 & 1 & 3 \\
2 & 0 & 3 & 3 \\
0 & 0 & 1 & 1 \\
0 & 0 & 0 & 0 \\
0 & 3 & 1 & 3 \\
0 & 0 & 0 & 0 \\
3 & 3 & 3 & 3 \\
3 & 3 & 3 & 3 \\
3 & 3 & 3 & 3 \\
3 & 3 & 3 & 3 \\
1 & 3 & 3 & 3 \\
3 & 3 & 3 & 3 \\
3 & 3 & 3 & 3
\end{array}\right]
$$

$$
\begin{aligned}
& \psi_{6}(7,1)=\operatorname{argmax}_{1 \leq i \leq 4}\left(\delta_{5}(7, i)+\log \left(a_{7 i 1}\right)\right) \\
& \delta_{5}(7,1)+\log \left(a_{711}\right)=\max _{1 \leq i \leq 4}\left(\delta_{4}(7, i)+\log \left(a_{7 i 1}\right)\right)+\lambda_{\max } \log \left(b_{71}(" \text { الجيدة" })\right)+\log \left(a_{711}\right) \\
& =\underbrace{\delta_{4}(7,1)}_{-134.9407}+\underbrace{\log \left(P\left(\Gamma_{r}=0 / \Gamma_{r-1}=0, T_{r-1}=" ن "\right)\right)}_{-2.7157} \\
& +\underbrace{\lambda_{\max } \log \left(P \left(V_{r}=" / \Gamma_{r}=0, T_{r}="\right.\right. \text { "نعيدة") }}_{-36.6363} \\
& +\underbrace{\log \left(P\left(\Gamma_{r}=0 / \Gamma_{r-1}=0, T_{r-1}=" ن ّ "\right)\right)}_{-2.7157} \\
& =-177.008
\end{aligned}
$$




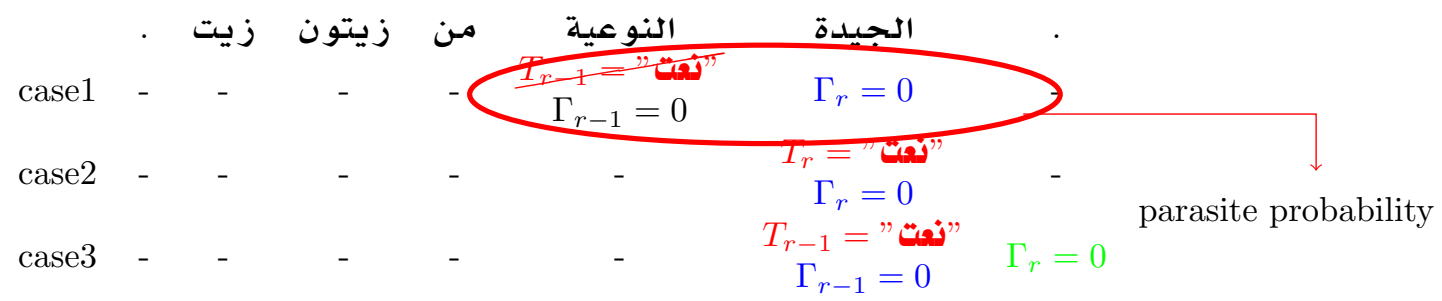

Table 16: situations table for $\delta_{5}(7,1)+\log \left(a_{711}\right)$ for a second order HMM estimation after adding the sentence كعبة طماطم من الحجم الكبير to the dataset, the

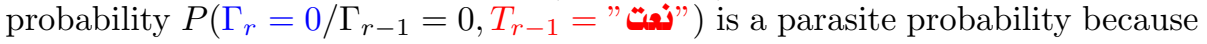
the POS tag of the word منعوت is النوعية and not نعت

$$
\begin{aligned}
& \delta_{5}(7,2)+\log \left(a_{721}\right)=\max _{1 \leq i \leq 4}\left(\delta_{4}(7, i)+\log \left(a_{7 i 2}\right)\right)+\lambda_{\max } \log \left(b_{72}(" \text { "الجيلة) })\right)+\log \left(a_{721}\right)
\end{aligned}
$$

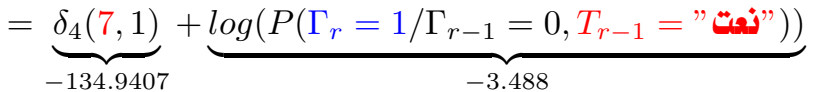

$$
\begin{aligned}
& +\underbrace{\lambda_{\max } \log \left(P\left(V_{r}=" \text { "لجيلة" } / \Gamma_{r}=1, T_{r}="\right)\right.}_{-38.02485} \\
& +\underbrace{\log \left(P\left(\Gamma_{r}=0 / \Gamma_{r-1}=1, T_{r-1}=" ن ّ "\right)\right)}_{-6.5843} \\
& =-183.0379
\end{aligned}
$$

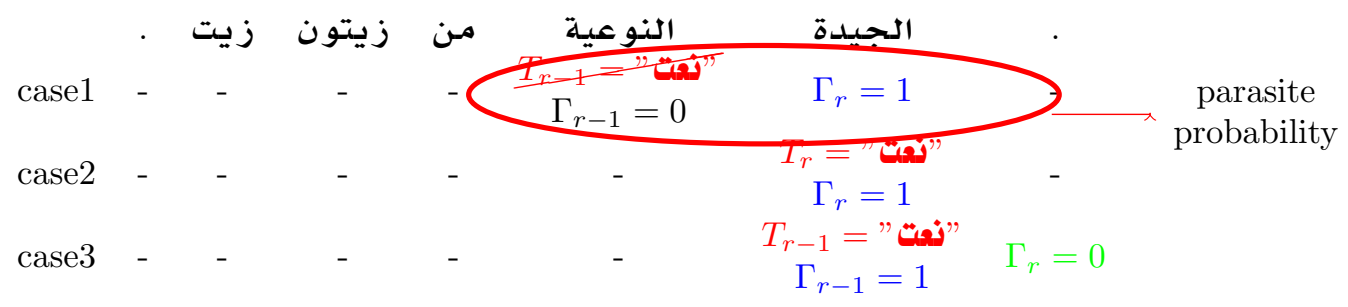

Table 17: situations table for $\delta_{5}(7,2)+\log \left(a_{721}\right)$ for a second order HMM estimation after adding the sentence كعبة طماطم من الحجم الكبير to the dataset, the

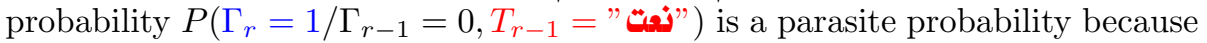
the POS tag of the word منعوت is النوعية and not نعت 


$$
\begin{aligned}
& \delta_{5}(7,3)+\log \left(a_{731}\right)=\max _{1 \leq i \leq 4}\left(\delta_{4}(7, i)+\log \left(a_{7 i 3}\right)\right)+\lambda_{\max } \log \left(b_{73}(" ا ل ج ي د ة ")\right)+\log \left(a_{731}\right) \\
& =\underbrace{\delta_{4}(7,3)}_{-137.8215}+\underbrace{\log \left(P\left(\Gamma_{r}=2 / \Gamma_{r-1}=3, T_{r-1}=" ن\right)\right.}_{-4.0775} \\
& +\underbrace{\lambda_{\max } \log \left(P\left(V_{r}=" \text { الجيدة" } / \Gamma_{r}=2, T_{r}="\right)\right.}_{-37.5509} \\
& +\underbrace{\log \left(P\left(\Gamma_{r}=0 / \Gamma_{r-1}=2, T_{r-1}=" ن ّ "\right)\right)}_{-0.85277} \\
& =-180.30279
\end{aligned}
$$

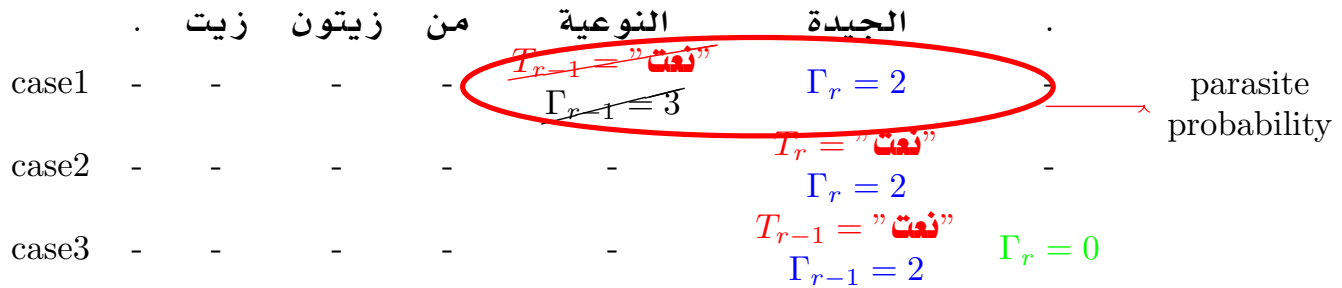

Table 18: situations table for $\delta_{5}(7,3)+\log \left(a_{731}\right)$ for a second order HMM estimation after adding the sentence كعبة طماطم من الحجم الكبير to the dataset, the

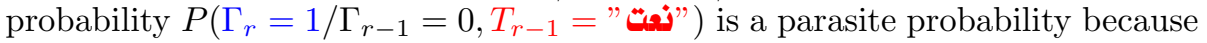
the POS tag of the word منعوت is and النو عية and nت

The modifications made in order to ameliorate the performances of a simple double agent Viterbi algorithm are:

- Inside the mathematical expression $\max _{j}\left[\delta_{l-1}(i, j)+\log \left(a_{i j k}\right)\right], a_{i j k}$ is replaced by $a_{y(l) j k}$ where $y(l)$ is the POS tag observed in the corresponding sequence of $\mathrm{POS}$ tags at position 1.

- Inside the mathematical expression $\max _{j}\left[\delta_{l-1}(i, j)+\log \left(a_{i j k}\right)\right], \delta_{l-1}(i, j)$ is replaced by $\delta_{l-1}(y(l), j)$ where $y(l)$ is the POS tag observed in the corresponding sequence of POS tags at position 1 .

We observe a tremendous decrease of the parasite probabilities infiltrated inside the equations of the most probable cases of a state matrix elements. For example, the parasite probability $P\left(\Gamma_{r}=0 / \Gamma_{r-1}=0, T_{r-1}=\right.$ "نع") in in Table 11 is eliminated and replaced by the sane probability $P\left(\Gamma_{r}=0 / \Gamma_{r-1}=\right.$

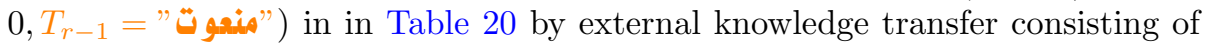
introducing the POS tag estimated in first layer at position $r-1$. 
Estimating an ingredient state using a double agent Viterbi algorithm with external knowledge transfer:

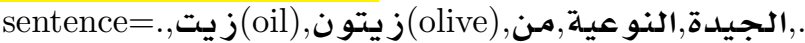

ingredient state $=[0,1,2,0,0,0,0]$

POS tags $=[., \mathrm{C}, \mathrm{D}, \mathrm{G}, \mathrm{E}, \mathrm{F},$.$] coded as [4,2,3,9,6,7,4]$

ingredient to be extracted=زيت زيتون

$$
\begin{aligned}
& \delta_{5}(7,1)+\log \left(a_{711}\right)=\max _{1 \leq i \leq 4}\left(\delta_{4}(P O S[5], i)+\log \left(a_{P O S[5] i 1}\right)\right)+\lambda_{\max } \log \left(b_{71}(" \text { "الجيدأ }\right.
\end{aligned}
$$

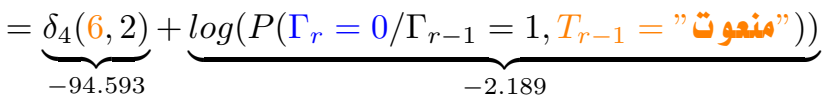

$$
\begin{aligned}
& +\underbrace{\lambda_{\max } \log \left(P\left(V_{r}=" / \Gamma_{r}=0, T_{r}=" ن\right)\right.}_{-36.63} \\
& +\underbrace{\log \left(P\left(\Gamma_{r}=0 / \Gamma_{r-1}=0, T_{r-1}=" \text { "ن" }\right)\right)}_{-2.7178} \\
& =-136.13
\end{aligned}
$$

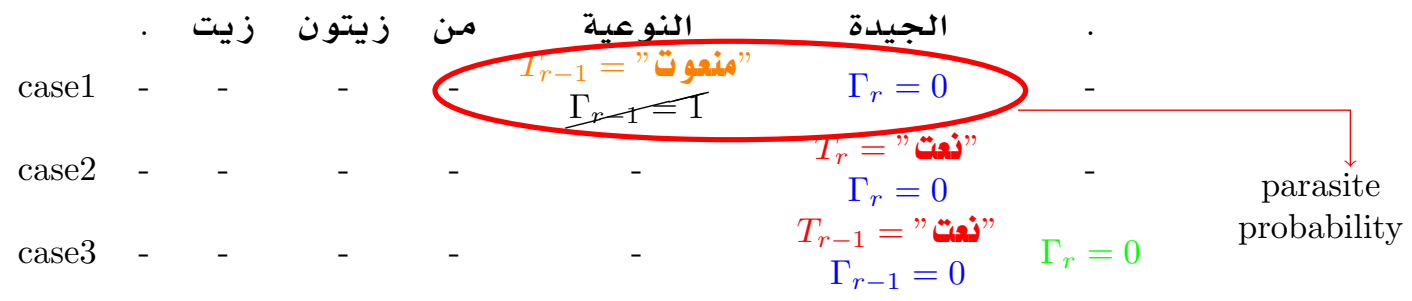

Table 19: situations table for $\delta_{5}(7,1)+\log \left(a_{711}\right)$ for a double agent Viterbi with

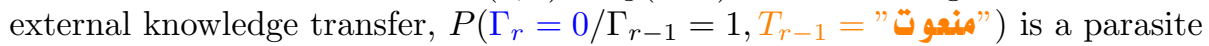
probability because the ingredient state of the word النو عية is $\Gamma_{r-1}=0$ and $\operatorname{not} \Gamma_{r-1}=1$

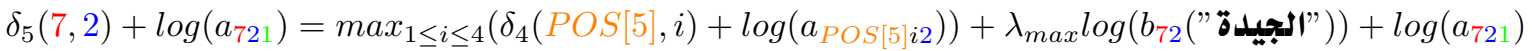

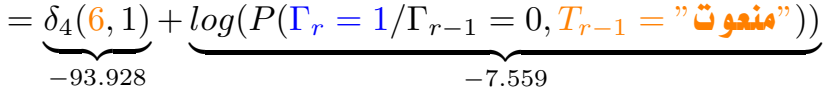

$$
\begin{aligned}
& +\underbrace{\lambda_{\max } \log \left(P\left(V_{r}=" \text { الجيلدة" } " \Gamma_{r}=1, T_{r}="\right)\right.}_{-38.015} \\
& +\underbrace{\log \left(P\left(\Gamma_{r}=0 / \Gamma_{r-1}=1, T_{r-1}=" \dot{*} "\right)\right)}_{-6.583} \\
& =-146.087
\end{aligned}
$$




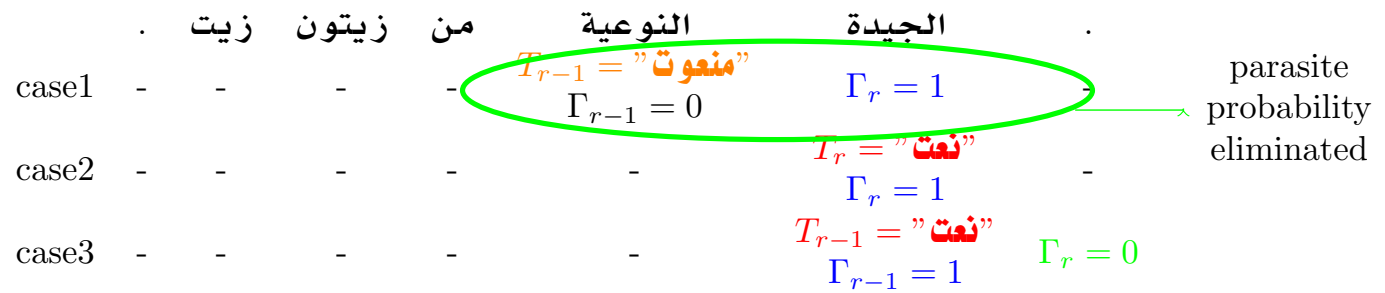

Table 20: situations table for $\delta_{5}(7,2)+\log \left(a_{721}\right)$ for a double agent Viterbi

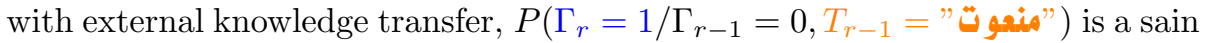
probability because the word منعوت is and is it is not an ingredient.

$$
\begin{aligned}
& \delta_{5}(7,3)+\log \left(a_{731}\right)=\max _{1 \leq i \leq 4}\left(\delta_{4}(P O S[5], i)+\log \left(a_{P O S[5] i 3}\right)\right)+\lambda_{\max } \log \left(b_{73}\left("{ }^{\prime}{ }^{2} "\right)\right)+\log \left(a_{731}\right)
\end{aligned}
$$

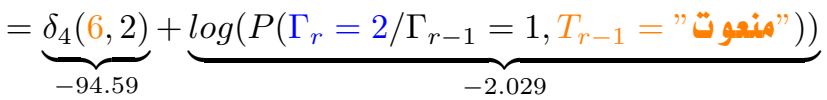

$$
\begin{aligned}
& +\underbrace{\lambda_{\max } \log \left(P\left(V_{r}=" / \Gamma_{r}=2, T_{r}=" ن\right)\right.}_{-37.541} \\
& +\underbrace{\log \left(P\left(\Gamma_{r}=0 / \Gamma_{r-1}=2, T_{r-1}=" \ddot{*} "\right)\right)}_{-0.851} \\
& =-135.015
\end{aligned}
$$

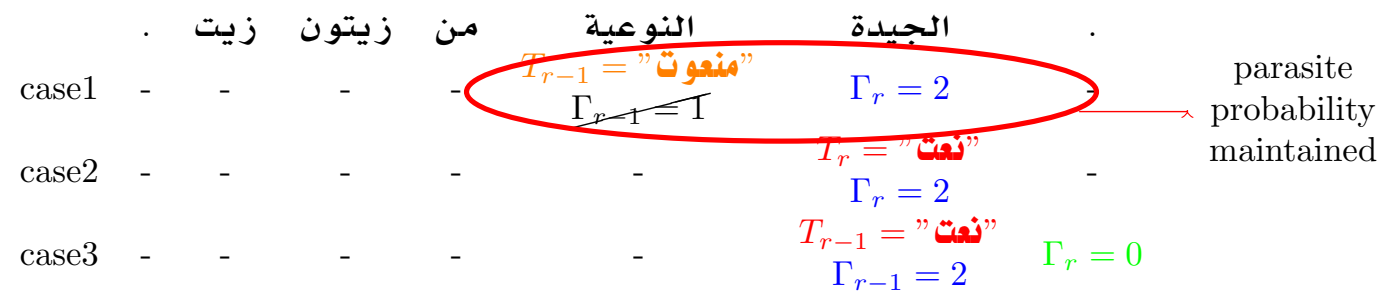

Table 21: situations table for $\delta_{5}(7,3)+\log \left(a_{731}\right)$ for a double agent Viterbi with

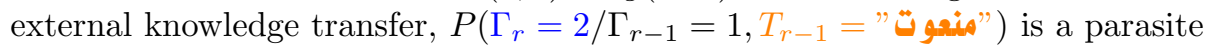
probability because the word النوعية is not an ingredient.

after adding the sentence كعبة طماطم من الحجم الكبير to the dataset:

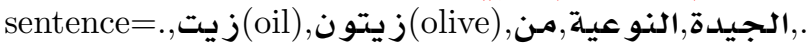
ingredient state $=[0,1,2,0,0,0,0]$ POS tags $=[., \mathrm{C}, \mathrm{D}, \mathrm{G}, \mathrm{E}, \mathrm{F},$.$] coded as [4,2,3,9,6,7,4]$ زيت زيتون=ان 


$$
\begin{aligned}
& \delta_{5}(7,1)+\log \left(a_{711}\right)=\max _{1 \leq i \leq 4}\left(\delta_{4}(P O S[5], i)+\log \left(a_{P O S[5] i 1}\right)\right)+\lambda_{\max } \log \left(b_{71}(" \text { "الجيدة" })\right)+\log \left(a_{711}\right)
\end{aligned}
$$

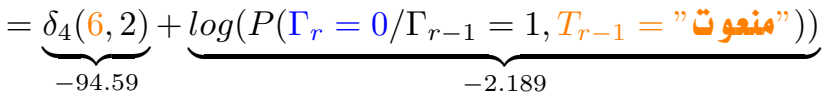

$$
\begin{aligned}
& +\underbrace{\lambda_{\max } \log \left(P \left(V_{r}=" / \Gamma_{r}=0, T_{r}="\right.\right. \text { الجيدة") }}_{-36.637} \\
& +\underbrace{\log \left(P\left(\Gamma_{r}=0 / \Gamma_{r-1}=0, T_{r-1}=" ن "\right)\right)}_{-2.715} \\
& =-136.133
\end{aligned}
$$

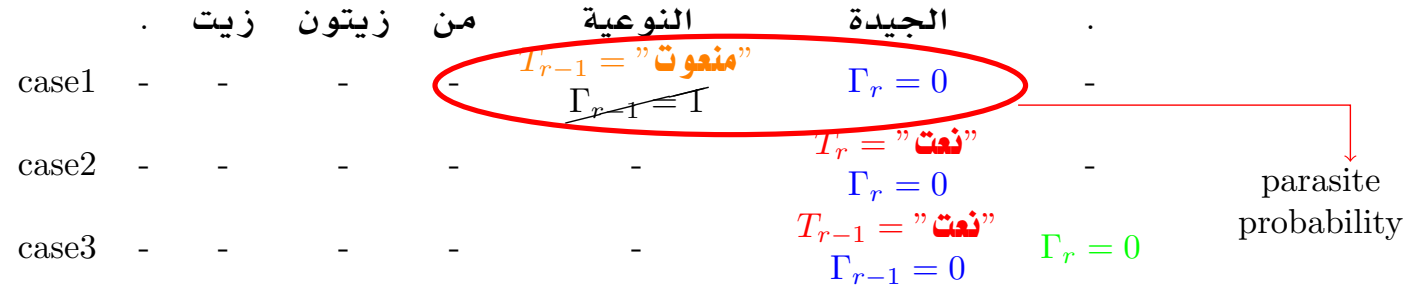

Table 22: situations table for $\delta_{5}(7,1)+\log \left(a_{711}\right)$ for a double agent Viterbi كعبة طماطم من to the dataset, $P\left(\Gamma_{r}=0 / \Gamma_{r-1}=1, T_{r-1}=\right.$ "منعو تصنم الكبير probability because the word النجيدة is not an ingredient in reality given النو have an ingredient state $\Gamma_{r}=0$.

$$
\begin{aligned}
& \delta_{5}(7,2)+\log \left(a_{721}\right)=\max _{1 \leq i \leq 4}\left(\delta_{4}(P O S[5], i)+\log \left(a_{P O S[5] i 2}\right)\right)+\lambda_{\max } \log \left(b_{72}(" \text { "الجيدة" })\right)+\log \left(a_{721}\right)
\end{aligned}
$$

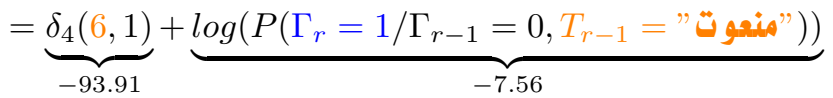

$$
\begin{aligned}
& +\underbrace{\lambda_{\max } \log \left(P\left(V_{r}=" / \Gamma_{r}=1, T_{r}=" ن\right)\right.}_{-38.024} \\
& +\underbrace{\log \left(P\left(\Gamma_{r}=0 / \Gamma_{r-1}=1, T_{r-1}=" ن ت "\right)\right)}_{-6.584} \\
& =-146.078
\end{aligned}
$$




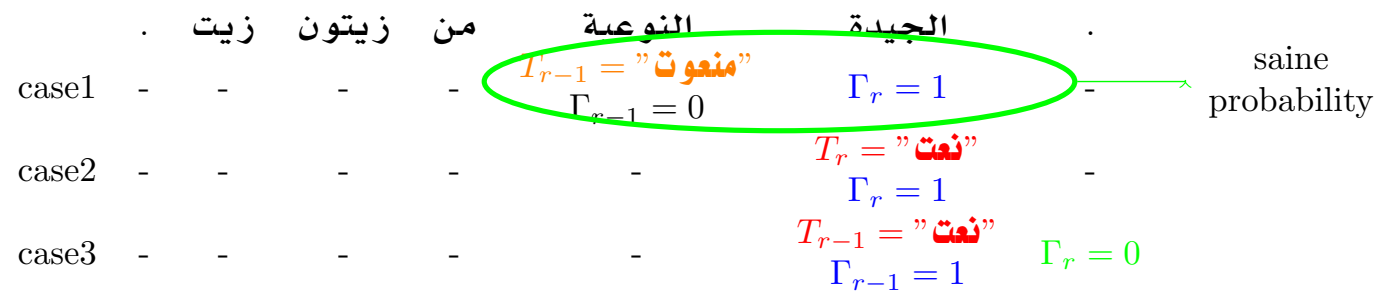

Table 23: situations table for $\delta_{5}(7,2)+\log \left(a_{721}\right)$ for a double agent Viterbi with

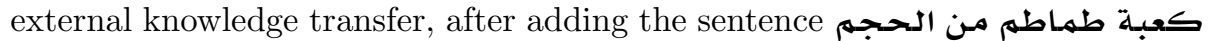

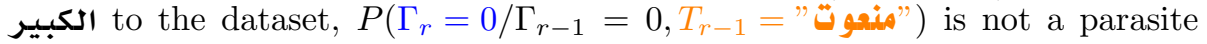
probability because the word النو عية is not an ingredient and النو عية POS tag is منعوت .

$$
\begin{aligned}
& \delta_{5}(7,3)+\log \left(a_{731}\right)=\max _{1 \leq i \leq 4}\left(\delta_{4}(P O S[5], i)+\log \left(a_{P O S[5] i 3}\right)\right)+\lambda_{\max } \log \left(b_{73}(" \text { "الجيد }\right.
\end{aligned}
$$

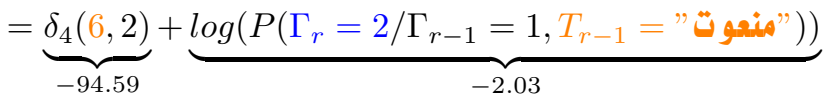

$$
\begin{aligned}
& +\underbrace{\lambda_{\text {max }} \log \left(P\left(V_{r}=" \text { الجيلدة" } " / \Gamma_{r}=2, T_{r}="\right)\right.}_{-37.55} \\
& +\underbrace{\log \left(P\left(\Gamma_{r}=0 / \Gamma_{r-1}=2, T_{r-1}=" \ddot{*} "\right)\right)}_{-0.852} \\
& =-135.02
\end{aligned}
$$

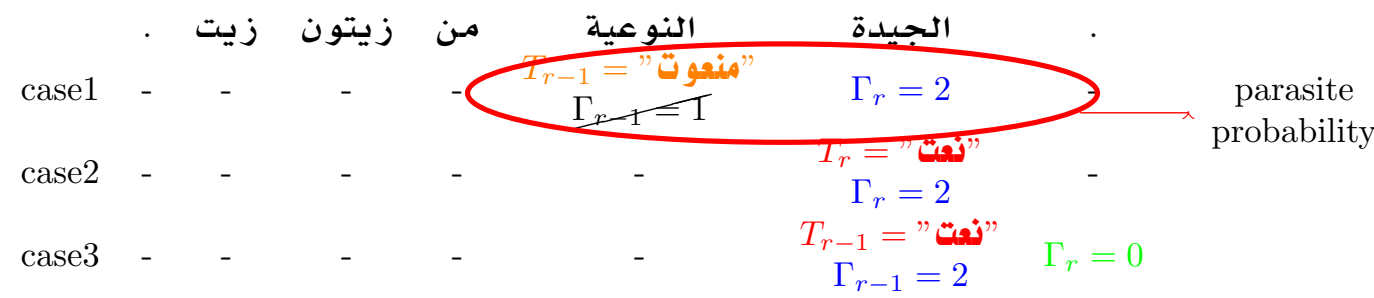

Table 24: situations table for $\delta_{5}(7,3)+\log \left(a_{731}\right)$ for a double agent Viterbi سعبة طماطم من فن with external knowledge transfer, after adding the sentence

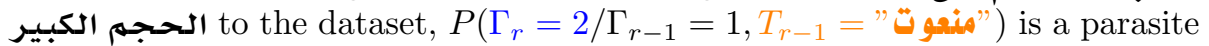
probability because the word النو عية have an ingredient state $\Gamma_{r-1}=0$ and not $\Gamma_{r-1}=1$.

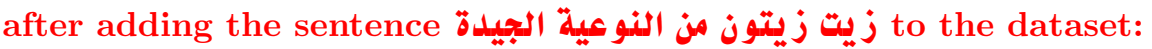

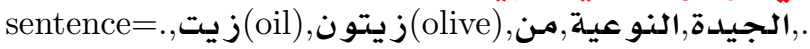


ingredient state $=[0,1,2,0,0,0,0]$

POS tags $=[., \mathrm{C}, \mathrm{D}, \mathrm{G}, \mathrm{E}, \mathrm{F},$.$] coded as [4,2,3,9,6,7,4]$

زيت زيتون=ان

$$
\begin{aligned}
& \delta_{5}(7,1)+\log \left(a_{711}\right)=\max _{1 \leq i \leq 4}\left(\delta_{4}(P O S[5], i)+\log \left(a_{P O S[5] i 1}\right)\right)+\lambda_{\max } \log \left(b_{71}\left("{ }^{2} \text { الجيد } "\right)\right)+\log \left(a_{711}\right)
\end{aligned}
$$

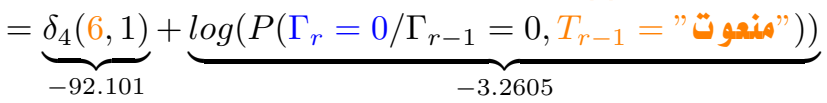

$$
\begin{aligned}
& +\underbrace{\lambda_{\max } \log \left(P\left(V_{r}=" \text { الجيدة" } " \Gamma_{r}=0, T_{r}=" ن\right)\right.}_{-35.009} \\
& +\underbrace{\log \left(P\left(\Gamma_{r}=0 / \Gamma_{r-1}=0, T_{r-1}=" ن "\right)\right)}_{-2.7159} \\
& =-133.08
\end{aligned}
$$

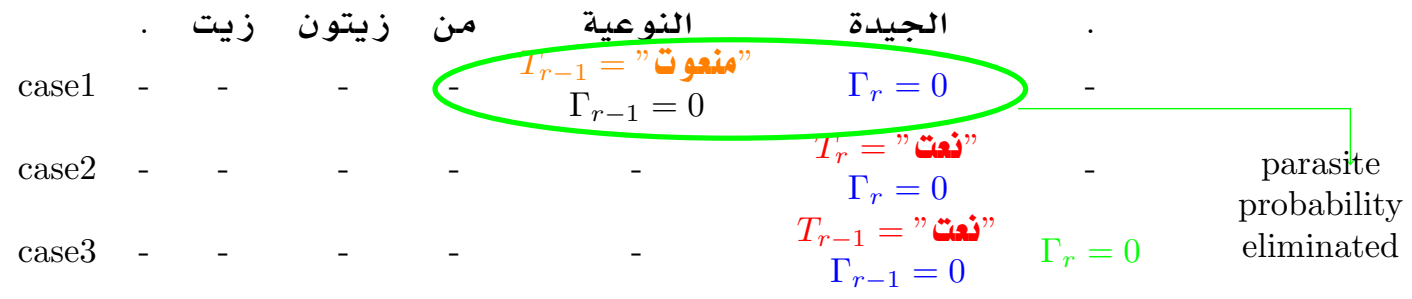

Table 25: situations table for $\delta_{5}(7,1)+\log \left(a_{711}\right)$ for a double agent Viterbi with زيت زيتون من النوعية external knowledge transfer after adding the sentence

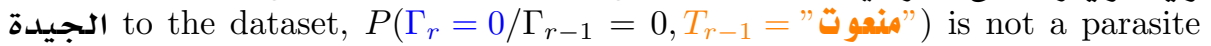
probability because the word النو عيد النو عية is not an ingredient and the word مئو is منعوت given the word النجيدة is not an ingredient.

$$
\begin{aligned}
& \delta_{5}(7,2)+\log \left(a_{721}\right)=\max _{1 \leq i \leq 4}\left(\delta_{4}(P O S[5], i)+\log \left(a_{P O S[5] i 2}\right)\right)+\lambda_{\max } \log \left(b_{72}(" \text { "الجيدأيل }\right.
\end{aligned}
$$

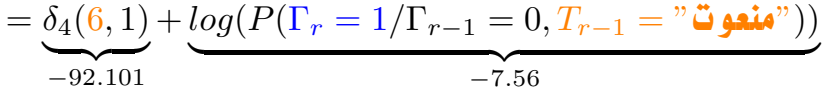

$$
\begin{aligned}
& +\underbrace{\lambda_{\max } \log \left(P\left(V_{r}=" \text { الجيلةة" } " \Gamma_{r}=1, T_{r}="\right)\right.}_{-38.016} \\
& +\underbrace{\log \left(P\left(\Gamma_{r}=0 / \Gamma_{r-1}=1, T_{r-1}=" \dot{*}\right)\right)}_{-6.584} \\
& =-144.26
\end{aligned}
$$




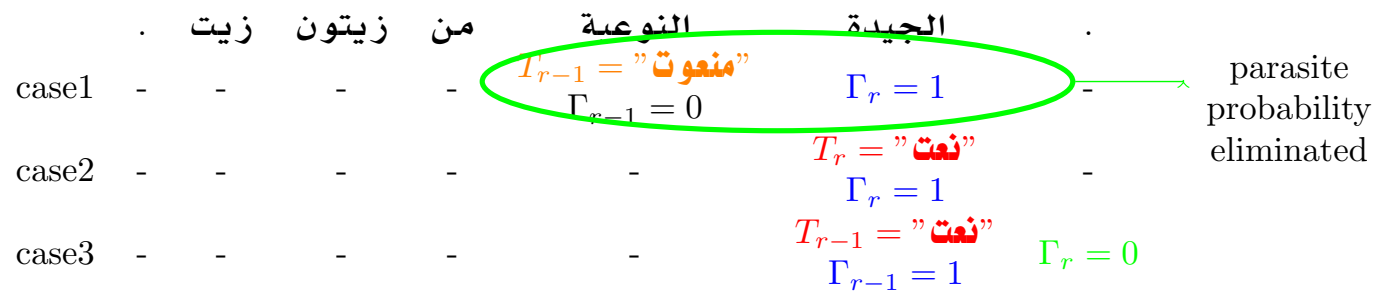

Table 26: situations table for $\delta_{5}(7,2)+\log \left(a_{721}\right)$ for a double agent Viterbi with زيت زيتون من النو عية لxternal knowledge transfer after adding the sentence

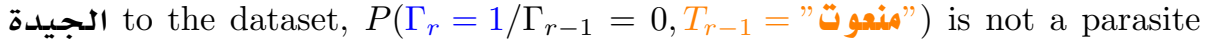

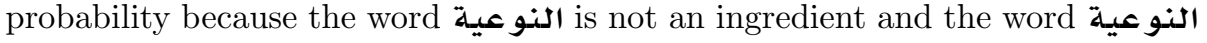
is منعوت given the word الجيدة is not an ingredient.

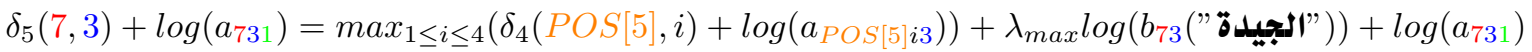

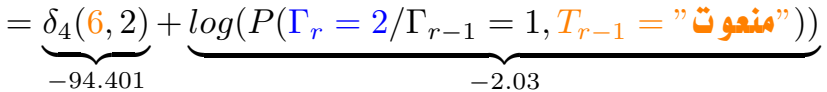

$$
\begin{aligned}
& +\underbrace{\lambda_{\max } \log \left(P\left(V_{r}=" \text { الجيلدة" } / \Gamma_{r}=2, T_{r}="\right)\right.}_{-37.541} \\
& +\underbrace{\log \left(P\left(\Gamma_{r}=0 / \Gamma_{r-1}=2, T_{r-1}=" \dot{*} "\right)\right)}_{-0.852} \\
& =-134.826
\end{aligned}
$$

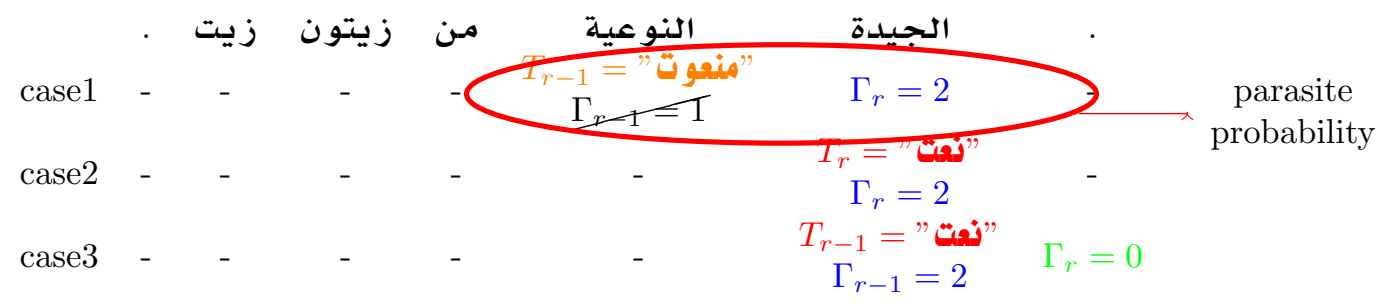

Table 27: situations table for $\delta_{5}(7,3)+\log \left(a_{731}\right)$ for a double agent Viterbi زيت زيتون من with external knowledge transfer after adding the sentence to the dataset, $P\left(\Gamma_{r}=2 / \Gamma_{r-1}=1, T_{r-1}="\right.$ النو عية الجيدة probability because the word النو عية is not an ingredient in reality. 
When the dataset is not modified

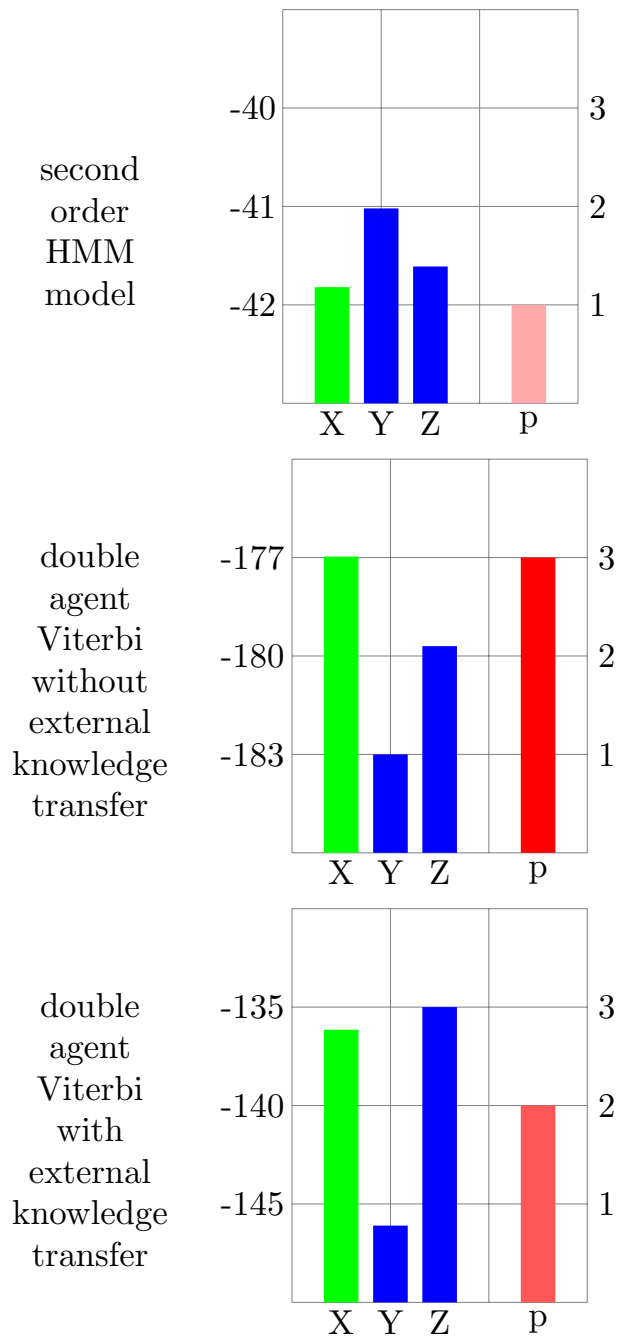

after adding the sentence
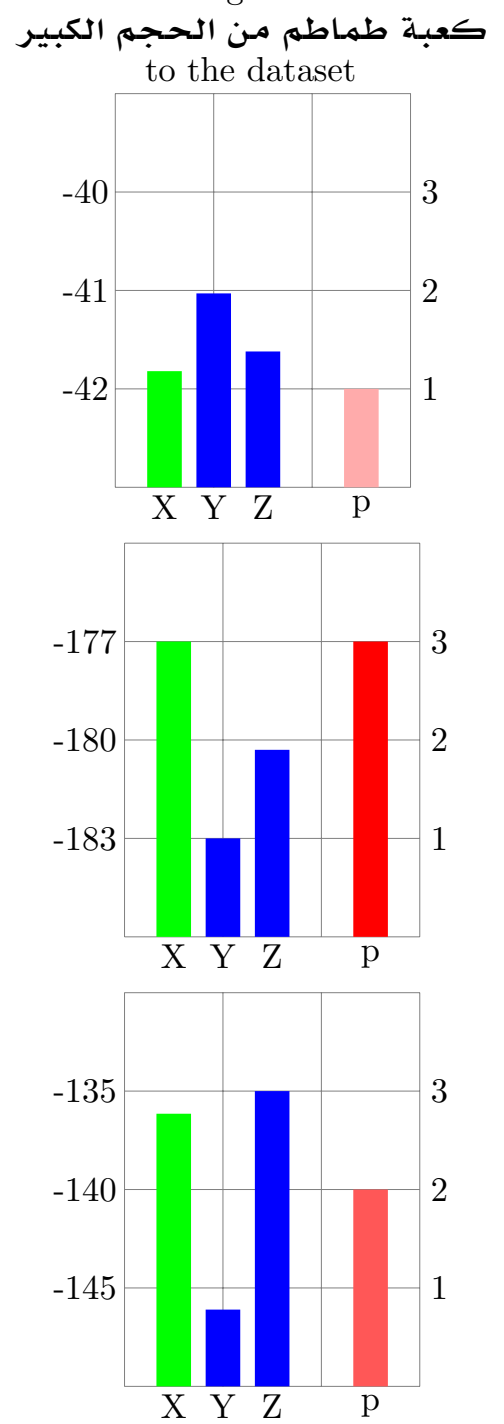

after adding the sentence

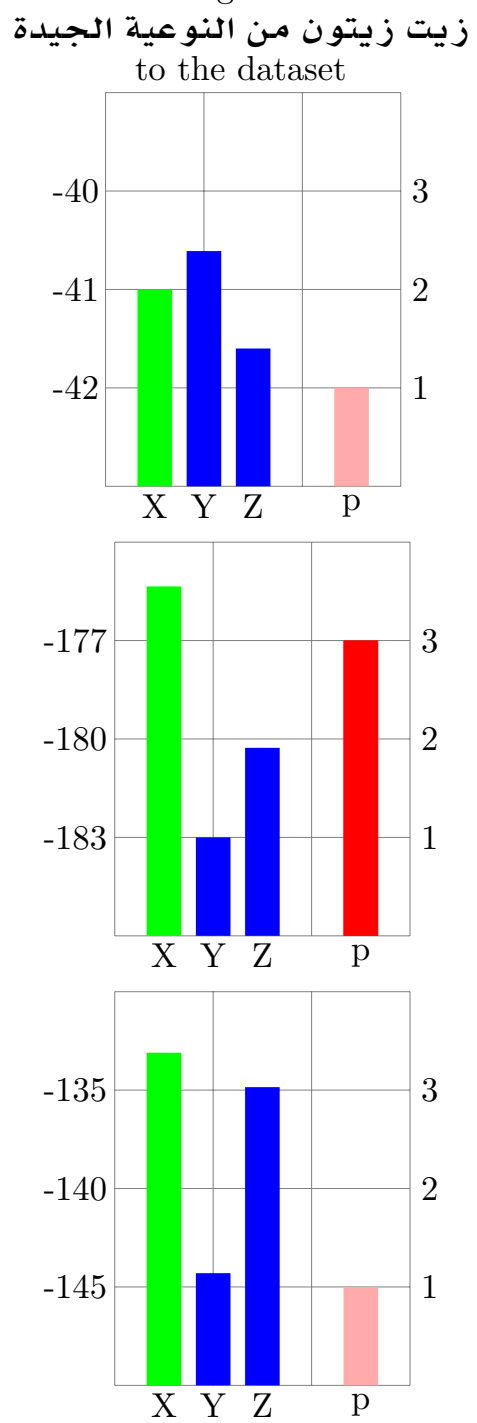

زيت inside the sentence الجيدة زلجيد 1: data sensitivity bar plot for the word زيتون من النوعية الجيدة probable case inside a state matrix الجيديدة is not an ingredient), Y is the second most probable case inside a state matrix الجيدة is an ingredient constituted with a single word) and $\mathrm{Z}$ is the third most probable case inside a state matrix (الجيدة is the second word of an ingredient constituted with two elements) , P is the number of parasite probabilities observed when calculating $\mathrm{X}$ and $\mathrm{Y}$ and $\mathrm{Z}$. 


\begin{tabular}{|c|c|c|c|c|c|c|}
\hline $\operatorname{tag}$ & accuracy & f1 score & $\begin{array}{l}\text { accuracy for } \\
\text { unknown } \\
\text { words }\end{array}$ & $\begin{array}{l}\text { accuracy for } \\
\text { known } \\
\text { words }\end{array}$ & $\begin{array}{l}\text { number of } \\
\text { unknown } \\
\text { words }\end{array}$ & $\begin{array}{l}\text { number of } \\
\text { known } \\
\text { words }\end{array}$ \\
\hline $\begin{array}{c}\text { A } \\
\text { (إسهم) }\end{array}$ & $98.47 \%$ & $65.57 \%$ & NULL & $98.47 \%$ & 0 & 1112 \\
\hline $\begin{array}{c}\text { B } \\
(ر ق م)\end{array}$ & $99.79 \%$ & $74.95 \%$ & NULL & $99.79 \%$ & 0 & 947 \\
\hline $\begin{array}{c}C \\
\text { (إسهر معرف) }\end{array}$ & $96.99 \%$ & $83.79 \%$ & NULL & $96.99 \%$ & 0 & 798 \\
\hline $\begin{array}{c}\text { D } \\
\text { (إضافة }\end{array}$ & $94.69 \%$ & $70.83 \%$ & NULL & $94.69 \%$ & 0 & 791 \\
\hline $\begin{array}{c}E \\
\text { (منعوت) }\end{array}$ & $98.8 \%$ & $87.95 \%$ & NULL & $98.8 \%$ & 0 & 750 \\
\hline $\begin{array}{c}F \\
\text { (نعت }\end{array}$ & $85.31 \%$ & $69.92 \%$ & NULL & $85.31 \%$ & 0 & 844 \\
\hline $\begin{array}{c}G \\
\text { (حر ف جر })\end{array}$ & $99.54 \%$ & $49.89 \%$ & NULL & $99.54 \%$ & 0 & 219 \\
\hline $\begin{array}{c}\mathrm{H} \\
\text { (إسهم مجرور }) \\
\end{array}$ & $86.81 \%$ & $60.21 \%$ & NULL & $86.81 \%$ & 0 & 182 \\
\hline $\begin{array}{c}\text { I } \\
\text { (وحدة قيس) }\end{array}$ & $99.36 \%$ & $49.89 \%$ & NULL & $99.36 \%$ & 0 & 469 \\
\hline $\begin{array}{c}J \\
\text { (و او العطف) }\end{array}$ & $98.77 \%$ & $49.69 \%$ & NULL & $98.77 \%$ & 0 & 162 \\
\hline (فعل مبني & $78.57 \%$ & $31.45 \%$ & NULL & $78.57 \%$ & 0 & 140 \\
\hline 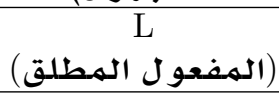 & $60 \%$ & $25 \%$ & NULL & $60 \%$ & 0 & 5 \\
\hline 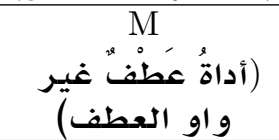 & $92.31 \%$ & $48 \%$ & NULL & $92.31 \%$ & 0 & 39 \\
\hline & $99.9 \%$ & $49.97 \%$ & NULL & $99.9 \%$ & 0 & 1972 \\
\hline
\end{tabular}

Table 28: Performances for each tag of a first order HMM , the trained dataset is used as a test dataset, and there is zero unknown words to predict 


\begin{tabular}{|c|c|c|c|c|c|c|}
\hline $\operatorname{tag}$ & accuracy & f1 score & $\begin{array}{l}\text { accuracy for } \\
\text { unknown } \\
\text { words }\end{array}$ & $\begin{array}{l}\text { accuracy for } \\
\text { known } \\
\text { words }\end{array}$ & $\begin{array}{l}\text { number of } \\
\text { unknown } \\
\text { words }\end{array}$ & $\begin{array}{l}\text { number of } \\
\text { known } \\
\text { words }\end{array}$ \\
\hline $\begin{array}{c}\text { A } \\
\text { (إسهم) }\end{array}$ & $97.3 \%$ & $64.68 \%$ & NULL & $97.3 \%$ & 0 & 1112 \\
\hline $\begin{array}{c}\text { B } \\
(ر ق م)\end{array}$ & $99.89 \%$ & $83.31 \%$ & NULL & $99.89 \%$ & 0 & 947 \\
\hline $\begin{array}{c}C \\
\text { (إسهر معرف) }\end{array}$ & $94.86 \%$ & $85.36 \%$ & NULL & $94.86 \%$ & 0 & 798 \\
\hline $\begin{array}{c}\text { D } \\
\text { (إضافة }\end{array}$ & $91.02 \%$ & $68.01 \%$ & NULL & $91.02 \%$ & 0 & 791 \\
\hline $\begin{array}{c}E \\
\text { (منعوت) }\end{array}$ & $98.53 \%$ & $98.84 \%$ & NULL & $98.53 \%$ & 0 & 750 \\
\hline $\begin{array}{c}F \\
\text { (نعت }\end{array}$ & $77.61 \%$ & $54.6 \%$ & NULL & $77.61 \%$ & 0 & 844 \\
\hline $\begin{array}{c}G \\
\text { (حر ف جر })\end{array}$ & $99.09 \%$ & $49.77 \%$ & NULL & $99.09 \%$ & 0 & 219 \\
\hline $\begin{array}{c}\mathrm{H} \\
\text { (إسهم مجرور }) \\
\end{array}$ & $76.37 \%$ & $52.49 \%$ & NULL & $76.37 \%$ & 0 & 182 \\
\hline $\begin{array}{c}\text { I } \\
\text { (وحدة قيس) }\end{array}$ & $99.57 \%$ & $74.89 \%$ & NULL & $99.57 \%$ & 0 & 469 \\
\hline $\begin{array}{c}J \\
\text { (و او العطف) }\end{array}$ & $98.77 \%$ & $49.69 \%$ & NULL & $98.77 \%$ & 0 & 162 \\
\hline (فعل مبني & $78.57 \%$ & $32.2 \%$ & NULL & $78.57 \%$ & 0 & 140 \\
\hline 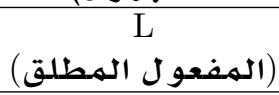 & $20 \%$ & $16.67 \%$ & NULL & $20 \%$ & 0 & 5 \\
\hline 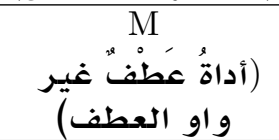 & $94.87 \%$ & $48.68 \%$ & NULL & $94.87 \%$ & 0 & 39 \\
\hline & $99.85 \%$ & $49.96 \%$ & NULL & $99.85 \%$ & 0 & 3945 \\
\hline
\end{tabular}

Table 29: Performances for each tag of a second order HMM , the trained dataset is used as a test dataset, and there is zero unknown words to predict 


\begin{tabular}{|c|c|c|c|c|c|c|}
\hline tag & accuracy & f1 score & $\begin{array}{l}\text { accuracy for } \\
\text { unknown } \\
\text { words }\end{array}$ & $\begin{array}{l}\text { accuracy for } \\
\text { known } \\
\text { words }\end{array}$ & $\begin{array}{l}\text { number of } \\
\text { unknown } \\
\text { words }\end{array}$ & $\begin{array}{c}\text { number of } \\
\text { known } \\
\text { words }\end{array}$ \\
\hline $\begin{array}{c}\text { A } \\
\text { (إسهم) }\end{array}$ & $97.84 \%$ & $97.06 \%$ & NULL & $97.84 \%$ & 0 & 1113 \\
\hline $\begin{array}{c}\text { B } \\
(ر ق م)\end{array}$ & $99.79 \%$ & $49.95 \%$ & NULL & $99.79 \%$ & 0 & 947 \\
\hline $\begin{array}{c}C \\
\text { (إسـى معرف) }\end{array}$ & $96.25 \%$ & $97.44 \%$ & NULL & $96.25 \%$ & 0 & 799 \\
\hline $\begin{array}{c}\mathrm{D} \\
(ا ٕ ض ا ف ة)\end{array}$ & $93.94 \%$ & $94.92 \%$ & NULL & $93.94 \%$ & 0 & 792 \\
\hline $\begin{array}{c}\mathrm{E} \\
\text { (منعوت) }\end{array}$ & $98.8 \%$ & $65.77 \%$ & NULL & $98.8 \%$ & 0 & 748 \\
\hline $\begin{array}{c}F \\
\text { (نعت })\end{array}$ & $88.02 \%$ & $58.34 \%$ & NULL & $88.02 \%$ & 0 & 843 \\
\hline 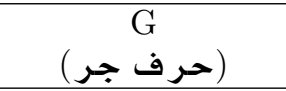 & $99.54 \%$ & $49.89 \%$ & NULL & $99.54 \%$ & 0 & 219 \\
\hline 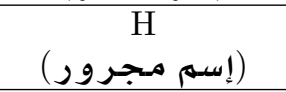 & $89.56 \%$ & $89.36 \%$ & NULL & $89.56 \%$ & 0 & 182 \\
\hline $\begin{array}{c}\text { I } \\
\text { (وحدة قيس) }\end{array}$ & $99.79 \%$ & $83.28 \%$ & NULL & $99.79 \%$ & 0 & 469 \\
\hline $\begin{array}{c}J \\
\text { (و او العطف) }\end{array}$ & $98.77 \%$ & $49.69 \%$ & NULL & $98.77 \%$ & 0 & 162 \\
\hline 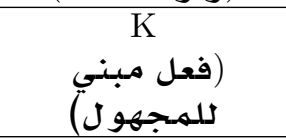 & $99.29 \%$ & $49.82 \%$ & NULL & $99.29 \%$ & 0 & 140 \\
\hline $\begin{array}{c}L \\
\text { (المفعول المطلق) }\end{array}$ & $100 \%$ & $100 \%$ & NULL & $100 \%$ & 0 & 5 \\
\hline 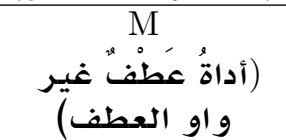 & $97.44 \%$ & $49.35 \%$ & NULL & $97.44 \%$ & 0 & 39 \\
\hline . & $100 \%$ & $100 \%$ & NULL & $100 \%$ & 0 & 3946 \\
\hline
\end{tabular}

Table 30: Performance comparison using a simple double agent Viterbi with external knowledge transfer with $100 \%$ accuracy on first layer, the trained dataset is used as a test dataset to avoid unknown words prediction 


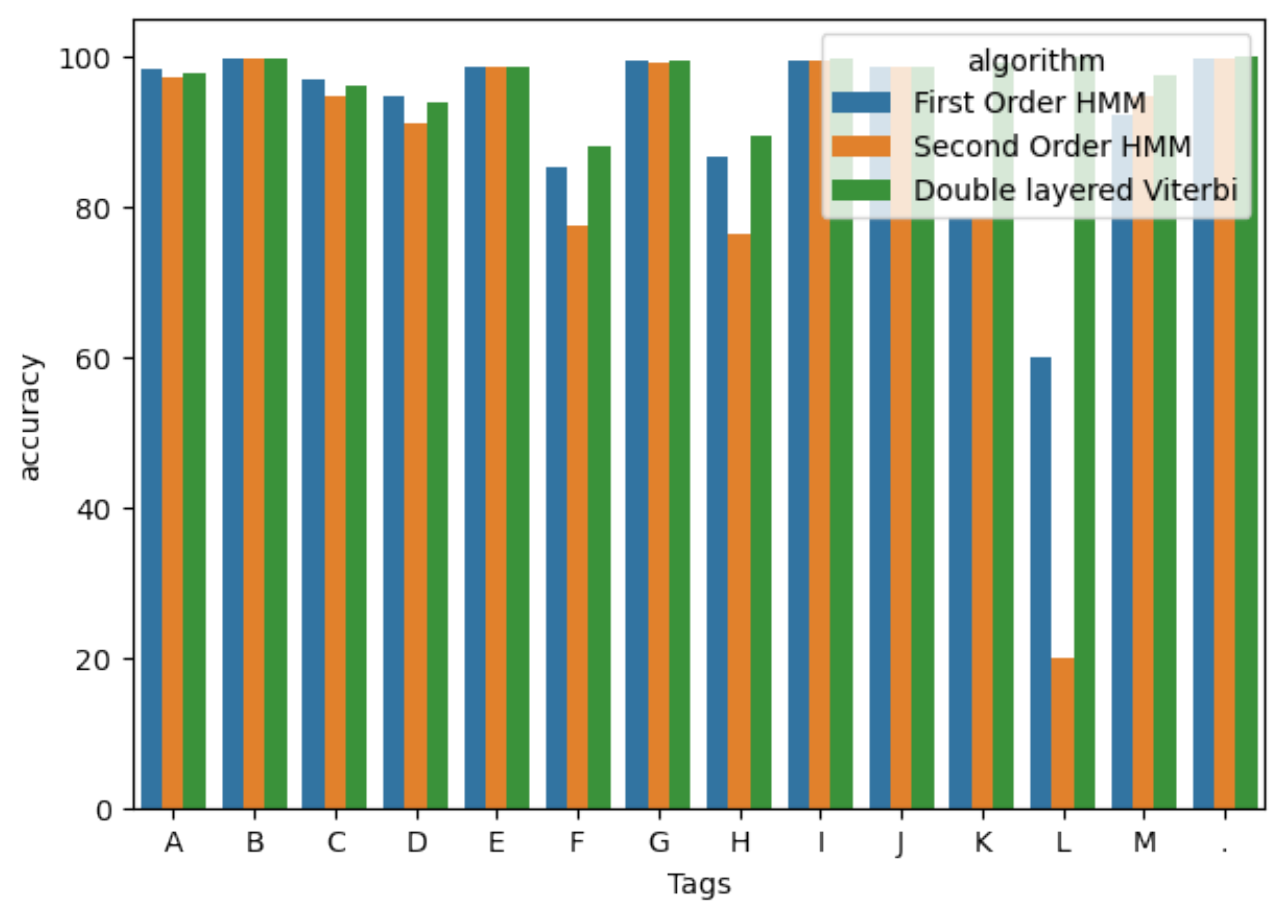

(a) accuracy for each tag without unknown words consideration

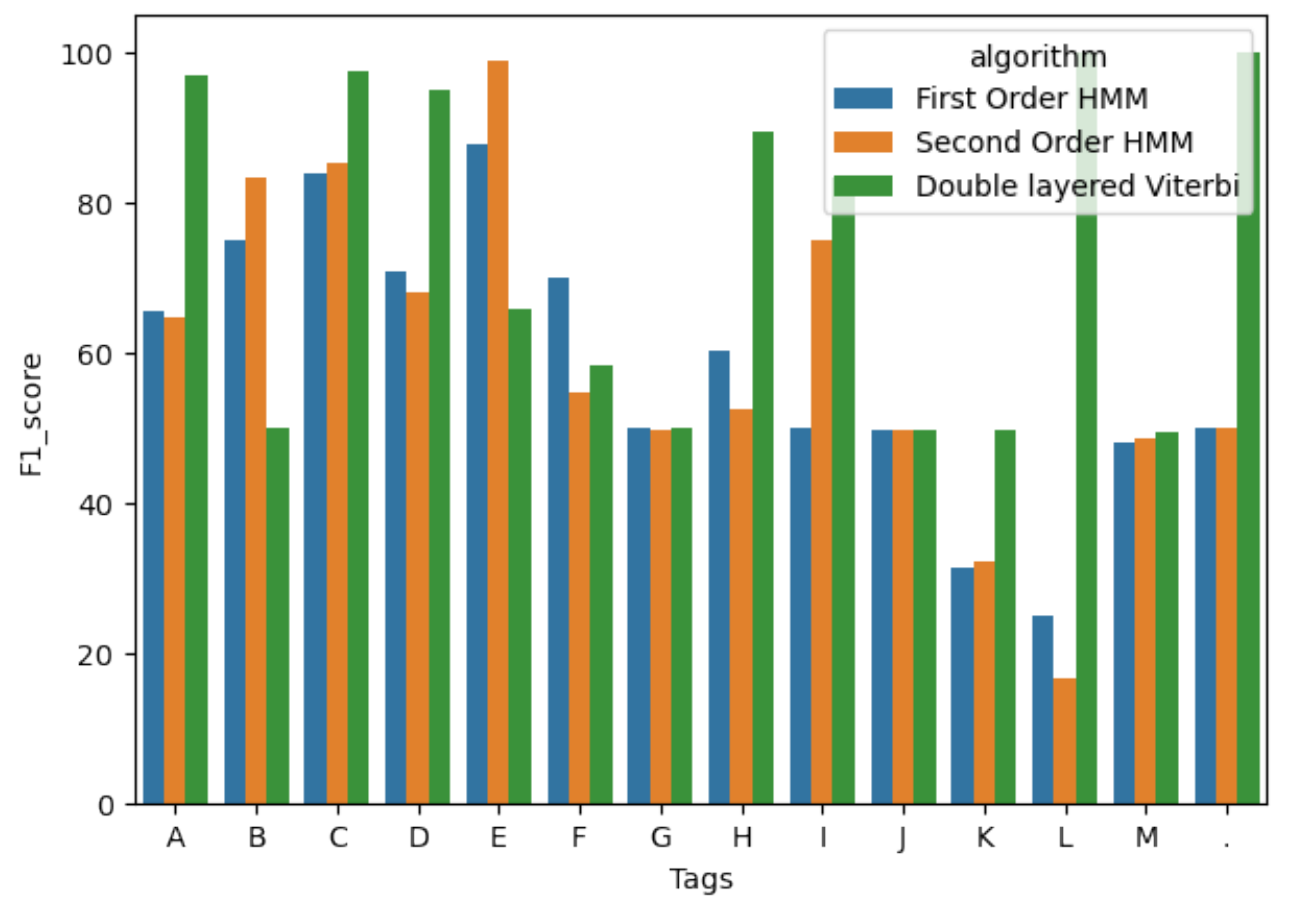

(b) f1 score for each tag without unknown words consideration

Figure 2: Performance comparison betteen a double agent Viterbi algorithm with external knowledge transfer and other mono layered Viterbi algorithm 


\begin{tabular}{|c|c|c|}
\cline { 2 - 3 } \multicolumn{1}{c|}{} & Accuracy & F1 score \\
\hline $\begin{array}{c}\text { First order Hidden } \\
\text { Markov Model applied to tokens } \\
\text { to predict ingredients }\end{array}$ & $96.61 \%$ & $70.06 \%$ \\
\hline \hline $\begin{array}{c}\text { Second order Hidden } \\
\text { Markov Model applied to tokens } \\
\text { to predict ingredients }\end{array}$ & $95.82 \%$ & $68.18 \%$ \\
\hline $\begin{array}{c}\text { Our ingredient extractor } \\
\text { with 100 \% accuracy on the first layer } \\
\text { with } \lambda=4\end{array}$ & $98.43 \%$ & $81.43 \%$ \\
\hline \hline $\begin{array}{c}\text { A double layered Viterbi algorithm } \\
\text { with } 100 \% \text { accuracy on the first layer } \\
\text { with } \lambda=4\end{array}$ & $97.7 \%$ & $96.32 \%$ \\
\hline
\end{tabular}

Table 31: Comparison of performances between a simple double agent Viterbi algorithm with external knowledge transfer and other HMM mono-agent methods using the trained corpus as a testing dataset

\begin{tabular}{|l|l|l|l|l|l|l|}
\hline tag & accuracy & f1 score & $\begin{array}{c}\text { accuracy for } \\
\text { unknown } \\
\text { words }\end{array}$ & $\begin{array}{c}\text { accuracy for } \\
\text { known } \\
\text { words }\end{array}$ & $\begin{array}{c}\text { number of } \\
\text { unknown } \\
\text { words }\end{array}$ & $\begin{array}{c}\text { unknown } \\
\text { words } \\
\text { percentage }\end{array}$ \\
\hline 0 & $94.77 \%$ & $67.67 \%$ & $67.78 \%$ & $96.33 \%$ & 78 & $9.67 \%$ \\
\hline 1 & $92.96 \%$ & $65.52 \%$ & $63.93 \%$ & $95.14 \%$ & 107 & $13.26 \%$ \\
\hline 2 & $94.03 \%$ & $67.36 \%$ & $69.9 \%$ & $95.68 \%$ & 88 & $10.9 \%$ \\
\hline 3 & $93.95 \%$ & $87.84 \%$ & $62.65 \%$ & $95.64 \%$ & 75 & $9.29 \%$ \\
\hline 4 & $92.91 \%$ & $87.29 \%$ & $66.99 \%$ & $94.54 \%$ & 92 & $11.4 \%$ \\
\hline 5 & $95.78 \%$ & $69.61 \%$ & $76.4 \%$ & $96.83 \%$ & 83 & $10.29 \%$ \\
\hline 6 & $94.38 \%$ & $67.53 \%$ & $54.65 \%$ & $96.49 \%$ & 80 & $9.91 \%$ \\
\hline 7 & $95.08 \%$ & $91.17 \%$ & $61.22 \%$ & $97.17 \%$ & 90 & $11.15 \%$ \\
\hline 8 & $96.83 \%$ & $94.04 \%$ & $79.76 \%$ & $97.7 \%$ & 77 & $9.54 \%$ \\
\hline 9 & $94.92 \%$ & $90.7 \%$ & $64.95 \%$ & $96.72 \%$ & 88 & $10.9 \%$ \\
\hline \hline Avg & $94.56 \%$ & $78.87 \%$ & $66.82 \%$ & $96.22 \%$ & 86 & $10.63 \%$ \\
\hline
\end{tabular}

Table 32: Performances of first order HMM used to predict ingredients state using 10 fold cross-validation with unknown word consideration, the test dataset have $20 \%$ sentences from the total dataset 


\begin{tabular}{|l|l|l|l|l|l|l|}
\hline tag & accuracy & f1 score & $\begin{array}{c}\text { accuracy for } \\
\text { unknown } \\
\text { words }\end{array}$ & $\begin{array}{c}\text { accuracy for } \\
\text { known } \\
\text { words }\end{array}$ & $\begin{array}{c}\text { number of } \\
\text { unknown } \\
\text { words }\end{array}$ & $\begin{array}{c}\text { unknown } \\
\text { words } \\
\text { percentage }\end{array}$ \\
\hline 0 & $93.72 \%$ & $64.13 \%$ & $70.0 \%$ & $94.81 \%$ & 78 & $9.67 \%$ \\
\hline 1 & $92.48 \%$ & $62.96 \%$ & $64.75 \%$ & $94.14 \%$ & 107 & $13.26 \%$ \\
\hline 2 & $94.04 \%$ & $65.53 \%$ & $70.87 \%$ & $95.29 \%$ & 88 & $10.9 \%$ \\
\hline 3 & $93.89 \%$ & $86.87 \%$ & $68.67 \%$ & $94.97 \%$ & 75 & $9.29 \%$ \\
\hline 4 & $93.42 \%$ & $86.61 \%$ & $66.02 \%$ & $94.81 \%$ & 92 & $11.4 \%$ \\
\hline 5 & $93.83 \%$ & $65.85 \%$ & $62.92 \%$ & $95.18 \%$ & 83 & $10.29 \%$ \\
\hline 6 & $93.76 \%$ & $65.63 \%$ & $60.47 \%$ & $95.19 \%$ & 80 & $9.91 \%$ \\
\hline 7 & $94.04 \%$ & $88.56 \%$ & $55.1 \%$ & $95.96 \%$ & 90 & $11.15 \%$ \\
\hline 8 & $95.34 \%$ & $90.99 \%$ & $60.71 \%$ & $96.77 \%$ & 77 & $9.54 \%$ \\
\hline 9 & $94.34 \%$ & $88.56 \%$ & $61.86 \%$ & $95.91 \%$ & 88 & $10.9 \%$ \\
\hline \hline Avg & $93.89 \%$ & $76.57 \%$ & $64.14 \%$ & $95.3 \%$ & 86 & $10.63 \%$ \\
\hline
\end{tabular}

Table 33: Performances of second order HMM used to predict ingredients state using 10 fold cross-validation with unknown word consideration, the test dataset have $20 \%$ sentences from the total dataset

\begin{tabular}{|l|l|l|l|l|l|l|}
\hline tag & accuracy & f1 score & $\begin{array}{c}\text { accuracy for } \\
\text { unknown } \\
\text { words }\end{array}$ & $\begin{array}{c}\text { accuracy for } \\
\text { known } \\
\text { words }\end{array}$ & $\begin{array}{c}\text { number of } \\
\text { unknown } \\
\text { words }\end{array}$ & $\begin{array}{c}\text { unknown } \\
\text { words } \\
\text { percentage }\end{array}$ \\
\hline 0 & $95.78 \%$ & $67.91 \%$ & $61.11 \%$ & $97.38 \%$ & 78 & $9.67 \%$ \\
\hline 1 & $94.34 \%$ & $66.51 \%$ & $68.85 \%$ & $95.87 \%$ & 107 & $13.26 \%$ \\
\hline 2 & $94.98 \%$ & $67.32 \%$ & $67.96 \%$ & $96.44 \%$ & 88 & $10.9 \%$ \\
\hline 3 & $95.83 \%$ & $67.71 \%$ & $62.65 \%$ & $97.25 \%$ & 75 & $9.29 \%$ \\
\hline 4 & $94.88 \%$ & $67.76 \%$ & $71.84 \%$ & $96.05 \%$ & 92 & $11.4 \%$ \\
\hline 5 & $95.9 \%$ & $69.57 \%$ & $70.79 \%$ & $97.0 \%$ & 83 & $10.29 \%$ \\
\hline 6 & $94.43 \%$ & $65.92 \%$ & $55.81 \%$ & $96.08 \%$ & 80 & $9.91 \%$ \\
\hline 7 & $94.04 \%$ & $65.54 \%$ & $51.02 \%$ & $96.17 \%$ & 90 & $11.15 \%$ \\
\hline 8 & $95.63 \%$ & $68.82 \%$ & $60.71 \%$ & $97.06 \%$ & 77 & $9.54 \%$ \\
\hline 9 & $94.39 \%$ & $65.95 \%$ & $56.7 \%$ & $96.21 \%$ & 88 & $10.9 \%$ \\
\hline \hline Avg & $95.02 \%$ & $67.3 \%$ & $62.74 \%$ & $96.55 \%$ & 86 & $10.63 \%$ \\
\hline
\end{tabular}

Table 34: Average performances in predicting ingredients states with $\lambda=4$ when accuracy is $100 \%$ on first layer with our ingredient extractor 


\begin{tabular}{|l|l|l|l|l|l|l|}
\hline tag & accuracy & f1 score & $\begin{array}{c}\text { accuracy for } \\
\text { unknown } \\
\text { words }\end{array}$ & $\begin{array}{c}\text { accuracy for } \\
\text { known } \\
\text { words }\end{array}$ & $\begin{array}{c}\text { number of } \\
\text { unknown } \\
\text { words }\end{array}$ & $\begin{array}{c}\text { unknown } \\
\text { words } \\
\text { percentage }\end{array}$ \\
\hline 0 & $96.61 \%$ & $69.39 \%$ & $80 \%$ & $97.38 \%$ & 78 & $9.67 \%$ \\
\hline 1 & $94.89 \%$ & $67.6 \%$ & $77.05 \%$ & $95.96 \%$ & 107 & $13.26 \%$ \\
\hline 2 & $95.13 \%$ & $67.76 \%$ & $85.44 \%$ & $95.65 \%$ & 88 & $10.9 \%$ \\
\hline 3 & $95.87 \%$ & $91.04 \%$ & $80.72 \%$ & $96.53 \%$ & 75 & $9.29 \%$ \\
\hline 4 & $95.49 \%$ & $90.68 \%$ & $78.64 \%$ & $96.34 \%$ & 92 & $11.4 \%$ \\
\hline 5 & $95.81 \%$ & $69.1 \%$ & $74.16 \%$ & $97.0 \%$ & 83 & $10.29 \%$ \\
\hline 6 & $94.43 \%$ & $65.92 \%$ & $55.81 \%$ & $96.08 \%$ & 80 & $9.91 \%$ \\
\hline 7 & $94.04 \%$ & $65.54 \%$ & $51.02 \%$ & $96.17 \%$ & 90 & $11.15 \%$ \\
\hline 8 & $95.63 \%$ & $68.82 \%$ & $60.71 \%$ & $97.06 \%$ & 77 & $9.54 \%$ \\
\hline 9 & $94.39 \%$ & $65.95 \%$ & $56.7 \%$ & $96.21 \%$ & 88 & $10.9 \%$ \\
\hline \hline Avg & $95.24 \%$ & $72.19 \%$ & $70.13 \%$ & $96.42 \%$ & 86 & $10.63 \%$ \\
\hline
\end{tabular}

Table 35: Average performances in predicting ingredients states with $\lambda=4$ when accuracy is $100 \%$ on first layer using a double layered Viterbi Algorithm

\begin{tabular}{|c|c|c|c|c|}
\cline { 2 - 5 } \multicolumn{1}{c|}{} & known & unknown & overall & F1 score \\
\hline $\begin{array}{c}\text { First order Hidden } \\
\text { Markov Model applied to tokens }\end{array}$ & $96.22 \%$ & $66.82 \%$ & $94.56 \%$ & $78.87 \%$ \\
\hline \hline $\begin{array}{c}\text { Second order Hidden } \\
\text { Markov Model applied to tokens }\end{array}$ & $95.3 \%$ & $64.14 \%$ & $93.89 \%$ & $76.57 \%$ \\
\hline \hline $\begin{array}{c}\text { Our ingredient extractor } \\
\text { with 100 \% accuracy on the first layer } \\
\text { with } \lambda=4\end{array}$ & $96.55 \%$ & $62.74 \%$ & $95.02 \%$ & $67.3 \%$ \\
\hline \hline $\begin{array}{c}\text { A double layered Viterbi algorithm } \\
\text { with } 100 \% \text { accuracy on the first layer } \\
\text { with } \lambda=4\end{array}$ & $96.42 \%$ & $70.13 \%$ & $95.24 \%$ & $72.19 \%$ \\
\hline
\end{tabular}

Table 36: Comparison of performances between the 4 methods using $20 \%$ of the total dataset as a test dataset 
Estimating an ingredient state using a simple double agent Viterbi without unknown words consideration:

sentence=.,10,غلاخبز ,جافة, خميـرة,

ingredient state $=[0,0,0,1,2,0,0]$

POS tags $=[., \mathrm{B}, \mathrm{I}, \mathrm{E}, \mathrm{F}, \mathrm{H},$.$] coded as [4,1,10,6,7,12,4]$

ingredient to be extracted=خميرة جافة

$$
\begin{aligned}
& \psi_{6}(i, j)=\left[\begin{array}{llll}
0 & 0 & 1 & 1 \\
3 & 3 & 1 & 3 \\
1 & 0 & 3 & 3 \\
0 & 0 & 1 & 1 \\
1 & 0 & 1 & 1 \\
1 & 3 & 1 & 3 \\
0 & 0 & 3 & 3 \\
1 & 3 & 1 & 3 \\
3 & 3 & 3 & 3 \\
3 & 3 & 3 & 3 \\
3 & 3 & 3 & 3 \\
0 & 3 & 3 & 3 \\
3 & 3 & 3 & 3 \\
3 & 3 & 3 & 3
\end{array}\right] \\
& \psi_{6}(12,1)=\operatorname{argmax}_{1 \leq i \leq 4}\left(\delta_{5}(12, i)+\log \left(a_{12 i 1}\right)\right) \\
& \delta_{5}(12,1)+\log \left(a_{1211}\right)=\max _{1 \leq i \leq 4}\left(\delta_{4}(12, i)+\log \left(a_{12 i 1}\right)\right)+\lambda_{\max } \log \left(b_{121}(" \text { "للخبز" })\right)+\log \left(a_{1211}\right)
\end{aligned}
$$

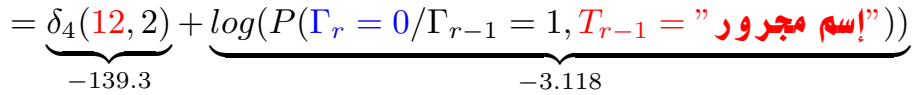

$$
\begin{aligned}
& +\lambda_{\max } \underbrace{\log \left(P\left(V_{r}=" \text { للخبز" / إسى مجر ور " } \Gamma_{r}=0, T_{r}\right)\right.}_{-36.629}
\end{aligned}
$$

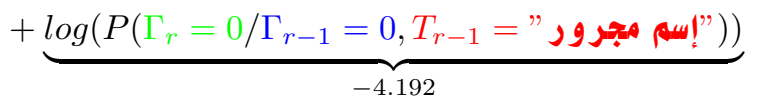

$$
\begin{aligned}
& =-183.24
\end{aligned}
$$




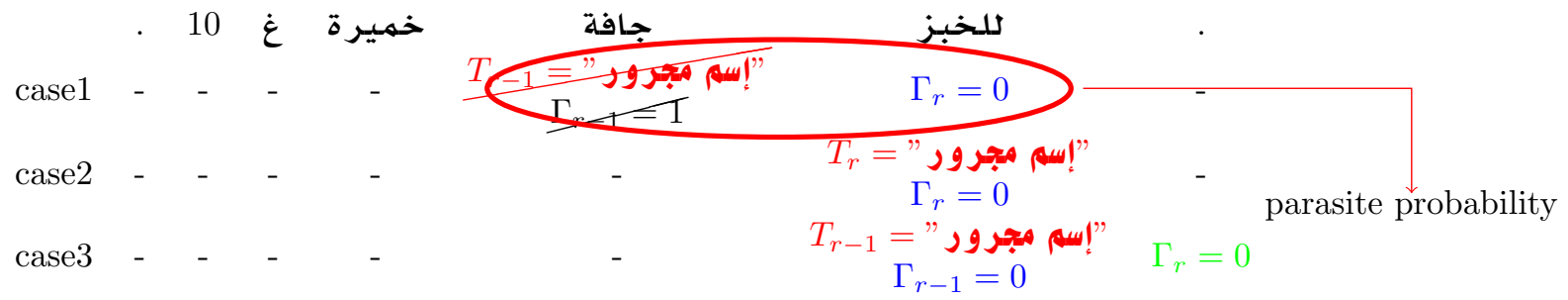

Table 37: situations table for $\delta_{5}(12,1)+\log \left(a_{1211}\right)$ for a simple double agent Viterbi without unknown words consideration, the probability $P\left(\Gamma_{r}=0 / \Gamma_{r-1}=\right.$ $1, T_{r-1}="$ "إسى مجرور

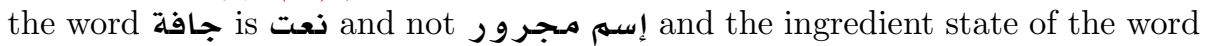
جافة is $\Gamma_{r-1}=2$ and not $\Gamma_{r-1}=1$

$$
\begin{aligned}
& \delta_{5}(12,2)+\log \left(a_{1221}\right)=\max _{1 \leq i \leq 4}\left(\delta_{4}(12, i)+\log \left(a_{12 i 2}\right)\right)+\lambda_{\max } \log \left(b_{122}(" \text { "لاخبز ") })\right)+\log \left(a_{1221}\right)
\end{aligned}
$$

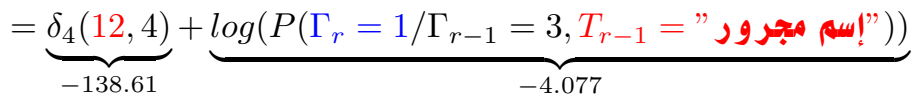

$$
\begin{aligned}
& +\lambda_{\max } \underbrace{\log \left(P\left(V_{r}=" \text { "لاخبز " } / \Gamma_{r}=1, T_{r}="\right)\right.}_{-38.016}
\end{aligned}
$$

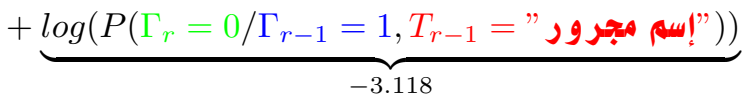

$$
\begin{aligned}
& =-183.82
\end{aligned}
$$

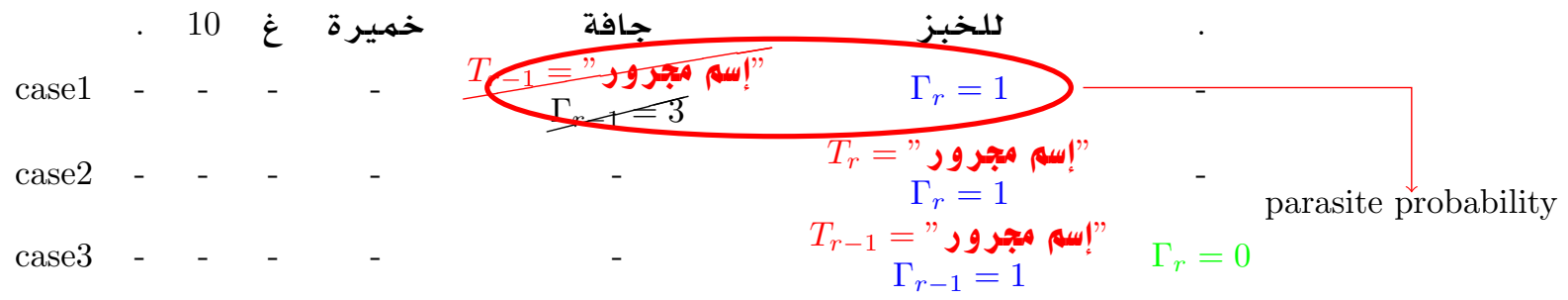

Table 38: situations table for $\delta_{5}(12,2)+\log \left(a_{1221}\right)$ for a simple double agent Viterbi without unknown words consideration, the probability $P\left(\Gamma_{r}=0 / \Gamma_{r-1}=\right.$

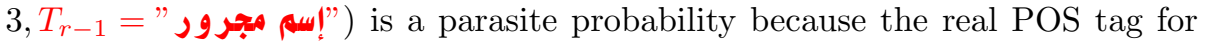

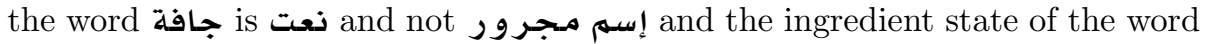
جافة is $\Gamma_{r-1}=2$ and not $\Gamma_{r-1}=3$ 
Estimating an ingredient state using a double agent Viterbi algorithm with external knowledge transfer :

sentence=.,10, للخبز ,جافة,خميرة,

ingredient state $=[0,0,0,1,2,0,0]$

POS tags $=[., \mathrm{B}, \mathrm{I}, \mathrm{E}, \mathrm{F}, \mathrm{H},$.$] coded as [4,1,10,6,7,12,4]$

ingredient to be extracted=خميرة جافة

$$
\begin{aligned}
& \delta_{5}(12,1)+\log \left(a_{1211}\right)=\max _{1 \leq i \leq 4}\left(\delta_{4}(P O S[5], i)+\log \left(a_{P O S[5] i 1}\right)\right)+\log \left(b_{121}\left(" ل{ }^{\prime \prime} "\right)\right)+\log \left(a_{1211}\right) \\
& =\underbrace{\delta_{4}(7,3)}_{-93.42}+\underbrace{\log \left(P\left(\Gamma_{r}=0 / \Gamma_{r-1}=2, T_{r-1}=" \text { "ن } "\right)\right)}_{-0.851} \\
& +\underbrace{\log \left(P\left(V_{r}=" \text { للخبز" } / \Gamma_{r}=0, T_{r}="\right)\right.}_{-36.63} \\
& +\underbrace{\log \left(P\left(\Gamma_{r}=0 / \Gamma_{r-1}=0, T_{r-1}=" \text { "إس مجرو مجر }\right)\right)}_{-4.192} \\
& =-135.094
\end{aligned}
$$

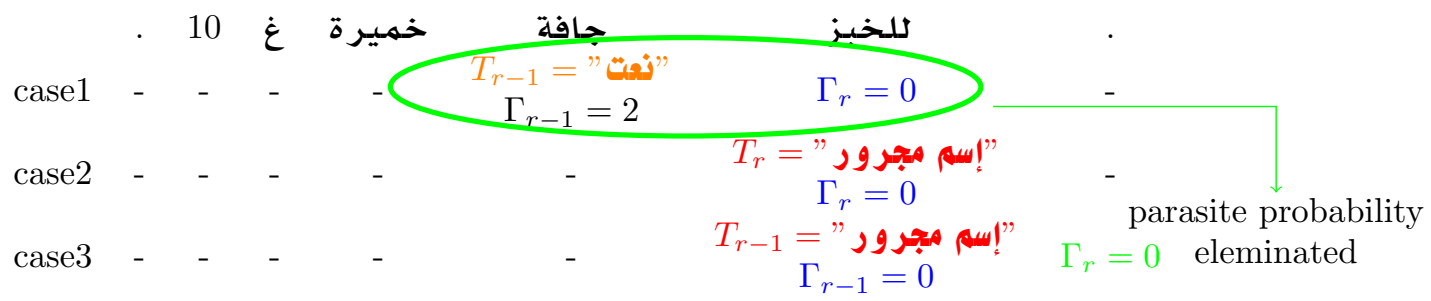

Table 39: Situations table for $\delta_{5}(12,1)+\log \left(a_{1211}\right)$ for a simple double agent Viterbi with external knowledge transfer without unknown words consideration, the parasite probability probability $P\left(\Gamma_{r}=0 / \Gamma_{r-1}=1, T_{r-1}=\right.$ " إسم مجرور") is eliminated and replaced by the probability $P\left(\Gamma_{r}=0 / \Gamma_{r-1}=2, T_{r-1}="\right.$ "ن

$$
\begin{aligned}
& \delta_{5}(12,2)+\log \left(a_{1221}\right)=\max _{1 \leq i \leq 4}\left(\delta_{4}(P O S[5], i)+\log \left(a_{P O S[5] i 2}\right)\right)+\log \left(b_{122}(" ل \mathbf{l} ")\right)+\log \left(a_{1221}\right) \\
& =\underbrace{\delta_{4}(7,3)}_{-93.42}+\underbrace{\log \left(P\left(\Gamma_{r}=1 / \Gamma_{r-1}=2, T_{r-1}=" \text { "نفt" }\right)\right)}_{-6.5}
\end{aligned}
$$

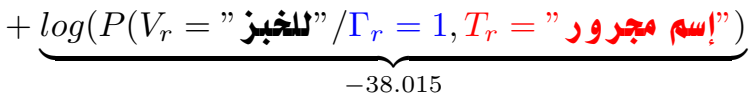

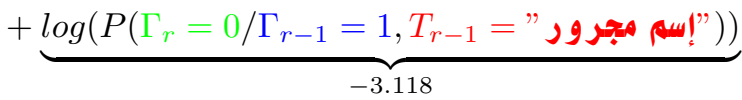

$$
\begin{aligned}
& =-141.062
\end{aligned}
$$




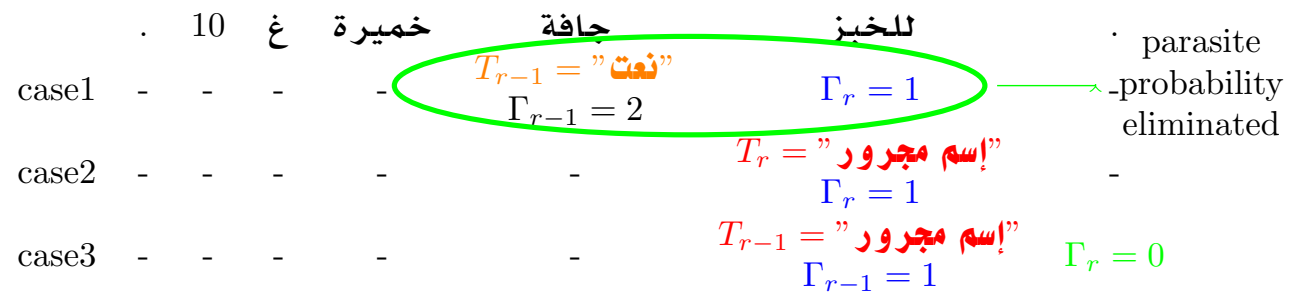

Table 40: Situations table for $\delta_{5}(12,2)+\log \left(a_{1221}\right)$ for a simple double agent Viterbi with external knowledge transfer without unknown words consideration, the parasite probability probability $P\left(\Gamma_{r}=1 / \Gamma_{r-1}=3, T_{r-1}=\right.$ "إسم مجرور") is eliminated and replaced by the probability $P\left(\Gamma_{r}=1 / \Gamma_{r-1}=2, T_{r-1}=\right.$ " "ن" $)$

Estimating an ingredient state using a simple double agent Viterbi with unknown words consideration without external knowledge transfer:

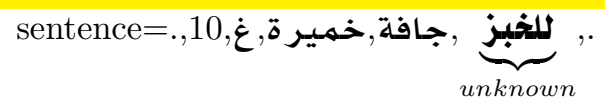

ingredient state $=[0,0,0,1,2,0,0]$

POS tags $=[., \mathrm{B}, \mathrm{I}, \mathrm{E}, \mathrm{F}, \mathrm{H},$.$] coded as [4,10,11,7,8,9,4]$

ingredient to be extracted=خميرة جافة

$$
\psi_{6}(i, j)=\left[\begin{array}{llll}
1 & 0 & 1 & 1 \\
3 & 0 & 3 & 3 \\
3 & 3 & 3 & 3 \\
0 & 0 & 1 & 1 \\
3 & 0 & 1 & 3 \\
1 & 0 & 1 & 3 \\
1 & 3 & 1 & 3 \\
0 & 0 & 0 & 0 \\
1 & 3 & 3 & 3 \\
0 & 0 & 1 & 0 \\
3 & 0 & 3 & 3 \\
3 & 3 & 3 & 3 \\
0 & 3 & 3 & 3 \\
3 & 3 & 3 & 3
\end{array}\right]
$$




$$
\begin{aligned}
& \delta_{5}(9,1)+\log \left(a_{911}\right)=\max _{1 \leq i \leq 4}\left(\delta_{4}(9, i)+\log \left(a_{9 i 1}\right)\right)+\lambda_{\max } \log \left(b_{91}(" \text { "للخبز") })+\log \left(a_{911}\right)\right.
\end{aligned}
$$

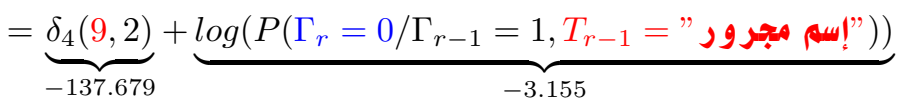

$$
\begin{aligned}
& +\underbrace{\log \left(P\left(V_{r}=" \text { "ل } / \Gamma_{r}=0, T_{r}="\right)\right.}_{-6.948}
\end{aligned}
$$

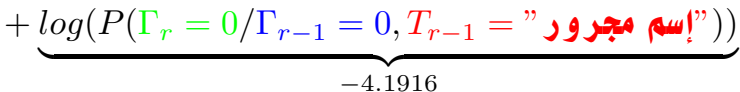

$$
\begin{aligned}
& =-151.97
\end{aligned}
$$

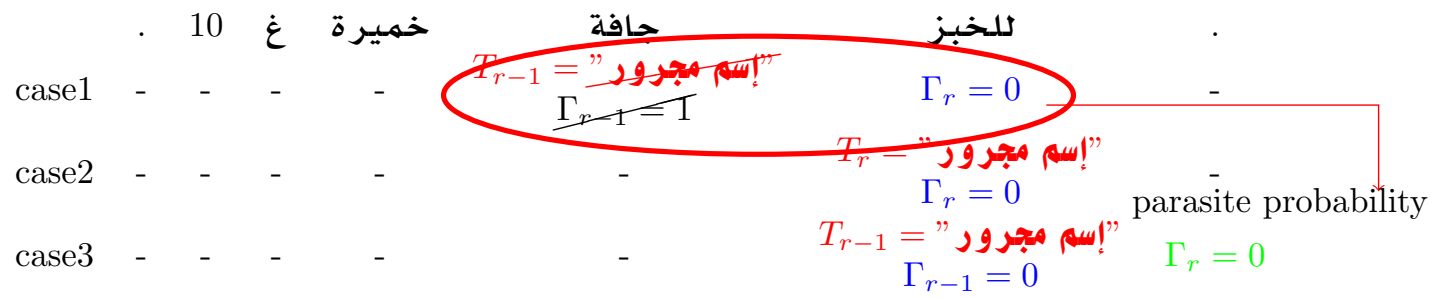

Table 41: Situations table for $\delta_{5}(9,1)+\log \left(a_{911}\right)$ for a simple double agent Viterbi with unknown words consideration without external knowledge transfer, $P\left(\Gamma_{r}=0 / \Gamma_{r-1}=1, T_{r-1}="\right.$ "إسه مجرور real ingredient state of the word جافة نعت is جافة word

$$
\begin{aligned}
& \delta_{5}(9,2)+\log \left(a_{921}\right)=\max _{1 \leq i \leq 4}\left(\delta_{4}(9, i)+\log \left(a_{9 i 2}\right)\right)+\lambda_{\max } \log \left(b_{92}(\text { "لل "ل) })+\log \left(a_{921}\right)\right. \\
& =\underbrace{\delta_{4}(9,4)}_{-137.062}+\underbrace{\log \left(P\left(\Gamma_{r}=1 / \Gamma_{r-1}=3, T_{r-1}="\right) " ~\right.}_{-4.0604} \\
& +\underbrace{\log \left(P\left(V_{r}=" \text { "ل } / \Gamma_{r}=1, T_{r}="\right)\right.}_{-6.7473} \\
& +\underbrace{\log \left(P\left(\Gamma_{r}=0 / \Gamma_{r-1}=1, T_{r-1}=" \text { "إسم مجرور") }\right)\right.}_{-3.155} \\
& =-151.025
\end{aligned}
$$

Estimating an ingredient state using a simple double agent Viterbi algorithm with external knowledge transfer :

sentence=.,10, جافة,خميرة, غير,

$$
\text { unknown }
$$




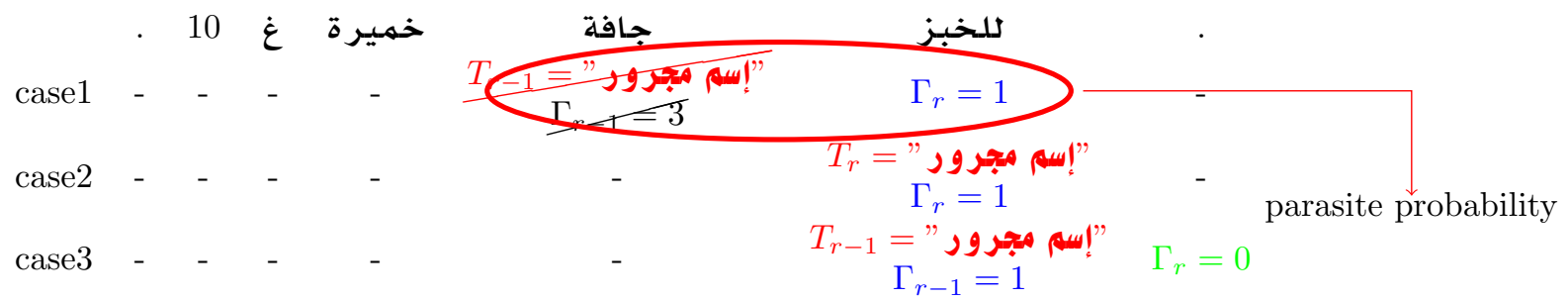

Table 42: Situations table for $\delta_{5}(9,2)+\log \left(a_{921}\right)$ for a simple double agent Viterbi with unknown words consideration, $P\left(\Gamma_{r}=1 / \Gamma_{r-1}=\right.$ $3, T_{r-1}="$ (إسم مجرور of the word جافت is

ingredient state $=[0,0,0,1,2,0,0]$

POS tags $=[., \mathrm{B}, \mathrm{I}, \mathrm{E}, \mathrm{F}, \mathrm{H},$.$] coded as [4,10,11,7,8,9,4]$

ingredient to be extracted=خميرة جافة

$$
\begin{aligned}
& \delta_{5}(9,1)+\log \left(a_{911}\right)=\max _{1 \leq i \leq 4}\left(\delta_{4}(P O S[5], i)+\log \left(a_{P O S[5 i 11}\right)\right)+\log \left(b_{91}\left(" ل{ }^{\prime \prime}\right)\right)+\log \left(a_{911}\right) \\
& =\underbrace{\delta_{4}(8,3)}_{-96.916}+\underbrace{\log \left(P\left(\Gamma_{r}=0 / \Gamma_{r-1}=2, T_{r-1}=" ن "\right)\right)}_{-0.8461} \\
& +\underbrace{\log \left(P\left(V_{r}=" \text { "ل " } / \Gamma_{r}=0, T_{r}="\right)\right.}_{-6.9488} \\
& +\underbrace{\log \left(P\left(\Gamma_{r}=0 / \Gamma_{r-1}=0, T_{r-1}=" \text { "إسم مجرور") }\right)\right)}_{-4.1916} \\
& =-108.902
\end{aligned}
$$

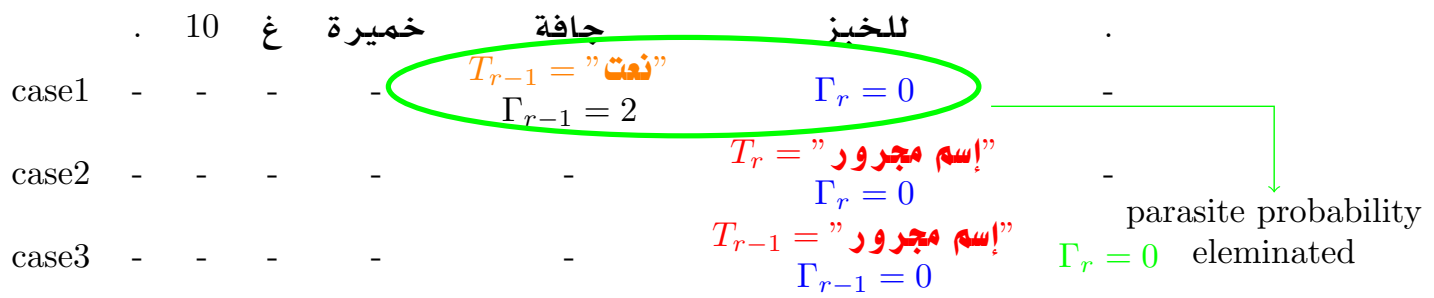

Table 43: Situations table for $\delta_{5}(9,1)+\log \left(a_{911}\right)$ for a simple double agent Viterbi with external knowledge transfer with unknown words consideration, the parasite probability probability $P\left(\Gamma_{r}=0 / \Gamma_{r-1}=1, T_{r-1}=\right.$ "إسم مجرور") is

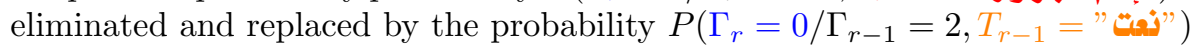




$$
\begin{aligned}
& \delta_{5}(9,2)+\log \left(a_{921}\right)=\max _{1 \leq i \leq 4}\left(\delta_{4}(P O S[5], i)+\log \left(a_{P O S[5] i 2}\right)\right)+\log \left(b_{92}\left(" ل{ }^{\prime \prime} "\right)\right)+\log \left(a_{921}\right) \\
& =\underbrace{\delta_{4}(8,3)}_{-96.91}+\underbrace{\log \left(P\left(\Gamma_{r}=1 / \Gamma_{r-1}=2, T_{r-1}=" \text { "نّ" }\right)\right)}_{-6.335} \\
& +\underbrace{\log \left(P\left(V_{r}=" \text { لل " } / \Gamma_{r}=1, T_{r}="\right)\right.}_{-6.747}
\end{aligned}
$$

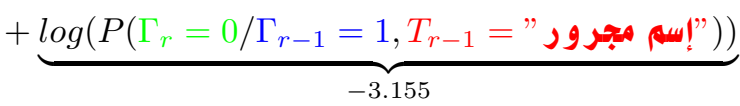

$$
\begin{aligned}
& =-113.153
\end{aligned}
$$

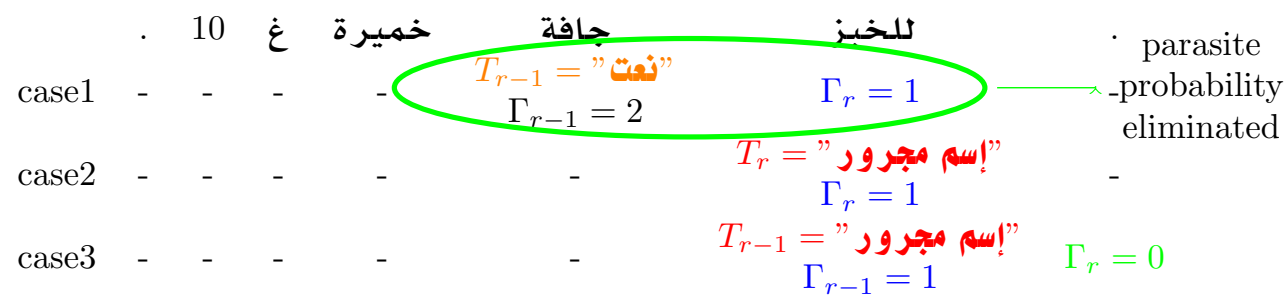

Table 44: Situations table for $\delta_{5}(9,2)+\log \left(a_{921}\right)$ for a primitive double agent Viterbi with external knowledge transfer with unknown words consideration, the parasite probability probability $P\left(\Gamma_{r}=1 / \Gamma_{r-1}=3, T_{r-1}=\right.$ " eliminated and replaced by the probability $P\left(\Gamma_{r}=1 / \Gamma_{r-1}=2, T_{r-1}=\right.$ "نّ"

\section{Results and Discussion}

When comparing the results obtained in table Table 31, we found that the double layered Viterbi algorithm with external knowledge transfer is overcoming largely the 3 other methods in terms of precision with a f-score value of 96,32 $\%$ versus $70,06 \%$ for a first order mono-layered HMM model , $68,18 \%$ for a second order mono-layered HMM model and $81,32 \%$ for a simple double agent Viterbi algorithm. This can be explained by the external knowledge transfer characterizing our developed algorithm that minimized the amount of parasite probabilities that may appear during the calculation of the most probable elements of a state matrix. For example for the sentence " where all the words are known both a simple double agent Viterbi and a simple double agent Viterbi with external knowlage transfer estimates well the token للخبز which is not an ingredient, but for the first algorithm we have $|X-Y|=\left|\delta_{5}(12,1)+\log \left(a_{1211}\right)-\delta_{5}(12,2)-\log \left(a_{1221}\right)\right|=0,58$ and we have for the second one $|X-Y|=\left|\delta_{5}(12,1)+\log \left(a_{1211}\right)-\delta_{5}(12,2)-\log \left(a_{1221}\right)\right|=5,97$ 


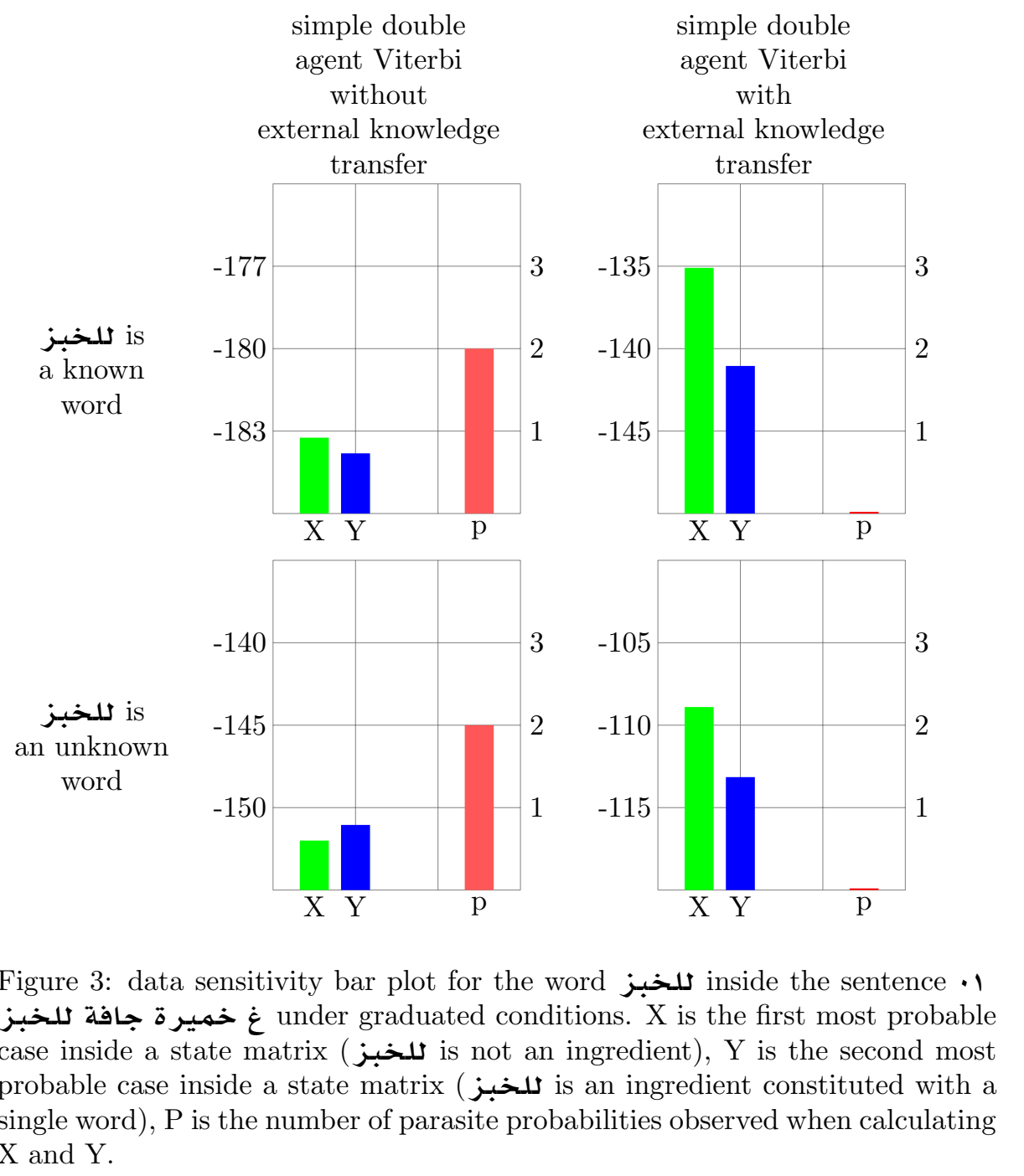


(figure 3) which means that the state matrix for a double agent Viterbi algorithm with external knowledge transfer differentiate well between the most probable cases inside a state matrix and it is more confident in estimating an ingredient state. We can explain the efficiency of our new algorithm by the fact that when the probabilities constituting the equation of the most probable elements of the state matrix are describing well the values hold by a token and not wrong parameters like we see in a parasite probability, the elements of the state matrix tend to enlarge the differences between a state describing the real estimation and a state describing a wrong estimation.

One important characteristic found in a double agent Viterbi algorithm with external knowledge transfer is its capacity to well estimate ingredients state against a mono-layered Viterbi algorithm and a simple double agent Viterbi algorithm without external knowledge transfer in a context of unknown words. When an unknown word is estimated, the lexical probability $P\left(V_{r}="\right.$ "للخبز" becomes $P\left(V_{r}="\right.$ "ل "إسم مجرور ") and its importance for estimating hidden states on the second layer of our model becomes lower . External knowledge transfer allowed us to clean our double layered Viterbi algorithm from parasite probabilities and maintain a good f-score of $72.19 \%$ (table 36) because we are confirming that knowledge transfer is increasing the precision comparing to what we got for our ingredient extractor (Baklouti, 2019, September 4) (table 36). Best accuracy for unknown words is detained by our new algorithm (table 36 ) . These promising performances can be explained by observing the equations determining the most probable cases of a state matrix. For example, in the sentence "10" when the token للخبز is unknown , a primitive Viterbi algorithm does not estimated the exact ingredient state for that token which is $\Gamma=0$ given that the word للخبز is not an ingredient, on the other side, a double layered Viterbi algorithm with internal knowledge transfer estimated well the ingredient state, this can be explained by the absence of parasite probabilities in the second algorithm

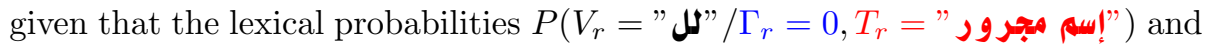
$P\left(V_{r}="\right.$ "إسم مجرور ") keep the same values when they are used in the a double agent Viterbi algorithm with and without external knowledge transfer.

Another concepts characterizing a simple double agent Viterbi algorithm with external knowledge transfer is its capacity to react effectively toward dataset tuning and also its capacity to resist data monotonicity logic. For example, our dataset is describing the ingredients used in a recipe and to achieve a better understanding, a typical sentence structure is frequently used to present an ingredient like using the preposition "of" and then announcing the wanted information but sometimes this monotonous logic is not always true when the preposition "of" is used to describe the ingredient like in the sentence "olive oil of good quality". We created an adapted graph to study the comportment of our new algorithm toward monotonous logic called a data sensitivity bar plot. A data sensitivity bar plot is presenting two informations : the value of the most probable cases inside a state matrix and the number of parasite probabilities observed. Those informations are experimented under graduated conditions. A 
graduate condition is used to explore the dynamical comportment of the algorithm , for example, we have in our dataset the sentence "olive oil of good quality" where the ingredient is situated on the beginning of the sentence and it is hard for any algorithm to give a correct prediction for this sentence when it is tagged only one time on the tag-set especially for a mono-agent Viterbi algorithm where the only parameters of this model are the tokens and the ingredients states. Data tuning is one of the graduated condition we can use by adding first a similar sentence that keep the same tags for part of speech and for ingredients state like the sentence "one tomatoes of big size", and second by adding the same sentence to obtain a tag-set with the sentence "olive oil of good quality" repeated twice.We can associate this graduated condition with the algorithm used to predict ingredients states and deployed in a data sensitivity plot gradually from the method with the lowest f-score to the algorithm with the highest f-score (figure 2). Data sensitivity bar plot with the previous described combination shows a certain static behaviour for a second order mono-agent Viterbi and a simple double agent Viterbi without external knowledge transfer. A dynamic behaviour is observed only for a simple double agent Viterbi without external knowledge transfer where the value of the correct state increase and the number of parasite probabilities decrease when we move from a condition with low grade to a condition with high grade. Moving from known to unknown word could be also a graduated condition used to analyse dynamic behaviour of an algorithm in a data sensitivity bar plot (figure 3).

\section{Conclusion}

We have proposed an algorithm mixing Hidden Markov Models and external knowledge transfer to solve the problem of information extraction in natural language processing, our algorithm can be used in other problems where Hidden Markov Models are deployed.This algorithm has proven a spectacular improvement in f1 score without unknown words consideration and performances for unknown words are improved comparing to old results for a simple double agents Viterbi without external knowledge transfer (Baklouti, 2019, September 4) but still can be improved by creating a full double agent Viterbi with external knowledge transfer where the number of parasite probabilities generated is less than we obtained on this paper. 


\section{A Detailed Iterations of a simple double agent Viterbi Algorithm with external knowledge transfer}

1. Predicting POS Tags for the first Layer:

We can use for predicting POS tags any method that provide a high accuracy and f-score. Some features used for natural language programming problems are directly extracted from the tokens like extracting the first letters from a token.

2. Predicting Ingredients state for the second Layer:

The variables:

- $\delta_{l}(i, j)=\max _{\tau_{1} \ldots \tau_{l-1}} P\left(\tau_{1} \ldots \tau_{l}=\left[t_{i}, \gamma_{j}\right] / v_{1} \ldots v_{l}, t_{1} \ldots t_{l}, y_{1} \ldots y_{l}\right), l=1 \ldots L$

- $\psi_{l}(i, j)=\operatorname{argmax}_{\tau_{1} \ldots \tau_{l-1}} P\left(\tau_{1} \ldots \tau_{l}=\left[t_{i}, \gamma_{j}\right] / v_{1} \ldots v_{l}, t_{1} \ldots t_{l}, y_{1} \ldots y_{l}\right), l=$ $1 \ldots L$

The procedure:

(1) Initialization step:

$$
\begin{gathered}
\delta_{1}(i, j)=\left\{\begin{array}{l}
\pi_{j} b_{i j}\left(v_{1}\right) \quad v_{1} \text { is known } \mathrm{i}=1 . .14 \mathrm{j}=1 . .4 \\
\pi_{j} c_{i j}\left(v_{1}\right) \quad v_{1} \text { is unknown } \mathrm{i}=1 . .14 \mathrm{j}=1 . .4
\end{array}\right. \\
\psi_{1}(i, j)=0 \mathrm{i}=1 . .14 \mathrm{j}=1 . .4
\end{gathered}
$$

(2) Iteration step:

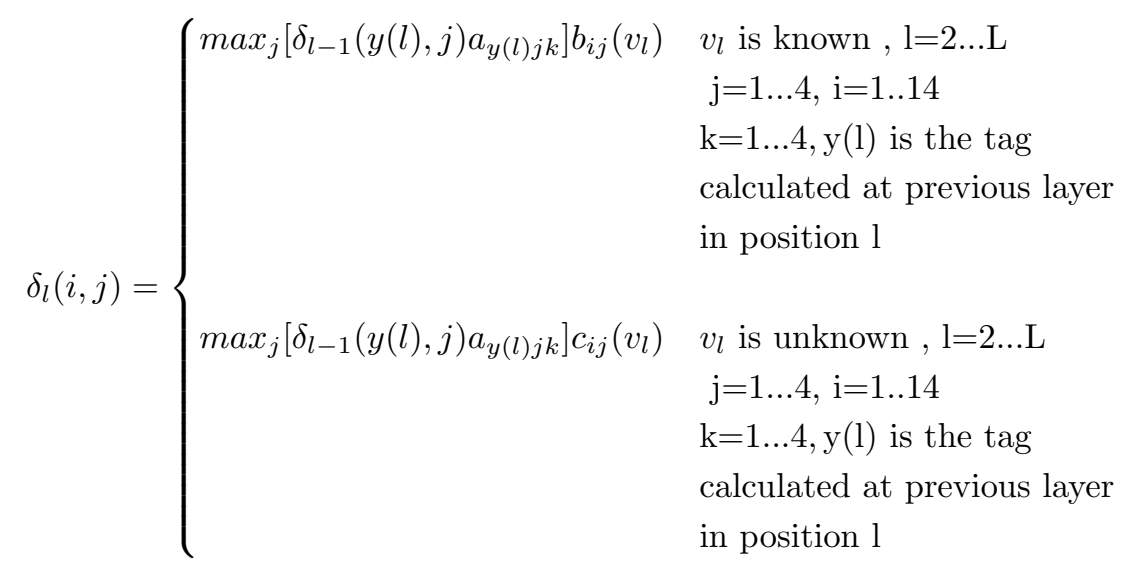


$\psi_{l}(i, j)=\operatorname{argmax}_{j}\left[\delta_{l-1}(y(l), j) a_{y(l) j k}\right]$
$\mathrm{j}=1 . .4, \mathrm{i}=1 . .14, \mathrm{k}=1 . .4, \mathrm{y}(\mathrm{l})$ is the tag calculated at previous layer in position $\mathrm{l}$

(3) Termination:

$$
\tau_{L}^{*}=\operatorname{argmax}_{i=y(L), j=1 . .4} \delta_{L}(i, j)
$$

where $\mathrm{y}(\mathrm{L})$ is the tag calculated at previous layer in position $\mathrm{L}$

(4) Backtracking:

$$
\tau_{l}^{*}=\psi_{l}\left(y(l), \tau_{l+1}^{*}\right) \mathrm{l}=\mathrm{L}-1 . .2,1
$$

where $\mathrm{y}(\mathrm{l})$ is the tag calculated at previous layer in position $\mathrm{l}$

3. Predicting Ingredients state for the second Layer in Log-space and introduction of the hyper-parameter $\lambda$

The variables:

- $\delta_{l}(i, j)=\max _{\tau_{1} \ldots \tau_{l-1}} P\left(\tau_{1} \ldots \tau_{l}=\left[t_{i}, \gamma_{j}\right] / v_{1} \ldots v_{l}, t_{1} \ldots t_{l}, y_{1} \ldots y_{l}\right), l=1 \ldots L$

- $\psi_{l}(i, j)=\operatorname{argmax}_{\tau_{1} \ldots \tau_{l-1}} P\left(\tau_{1} \ldots \tau_{l}=\left[t_{i}, \gamma_{j}\right] / v_{1} \ldots v_{l}, t_{1} \ldots t_{l}, y_{1} \ldots y_{l}\right), l=$ $1 \ldots L$

\section{The procedure:}

(1) Initialization step:

$$
\begin{gathered}
\delta_{1}(i, j)=\left\{\begin{array}{cc}
\log \left(\pi_{j}\right)+\log \left(b_{i j}\left(v_{1}\right)\right) & v_{1} \text { is known } \mathrm{i}=1 . .14 \mathrm{j}=1 . .4 \\
\log \left(\pi_{j}\right)+\log \left(c_{i j}\left(v_{1}\right)\right) & v_{1} \text { is unknown } \mathrm{i}=1 . .14 \mathrm{j}=1 . .4
\end{array}\right. \\
\psi_{1}(i, j)=0 \mathrm{i}=1 . .14 \mathrm{j}=1 . .4
\end{gathered}
$$

(2) Iteration step:

$$
\delta_{l}(i, j)= \begin{cases}\max _{j}\left[\delta_{l-1}(y(l), j)+\log \left(a_{y(l) j k}\right)\right]+\lambda_{\max } \log \left(b_{i j}\left(v_{l}\right)\right) & v_{l} \text { is known } \mathrm{l}=2 . . \mathrm{L} \\ & \mathrm{j}=1 \ldots 4, \mathrm{i}=1 . .14 \\ & \mathrm{k}=1 \ldots 4, \mathrm{y}(\mathrm{l}) \text { is the tag } \\ & \text { calculated at previous layer } \\ & \text { in position } \mathrm{l} \\ \max _{j}\left[\delta_{l-1}(y(l), j)+\log \left(a_{y(l) j k}\right)\right]+\lambda_{\max } \log \left(c_{i j}\left(v_{l}\right)\right) & \\ & v_{l} \text { is unknown } \\ & \mathrm{l}=2 \ldots \mathrm{L} \mathrm{j}=1 . .4 \\ & \mathrm{i}=1 . .14 \mathrm{k}=1 . .4, \mathrm{y}(\mathrm{l}) \text { is the tag } \\ & \text { calculated at previous layer } \\ & \text { in position } \mathrm{l}\end{cases}
$$




$$
\psi_{l}(i, j)=\operatorname{argmax}_{j}\left[\delta_{l-1}(y(l), j)+\log \left(a_{y(l) j k}\right)\right] \mathrm{j}=1 . .4, \mathrm{i}=1 . .14, \mathrm{k}=1 . .4, \mathrm{y}(\mathrm{l}) \text { is the tag }
$$
calculated at previous layer in position $\mathrm{l}$

(3) Termination:

$$
\tau_{L}^{*}=\operatorname{argmax}_{i=y(L), j=1 . .4} \delta_{L}(i, j)
$$

where $\mathrm{y}(\mathrm{L})$ is the tag calculated at previous layer in position $\mathrm{L}$

(4) Backtracking:

$$
\tau_{l}^{*}=\psi_{l}\left(y(l), \tau_{l+1}^{*}\right) \mathrm{l}=\mathrm{L}-1 . .2,1
$$

where $\mathrm{y}(\mathrm{l})$ is the tag calculated at previous layer in position 1

- Initialization step:

$$
\begin{aligned}
& {\left[\begin{array}{cccc}
d_{1,1,1} & d_{1,1,2} & d_{1,1,3} & d_{1,1,4} \\
d_{1,2,1} & d_{1,2,2} & d_{1,2,3} & d_{1,2,4} \\
d_{1,3,1} & d_{1,3,2} & d_{1,3,3} & d_{1,3,4} \\
\vdots & \vdots & \vdots & \vdots \\
d_{1,14,1} & d_{1,14,2} & d_{1,14,3} & d_{1,14,4}
\end{array}\right]\left[\begin{array}{llll}
p i_{1} & p i_{2} & p i_{3} & p i_{4}
\end{array}\right]\left[\begin{array}{cccc}
b_{1,1, x[1]} & b_{1,2, x[1]} & b_{1,3, x[1]} & b_{1,4, x[1]} \\
b_{2,1, x[1]} & b_{2,2, x[1]} & b_{2,3, x[1]} & b_{2,4, x[1]} \\
b_{3,1, x[1]} & b_{3,2, x[1]} & b_{3,3, x[1]} & b_{3,4, x[1]} \\
\vdots & \vdots & \vdots & \vdots \\
b_{14,1, x[1]} & b_{14,2, x[1]} & b_{14,3, x[1]} & b_{14,4, x[1]}
\end{array}\right]} \\
& d_{1,1,1}=p i_{1} \times b_{1,1, x[1]}
\end{aligned}
$$

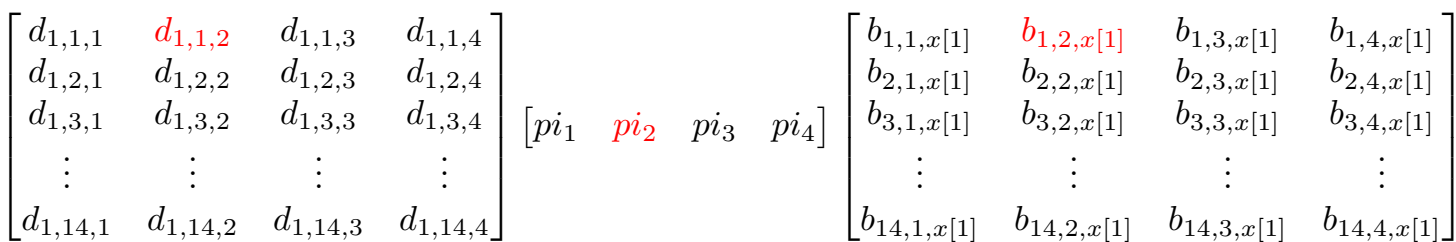

$$
\begin{aligned}
& d_{1,1,2}=p i_{2} \times b_{1,2, x[1]} \\
& {\left[\begin{array}{cccc}
d_{1,1,1} & d_{1,1,2} & d_{1,1,3} & d_{1,1,4} \\
d_{1,2,1} & d_{1,2,2} & d_{1,2,3} & d_{1,2,4} \\
d_{1,3,1} & d_{1,3,2} & d_{1,3,3} & d_{1,3,4} \\
\vdots & \vdots & \vdots & \vdots \\
d_{1,14,1} & d_{1,14,2} & d_{1,14,3} & d_{1,14,4}
\end{array}\right]\left[\begin{array}{llll}
p i_{1} & p i_{2} & p i_{3} & p i_{4}
\end{array}\right]\left[\begin{array}{cccc}
b_{1,1, x[1]} & b_{1,2, x[1]} & b_{1,3, x[1]} & b_{1,4, x[1]} \\
b_{2,1, x[1]} & b_{2,2, x[1]} & b_{2,3, x[1]} & b_{2,4, x[1]} \\
b_{3,1, x[1]} & b_{3,2, x[1]} & b_{3,3, x[1]} & b_{3,4, x[1]} \\
\vdots & \vdots & \vdots & \vdots \\
b_{14,1, x[1]} & b_{14,2, x[1]} & b_{14,3, x[1]} & b_{14,4, x[1]}
\end{array}\right]} \\
& d_{1,1,3}=p i_{3} \times b_{1,3, x[1]} \\
& {\left[\begin{array}{cccc}
d_{1,1,1} & d_{1,1,2} & d_{1,1,3} & d_{1,1,4} \\
d_{1,2,1} & d_{1,2,2} & d_{1,2,3} & d_{1,2,4} \\
d_{1,3,1} & d_{1,3,2} & d_{1,3,3} & d_{1,3,4} \\
\vdots & \vdots & \vdots & \vdots \\
d_{1,14,1} & d_{1,14,2} & d_{1,14,3} & d_{1,14,4}
\end{array}\right]\left[\begin{array}{llll}
p i_{1} & p i_{2} & p i_{3} & p i_{4}
\end{array}\right]\left[\begin{array}{cccc}
b_{1,1, x[1]} & b_{1,2, x[1]} & b_{1,3, x[1]} & b_{1,4, x[1]} \\
b_{2,1, x[1]} & b_{2,2, x[1]} & b_{2,3, x[1]} & b_{2,4, x[1]} \\
b_{3,1, x[1]} & b_{3,2, x[1]} & b_{3,3, x[1]} & b_{3,4, x[1]} \\
\vdots & \vdots & \vdots & \vdots \\
b_{14,1, x[1]} & b_{14,2, x[1]} & b_{14,3, x[1]} & b_{14,4, x[1]}
\end{array}\right]}
\end{aligned}
$$




$$
d_{1,1,4}=p i_{4} \times b_{1,4, x[1]}
$$

$\left[\begin{array}{cccc}d_{1,1,1} & d_{1,1,2} & d_{1,1,3} & d_{1,1,4} \\ d_{1,2,1} & d_{1,2,2} & d_{1,2,3} & d_{1,2,4} \\ d_{1,3,1} & d_{1,3,2} & d_{1,3,3} & d_{1,3,4} \\ \vdots & \vdots & \vdots & \vdots \\ d_{1,14,1} & d_{1,14,2} & d_{1,14,3} & d_{1,14,4}\end{array}\right]\left[\begin{array}{llll}p i_{1} & p i_{2} & p i_{3} & p i_{4}\end{array}\right]\left[\begin{array}{cccc}b_{1,1, x[1]} & b_{1,2, x[1]} & b_{1,3, x[1]} & b_{1,4, x[1]} \\ b_{2,1, x[1]} & b_{2,2, x[1]} & b_{2,3, x[1]} & b_{2,4, x[1]} \\ b_{3,1, x[1]} & b_{3,2, x[1]} & b_{3,3, x[1]} & b_{3,4, x[1]} \\ \vdots & \vdots & \vdots & \vdots \\ b_{14,1, x[1]} & b_{14,2, x[1]} & b_{14,3, x[1]} & b_{14,4, x[1]}\end{array}\right]$

$$
d_{1,2,1}=p i_{1} \times b_{2,1, x[1]}
$$

$$
\left[\begin{array}{cccc}
d_{1,1,1} & d_{1,1,2} & d_{1,1,3} & d_{1,1,4} \\
d_{1,2,1} & d_{1,2,2} & d_{1,2,3} & d_{1,2,4} \\
d_{1,3,1} & d_{1,3,2} & d_{1,3,3} & d_{1,3,4} \\
\vdots & \vdots & \vdots & \vdots \\
d_{1,14,1} & d_{1,14,2} & d_{1,14,3} & d_{1,14,4}
\end{array}\right]\left[\begin{array}{llll}
p i_{1} & p i_{2} & p i_{3} & p i_{4}
\end{array}\right]\left[\begin{array}{cccc}
b_{1,1, x[1]} & b_{1,2, x[1]} & b_{1,3, x[1]} & b_{1,4, x[1]} \\
b_{2,1, x[1]} & b_{2,2, x[1]} & b_{2,3, x[1]} & b_{2,4, x[1]} \\
b_{3,1, x[1]} & b_{3,2, x[1]} & b_{3,3, x[1]} & b_{3,4, x[1]} \\
\vdots & \vdots & \vdots & \vdots \\
b_{14,1, x[1]} & b_{14,2, x[1]} & b_{14,3, x[1]} & b_{14,4, x[1]}
\end{array}\right]
$$

$$
d_{1,14,4}=p i_{4} \times b_{14,4, x[1]}
$$

- Iteration step:

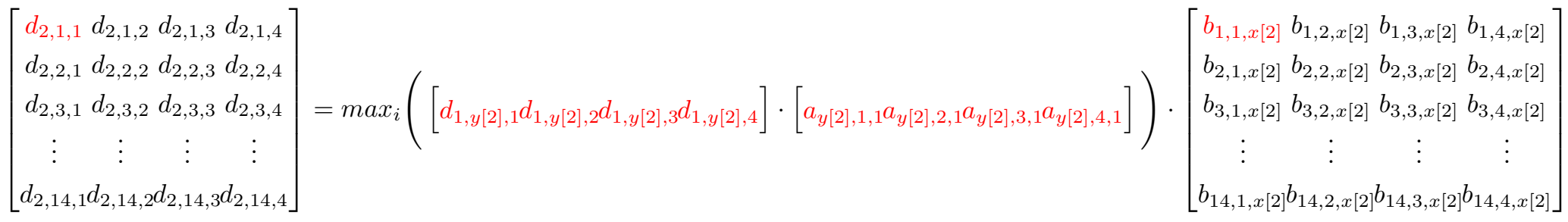

$$
d_{2,1,1}=\max \left(d_{1, y[2], 1} \times a_{y[2], 1,1}, d_{1, y[2], 2} \times a_{y[2], 2,1}, \cdots, d_{1, y[2], 4} \times a_{y[2], 4,1}\right) \times b_{1,1, x[2]}
$$$$
\left[\begin{array}{cccc}
p_{2,1,1} & p_{2,1,2} & p_{2,1,3} & p_{2,1,4} \\
p_{2,2,1} & p_{2,2,2} & p_{2,2,3} & p_{2,2,4} \\
p_{2,3,1} & p_{2,3,2} & p_{2,3,3} & p_{2,3,4} \\
\vdots & \vdots & \vdots & \vdots \\
p_{2,14,1} & p_{2,14,2} & p_{2,14,3} & p_{2,14,4}
\end{array}\right]=\operatorname{argmax}_{i}\left(\left[d_{1, y[2], 1} d_{1, y[2], 2} d_{1, y[2], 3} d_{1, y[2], 4}\right] \cdot\left[a_{y[2], 1,1} a_{y[2], 2,1} a_{y[2], 3,1} a_{y[2], 4,1}\right]\right)
$$$$
p_{2,1,1}=\operatorname{argmax}\left(d_{1, y[2], 1} \times a_{y[2], 1,1}, d_{1, y[2], 2} \times a_{y[2], 2,1}, \cdots, d_{1, y[2], 4} \times a_{y[2], 4,1}\right)
$$ 


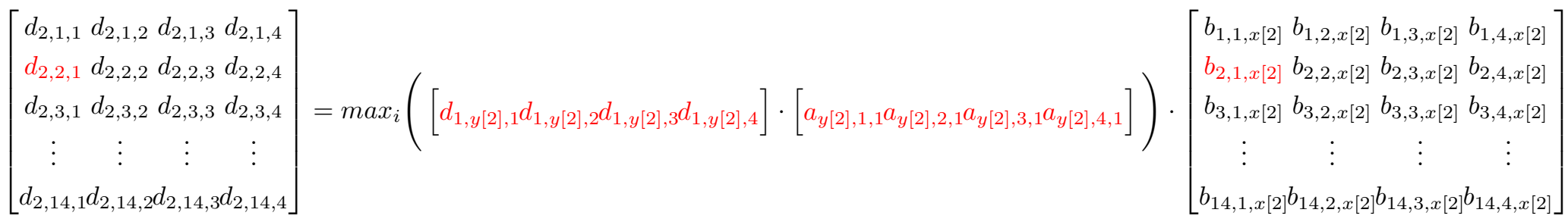

$$
d_{2,2,1}=\max \left(d_{1, y[2], 1} \times a_{y[2], 1,1}, d_{1, y[2], 2} \times a_{y[2], 2,1}, \cdots, d_{1, y[2], 4} \times a_{y[2], 4,1}\right) \times b_{2,1, x[2]}
$$

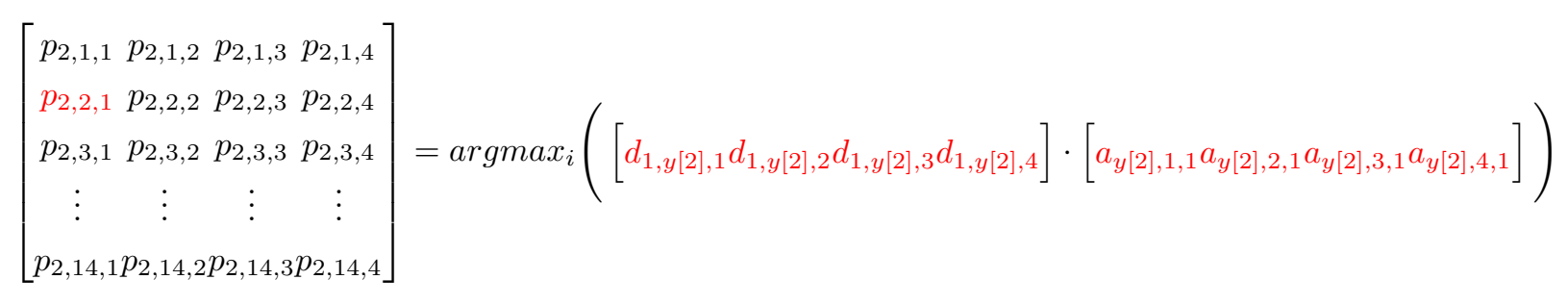

$$
p_{2,2,1}=\operatorname{argmax}\left(d_{1, y[2], 1} \times a_{y[2], 1,1}, d_{1, y[2], 2} \times a_{y[2], 2,1}, \cdots, d_{1, y[2], 4} \times a_{y[2], 4,1}\right)
$$

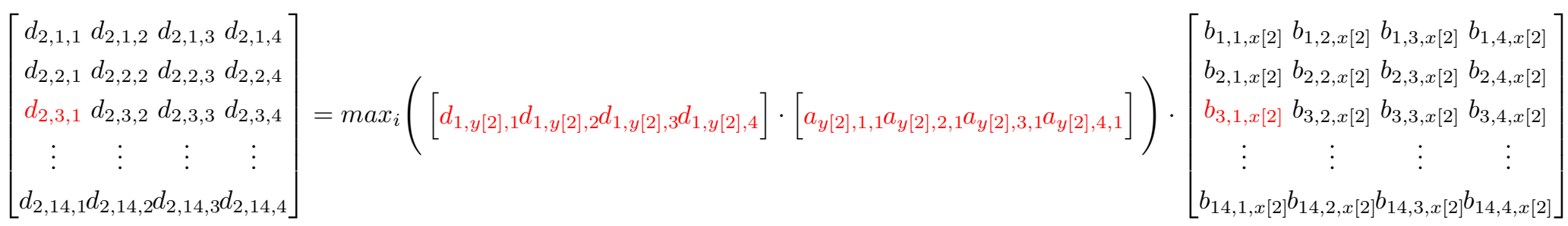

$$
d_{2,3,1}=\max \left(d_{1, y[2], 1} \times a_{y[2], 1,1}, d_{1, y[2], 2} \times a_{y[2], 2,1}, \cdots, d_{1, y[2], 4} \times a_{y[2], 4,1}\right) \times b_{3,1, x[2]}
$$

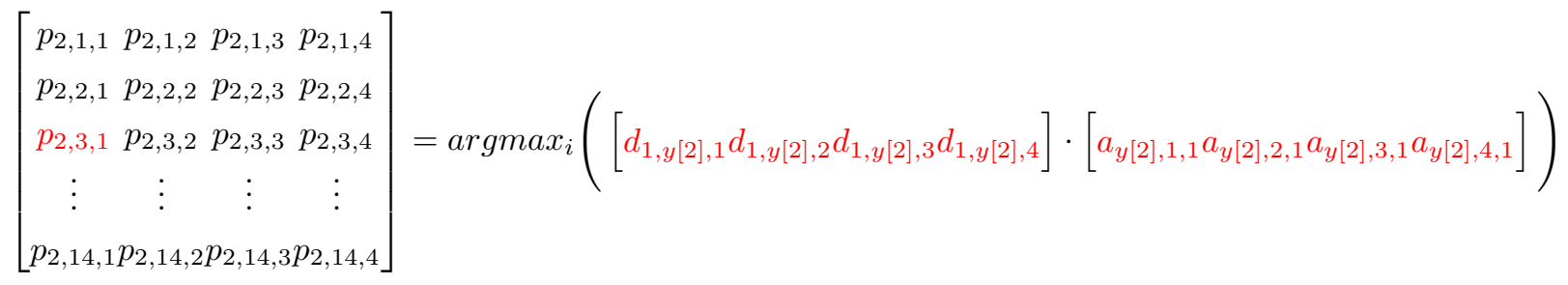

$$
p_{2,3,1}=\operatorname{argmax}\left(d_{1, y[2], 1} \times a_{y[2], 1,1}, d_{1, y[2], 2} \times a_{y[2], 2,1}, \cdots, d_{1, y[2], 4} \times a_{y[2], 4,1}\right)
$$




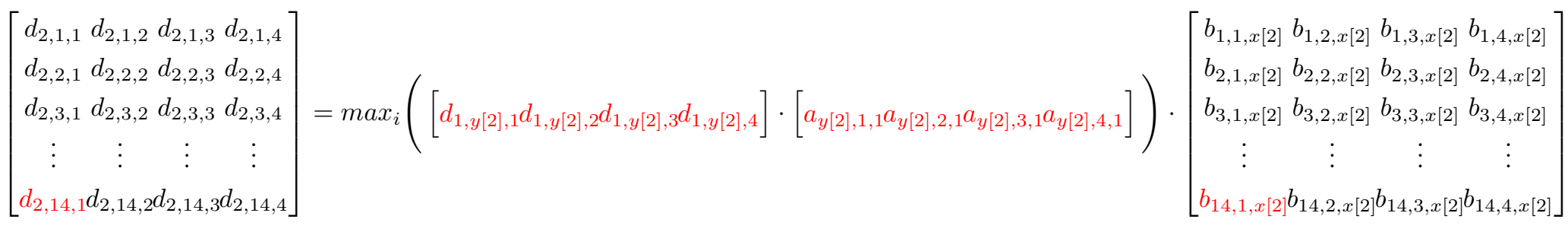

$$
d_{2,14,1}=\max \left(d_{1, y[2], 1} \times a_{y[2], 1,1}, d_{1, y[2], 2} \times a_{y[2], 2,1}, \cdots, d_{1, y[2], 4} \times a_{y[2], 4,1}\right) \times b_{14,1, x[2]}
$$

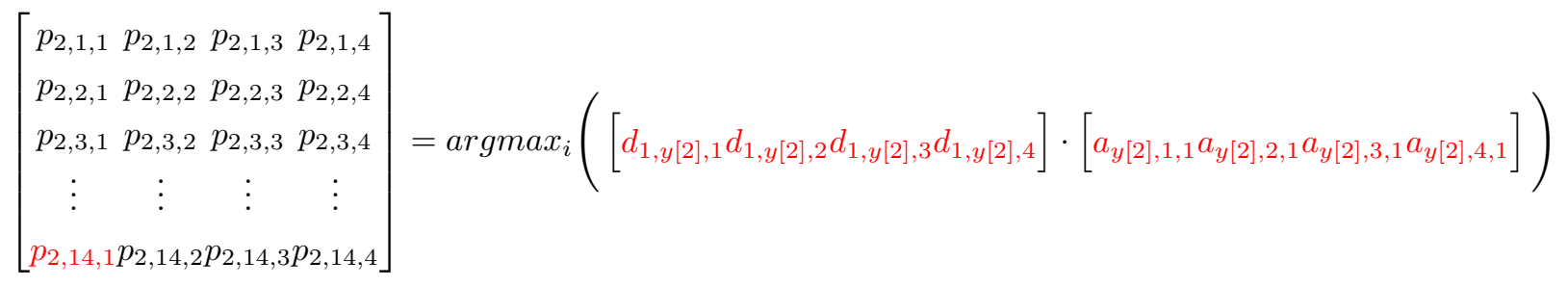

$$
p_{2,14,1}=\operatorname{argmax}\left(d_{1, y[2], 1} \times a_{y[2], 1,1}, d_{1, y[2], 2} \times a_{y[2], 2,1}, \cdots, d_{1, y[2], 4} \times a_{y[2], 4,1}\right)
$$

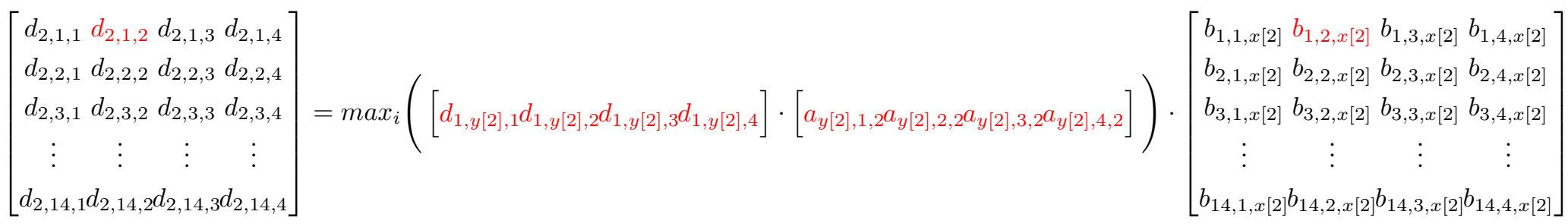

$$
d_{2,1,2}=\max \left(d_{1, y[2], 1} \times a_{y[2], 1,2}, d_{1, y[2], 2} \times a_{y[2], 2,2}, \cdots, d_{1, y[2], 4} \times a_{y[2], 4,2}\right) \times b_{1,2, x[2]}
$$

$$
\left[\begin{array}{cccc}
p_{2,1,1} & p_{2,1,2} & p_{2,1,3} & p_{2,1,4} \\
p_{2,2,1} & p_{2,2,2} & p_{2,2,3} & p_{2,2,4} \\
p_{2,3,1} & p_{2,3,2} & p_{2,3,3} & p_{2,3,4} \\
\vdots & \vdots & \vdots & \vdots \\
p_{2,14,1} & p_{2,14,2} & p_{2,14,3} & p_{2,14,4}
\end{array}\right]=\operatorname{argmax}_{i}\left(\left[d_{1, y[2], 1} d_{1, y[2], 2} d_{1, y[2], 3} d_{1, y[2], 4}\right] \cdot\left[a_{y[2], 1,2} a_{y[2], 2,2} a_{y[2], 3,2} a_{y[2], 4,2}\right]\right)
$$


$p_{2,1,2}=\operatorname{argmax}\left(d_{1, y[2], 1} \times a_{y[2], 1,2}, d_{1, y[2], 2} \times a_{y[2], 2,2}, \cdots, d_{1, y[2], 4} \times a_{y[2], 4,2}\right)$

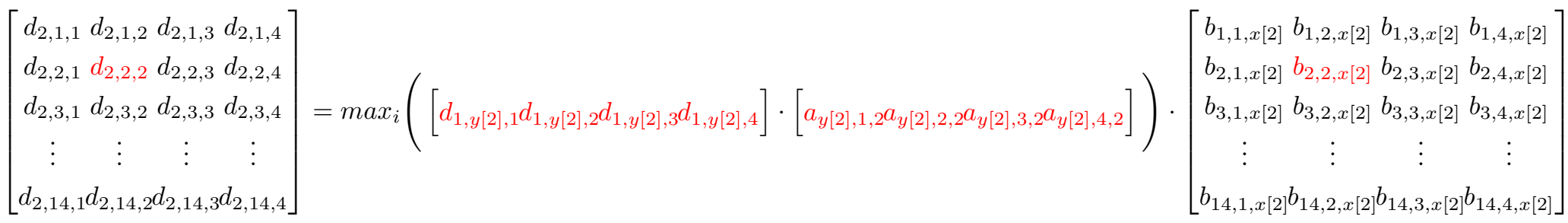

$$
d_{2,2,2}=\max \left(d_{1, y[2], 1} \times a_{y[2], 1,2}, d_{1, y[2], 2} \times a_{y[2], 2,2}, \cdots, d_{1, y[2], 4} \times a_{y[2], 4,2}\right) \times b_{2,2, x[2]}
$$

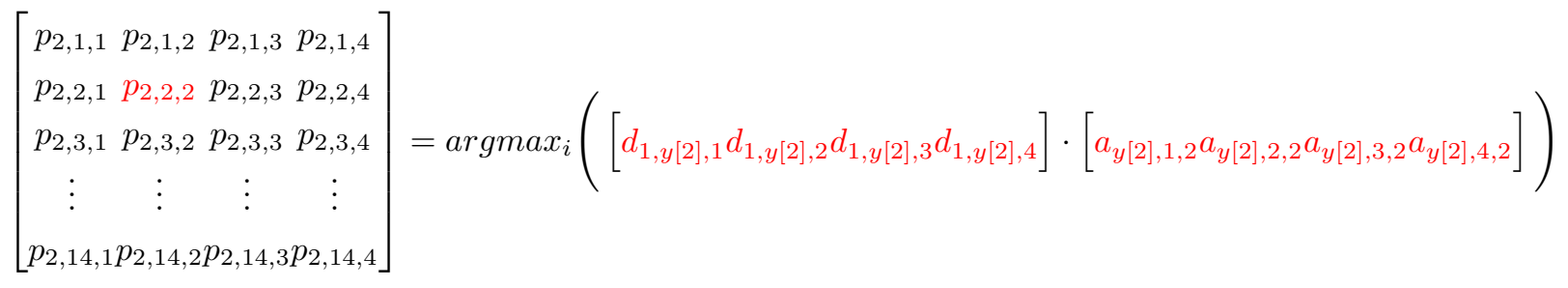

$p_{2,2,2}=\operatorname{argmax}\left(d_{1, y[2], 1} \times a_{y[2], 1,2}, d_{1, y[2], 2} \times a_{y[2], 2,2}, \cdots, d_{1, y[2], 4} \times a_{y[2], 4,2}\right)$

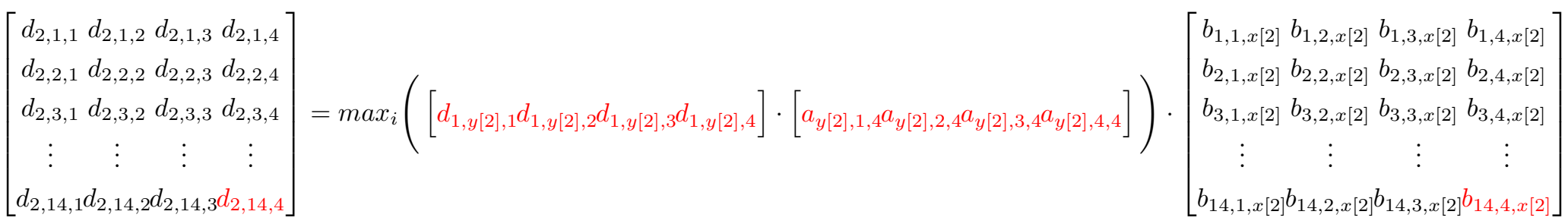

$$
d_{2,14,4}=\max \left(d_{1, y[2], 1} \times a_{y[2], 1,4}, d_{1, y[2], 2} \times a_{y[2], 2,4}, \cdots, d_{1, y[2], 4} \times a_{y[2], 4,4}\right) \times b_{14,4, x[2]}
$$

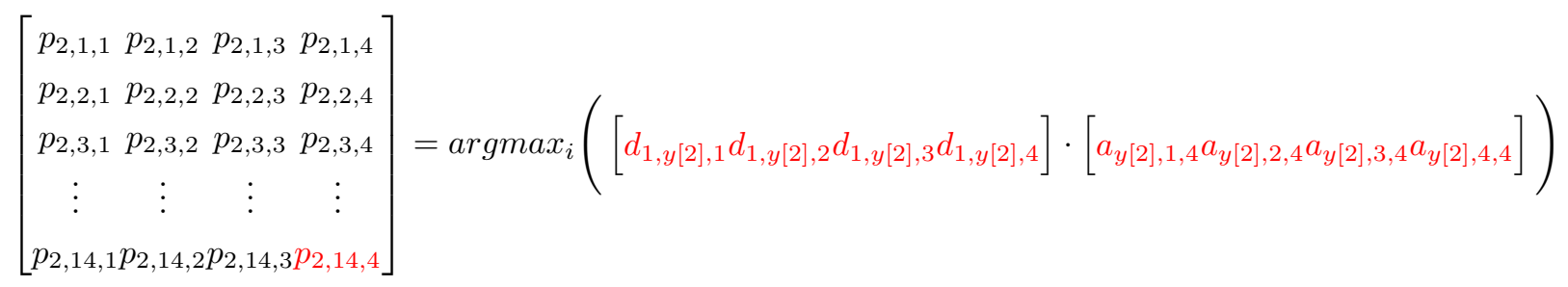




$$
p_{2,14,4}=\operatorname{argmax}\left(d_{1, y[2], 1} \times a_{y[2], 1,4}, d_{1, y[2], 2} \times a_{y[2], 2,4}, \cdots, d_{1, y[2], 4} \times a_{y[2], 4,4}\right)
$$

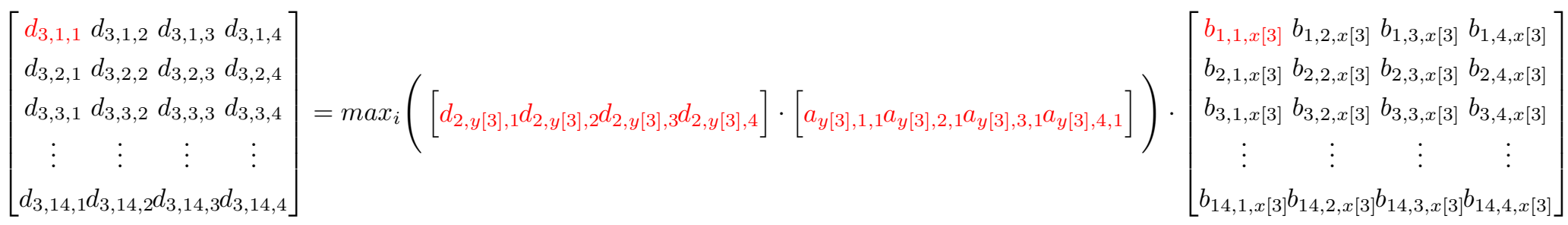

$$
d_{3,1,1}=\max \left(d_{2, y[3], 1} \times a_{y[3], 1,1}, d_{2, y[3], 2} \times a_{y[3], 2,1}, \cdots, d_{2, y[3], 4} \times a_{y[3], 4,1}\right) \times b_{1,1, x[3]}
$$

$$
\left[\begin{array}{cccc}
p_{3,1,1} & p_{3,1,2} & p_{3,1,3} & p_{3,1,4} \\
p_{3,2,1} & p_{3,2,2} & p_{3,2,3} & p_{3,2,4} \\
p_{3,3,1} & p_{3,3,2} & p_{3,3,3} & p_{3,3,4} \\
\vdots & \vdots & \vdots & \vdots \\
p_{3,14,1} & p_{3,14,2} & p_{3,14,3} & p_{3,14,4}
\end{array}\right]=\operatorname{argmax}_{i}\left(\left[d_{2, y[3], 1} d_{2, y[3], 2} d_{2, y[3], 3} d_{2, y[3], 4}\right] \cdot\left[a_{y[3], 1,1} a_{y[3], 2,1} a_{y[3], 3,1} a_{y[3], 4,1}\right]\right)
$$

$$
p_{3,1,1}=\operatorname{argmax}\left(d_{2, y[3], 1} \times a_{y[3], 1,1}, d_{2, y[3], 2} \times a_{y[3], 2,1}, \cdots, d_{2, y[3], 4} \times a_{y[3], 4,1}\right)
$$

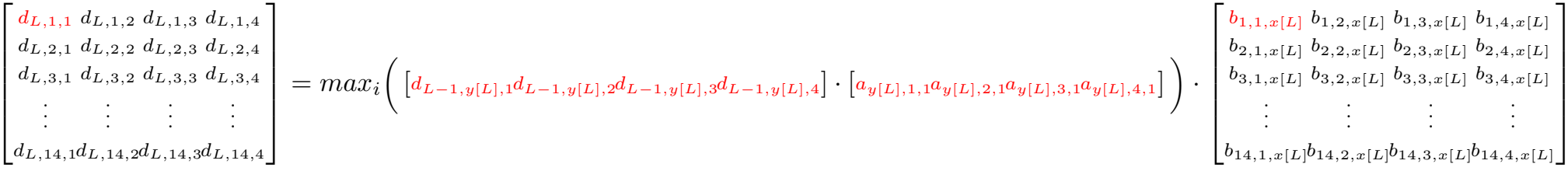

$$
d_{L, 1,1}=\max \left(d_{L-1, y[L], 1} \times a_{y[L], 1,1}, d_{L-1, y[L], 2} \times a_{y[L], 2,1}, \cdots, d_{L-1, y[L], 4} \times a_{y[L], 4,1}\right) \times b_{1,1, x[L]}
$$

$$
\left[\begin{array}{cccc}
p_{L, 1,1} & p_{L, 1,2} & p_{L, 1,3} & p_{L, 1,4} \\
p_{L, 2,1} & p_{L, 2,2} & p_{L, 2,3} & p_{L, 2,4} \\
p_{L, 3,1} & p_{L, 3,2} & p_{L, 3,3} & p_{L, 3,4} \\
\vdots & \vdots & \vdots & \vdots \\
p_{L, 14,1} & p_{L, 14,2} & p_{L, 14,3} & p_{L, 14,4}
\end{array}\right]=\operatorname{argmax}_{i}\left(\left[d_{L-1, y[L], 1} d_{L-1, y[L], 2} d_{L-1, y[L], 3} d_{L-1, y[L], 4}\right] \cdot\left[a_{y[L], 1,1} a_{y[L], 2,1} a_{y[L], 3,1} a_{y[L], 4,1}\right]\right)
$$


$p_{L, 1,1}=\operatorname{argmax}\left(d_{L-1, y[L], 1} \times a_{y[L], 1,1}, d_{L-1, y[L], 2} \times a_{y[L], 2,1}, \cdots, d_{L-1, y[L], 4} \times a_{y[L], 4,1}\right)$

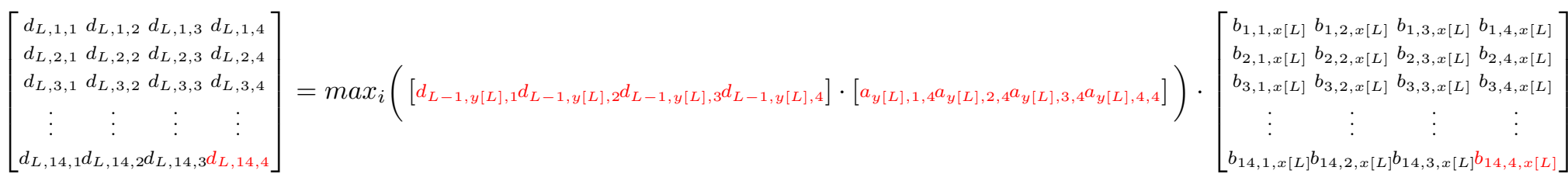

$$
d_{L, 14,4}=\max \left(d_{L-1, y[L], 1} \times a_{y[L], 1,4}, d_{L-1, y[L], 2} \times a_{y[L], 2,4}, \cdots, d_{L-1, y[L], 4} \times a_{y[L], 4,4}\right) \times b_{14,4, x[L]}
$$

$$
\left[\begin{array}{cccc}
p_{L, 1,1} & p_{L, 1,2} & p_{L, 1,3} & p_{L, 1,4} \\
p_{L, 2,1} & p_{L, 2,2} & p_{L, 2,3} & p_{L, 2,4} \\
p_{L, 3,1} & p_{L, 3,2} & p_{L, 3,3} & p_{L, 3,4} \\
\vdots & \vdots & \vdots & \vdots \\
p_{L, 14,1} & p_{L, 14,2} & p_{L, 14,3} & p_{L, 14,4}
\end{array}\right]=\operatorname{argmax}_{i}\left(\left[d_{L-1, y[L], 1} d_{L-1, y[L], 2} d_{L-1, y[L], 3} d_{L-1, y[L], 4}\right] \cdot\left[a_{y[L], 1,1} a_{y[L], 2,1} a_{y[L], 3,1} a_{y[L], 4,1}\right]\right)
$$

$$
p_{L, 14,4}=\operatorname{argmax}\left(d_{L-1, y[L], 1} \times a_{y[L], 1,4}, d_{L-1, y[L], 2} \times a_{y[L], 2,4}, \cdots, d_{L-1, y[L], 4} \times a_{y[L], 4,4}\right)
$$

- Termination:

$$
\left[\begin{array}{llllll}
\tau_{1} & \tau_{2} & \cdots & \tau_{L-2} & \tau_{L-1} & \tau_{L}
\end{array}\right]=\arg _{j} \max _{1 \leq i \leq 14,1 \leq j \leq 4}\left(\left[\begin{array}{cccc}
d_{L, 1,1} & d_{L, 1,2} & d_{L, 1,3} & d_{L, 1,4} \\
d_{L, 2,1} & d_{L, 2,2} & d_{L, 2,3} & d_{L, 2,4} \\
d_{L, 3,1} & d_{L, 3,2} & d_{L, 3,3} & d_{L, 3,4} \\
\vdots & \vdots & \vdots & \vdots \\
d_{L, 14,1} & d_{L, 14,2} & d_{L, 14,3} & d_{L, 14,4}
\end{array}\right]\right)
$$

- Backtracking:

$$
\begin{aligned}
& {\left[\begin{array}{llllll}
\tau_{1} & \tau_{2} & \cdots & \tau_{L-2} & \tau_{L-1} & \tau_{L}
\end{array}\right]=\psi\left(L, Y_{L}, \tau_{L}\right)} \\
& {\left[\begin{array}{llllll}
\tau_{1} & \tau_{2} & \cdots & \tau_{L-2} & \tau_{L-1} & \tau_{L}
\end{array}\right]=\psi\left(2, Y_{2}, \tau_{2}\right)}
\end{aligned}
$$




\section{List of Figures}

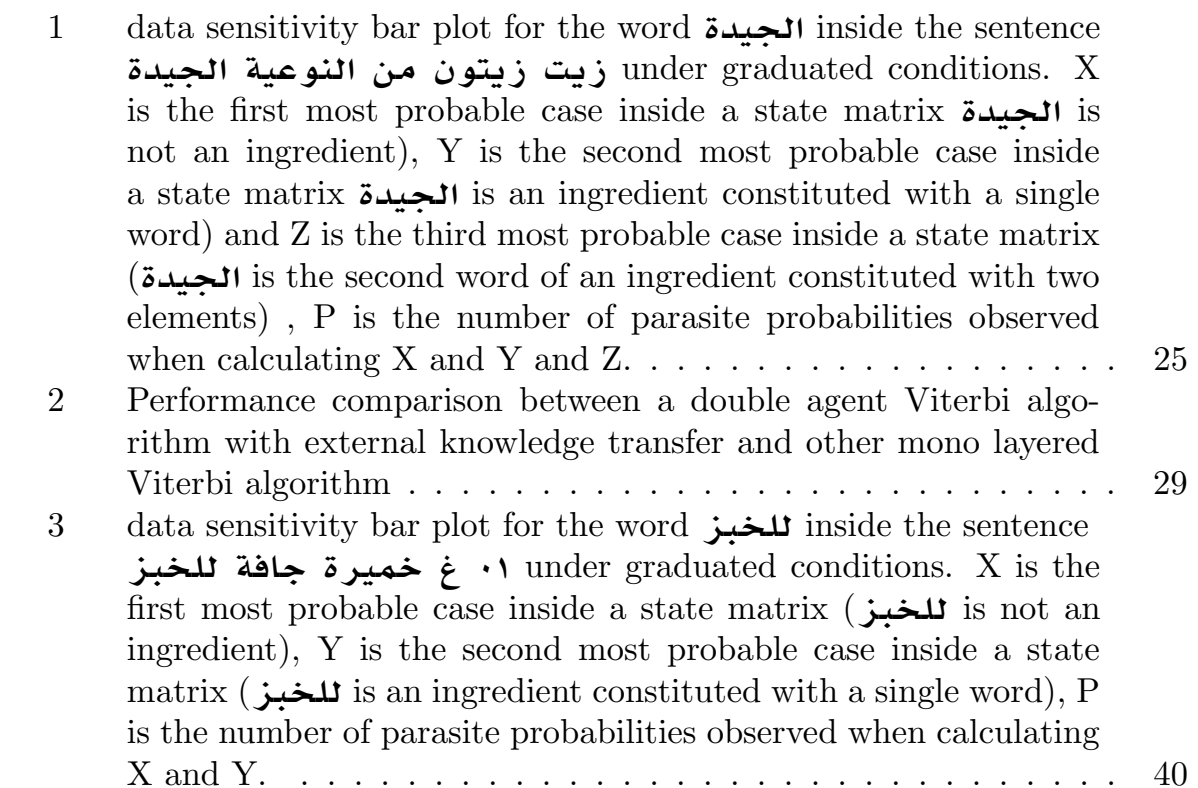

\section{List of Tables}

$1 \quad$ situations table for $\delta_{6}(1,1)$ for a second order HMM estimation with all the words are known . The probabilities $P\left(\Gamma_{r}=0 / \Gamma_{r-1}=0, \Gamma_{r}-2=0\right)$ and $P\left(V_{r}=" . " / \Gamma_{r}=0, \Gamma_{r-1}=0\right)$ are describing existing cases

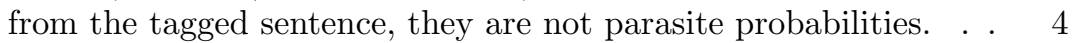

2 Situations table for $\delta_{6}(1,2)$ for a second order HMM estimation. The probabilities $P\left(\Gamma_{r}=0 / \Gamma_{r-1}=1, \Gamma_{r-2}=0\right)$ and $P\left(V_{r}=" . " / \Gamma_{r}=\phi, \Gamma_{r-1}=1\right)$ are describing existing cases from the tagged sentence, supposing that the word الحيدة is an ingredient. These probabilities are

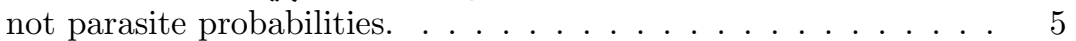

3 Situations table for $\delta_{6}(3,1)$ for a second order HMM estimation. The probability $P\left(\Gamma_{r}=0 / \Gamma_{r-1}=2, \Gamma_{r-2}=1\right)$ is a parasite probability because $\Gamma_{r-2}=1$ is not the real state of the word النو عية and $P\left(V_{r}="\right.$." $\left./ \Gamma_{r}=0, \Gamma_{r-1}=1\right)$ is not a parasite probability because it is describing an existing case from the tagged sentence after considering the word الجيدة as the second word of an ingredient. . . . . . . . . . . . . . . . 5 5 
4 situations table for $\delta_{6}(1,1)$ for a second order HMM estimation with all the words are known after adding the sentence زيت زيتو زيتون من النو عيـة الجيدة to the dataset. The probabilities $P\left(\Gamma_{r}=0 / \Gamma_{r-1}=0, \Gamma_{r-2}=0\right)$ and $P\left(V_{r}=" . " / \Gamma_{r}=0, \Gamma_{r-1}=0\right)$ are describing existing cases from the tagged sentence, they are not parasite probabilities. . . . . . . . . . . . . 6

$5 \quad$ Situations table for $\delta_{6}(2,1)$ for a second order HMM estimation with all the words are known after adding the sentence زيت زيتون من النو عية الجيدة $P\left(\Gamma_{r}=0 / \Gamma_{r-1}=1, \Gamma_{r-2}=0\right)$ and $P\left(V_{r}=" . " / \Gamma_{r}=0, \Gamma_{r-1}=1\right)$ are describing existing cases from the tagged sentence, supposing that the word الجيدة is an ingredient . These probabilities are not parasite probabilities. . . . . . . . . . . . . . 7

6 Situations table for $\delta_{6}(3,1)$ for a second order HMM estimation with all the words are known after adding the sentence زيت زيتون من النو عية الجيدة to the dataset. The probability $P\left(\Gamma_{r}=0 / \Gamma_{r-1}=2, \Gamma_{r-2}=1\right)$ is a parasite probability because $\Gamma_{r-2}=1$ is not the real state of the word النوعية and $P\left(V_{r}=" . " / \Gamma_{r}=0, \Gamma_{r-1}=1\right)$ is not a parasite probability because it is describing an existing case from the tagged sentence after considering the word الجيدة as the second word of an ingredient. .................... . . . 7

7 situations table for $\delta_{6}(1,1)$ for a second order HMM estimation with all the words are known after adding the sentence كعبـة to the dataset. The probabilities $P\left(\Gamma_{r}=0 / \Gamma_{r-1}=0, \Gamma_{r-2}=0\right)$ and $P\left(V_{r}="\right.$ ". $\left./ \Gamma_{r}=0, \Gamma_{r-1}=0\right)$ are describing existing cases from the tagged sentence, they are not parasite probabilities. . . . . . . . . . . . . . 8

8 Situations table for $\delta_{6}(2,1)$ for a second order HMM estimation with all the words are known after adding the sentence كعبـة

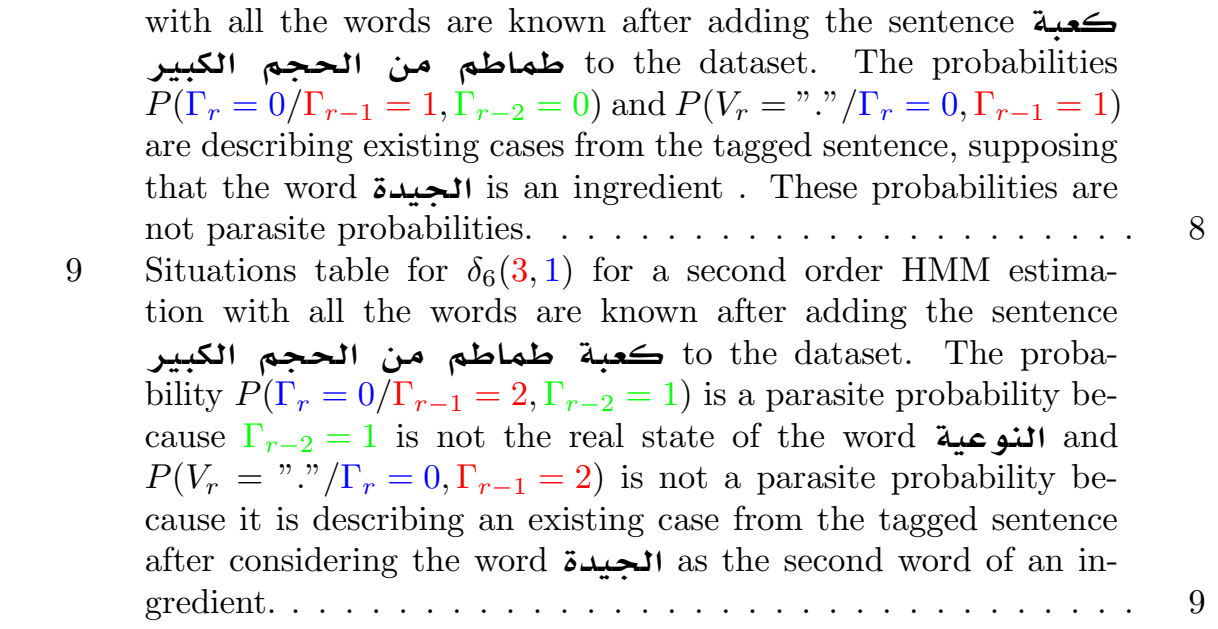


10 situations table for $\delta_{5}(7,1)+\log \left(a_{711}\right)$ for a second order HMM estimation, the probability $P\left(\Gamma_{r}=0 / \Gamma_{r-1}=0, T_{r-1}=\right.$ "نّ" a parasite probability because the POS tag of the word النو عيدة

is منعوت and not نعت 11

11 situations table for $\delta_{5}(7,2)+\log \left(a_{721}\right)$ for a second order HMM estimation, the probability $P\left(\Gamma_{r}=1 / \Gamma_{r-1}=0, T_{r-1}=\right.$ "عi" a parasite probability because the POS tag of the word النوعية

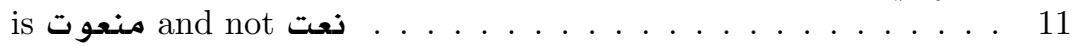

12 situations table for $\delta_{5}(7,3)+\log \left(a_{731}\right)$ for a second order HMM estimation, the probability $P\left(\Gamma_{r}=2 / \Gamma_{r-1}=3, T_{r-1}=\right.$ "نَ" a parasite probability because the POS tag of the word النو عيـة '،

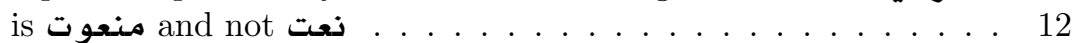

13 situations table for $\delta_{5}(7,1)+\log \left(a_{711}\right)$ for a second order HMM estimation after adding the sentence زيت زيتون من النو عية الجيدة to the dataset, the probability $P\left(\Gamma_{r}=0 / \Gamma_{r-1}=0, T_{r-1}=\right.$ "ن is a parasite probability because the POS tag of the word النو عيـة

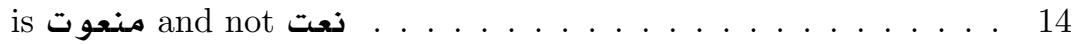

14 situations table for $\delta_{5}(7,2)+\log \left(a_{721}\right)$ for a second order HMM esزيت زيتون من النو عية الجيدة

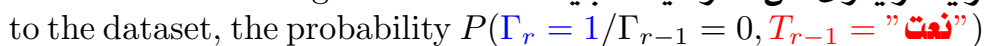
is a parasite probability because the POS tag of the word النوعية

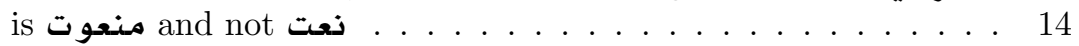

15 situations table for $\delta_{5}(7,3)+\log \left(a_{731}\right)$ for a second order HMM esزيت زيتون من النو عية الجيدة

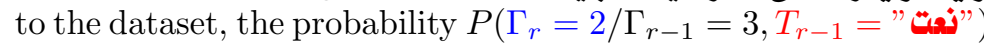
is a parasite probability because the POS tag of the word النو عية

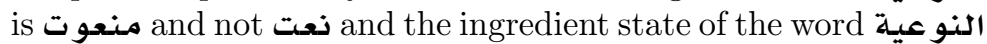
is $\Gamma_{r}=0$ and not $\Gamma_{r}=3$. . . . . . . . . . . . . . . 15

16 situations table for $\delta_{5}(7,1)+\log \left(a_{711}\right)$ for a second order HMM esكعبة طماطم من الحجم الكبير 1imation after adding the sentence

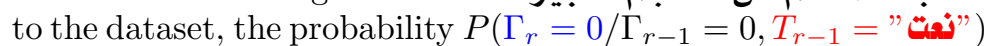
is a parasite probability because the POS tag of the word النو عية

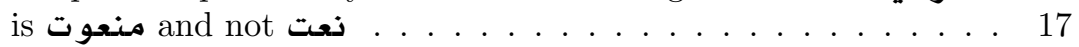

17 situations table for $\delta_{5}(7,2)+\log \left(a_{721}\right)$ for a second order HMM esكعبـة طماطم من الحجم الكبير 1imation after adding the sentence

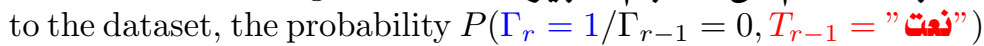
is a parasite probability because the POS tag of the word النو عية

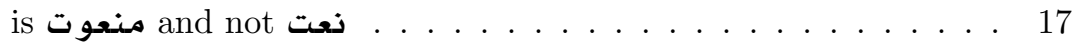

18 situations table for $\delta_{5}(7,3)+\log \left(a_{731}\right)$ for a second order HMM esكعبة طماطهم من الحجهم الكبير timation after adding the sentence

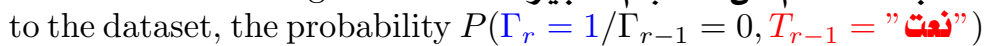
is a parasite probability because the POS tag of the word النو عيت . is منعوت and not نعت 18 
19 situations table for $\delta_{5}(7,1)+\log \left(a_{711}\right)$ for a double agent Viterbi

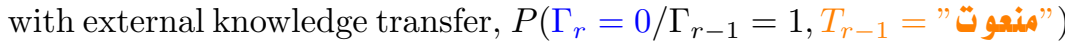
is a parasite probability because the ingredient state of the word النو

20 situations table for $\delta_{5}(7,2)+\log \left(a_{721}\right)$ for a double agent Viterbi

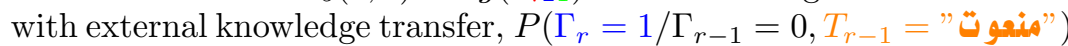
is a sain probability because the word منعوت is a النو عية and it

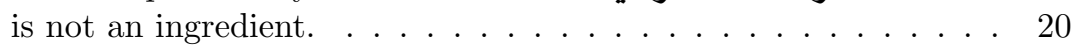

21 situations table for $\delta_{5}(7,3)+\log \left(a_{731}\right)$ for a double agent Viterbi

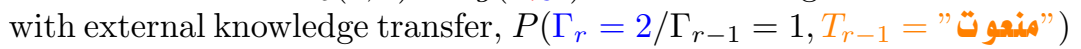
is a parasite probability because the word النوعية is not an in-

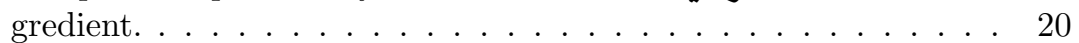

22 situations table for $\delta_{5}(7,1)+\log \left(a_{711}\right)$ for a double agent Viterbi

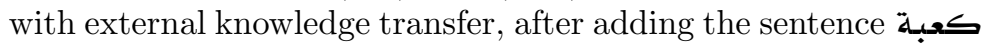
طماطم من الحجه الكبير to the dataset, $P\left(\Gamma_{r}=0 / \Gamma_{r-1}=\right.$

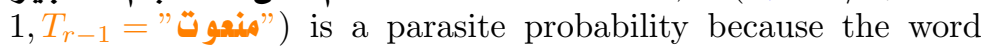
الجيدة have an ingredient state $\Gamma_{r}=0 . \ldots \ldots \ldots \ldots \ldots$

23 situations table for $\delta_{5}(7,2)+\log \left(a_{721}\right)$ for a double agent Viterbi

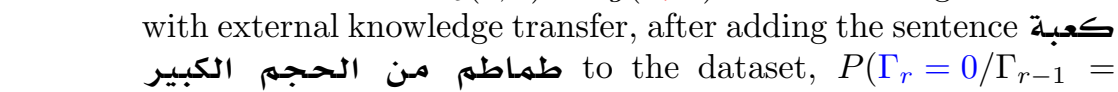

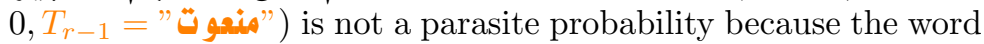

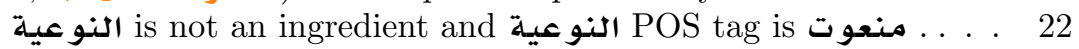

24 situations table for $\delta_{5}(7,3)+\log \left(a_{731}\right)$ for a double agent Viterbi

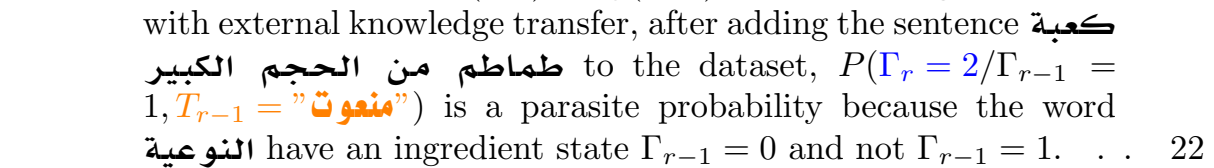

25 situations table for $\delta_{5}(7,1)+\log \left(a_{711}\right)$ for a double agent Viterbi

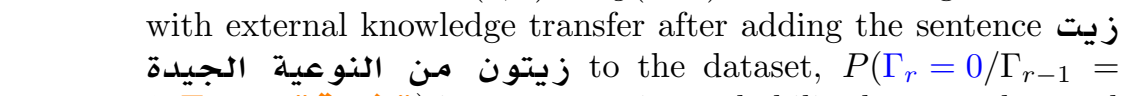

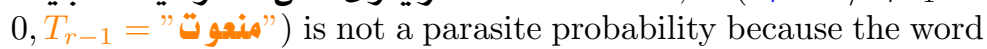
is not an ingredient and the word منعوت is النوعية given

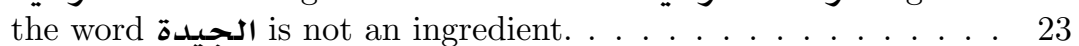

26 situations table for $\delta_{5}(7,2)+\log \left(a_{721}\right)$ for a double agent Viterbi with external knowledge transfer after adding the sentence زيت زيتون من النوعية الجيدة to the dataset, $P\left(\Gamma_{r}=1 / \Gamma_{r-1}=\right.$

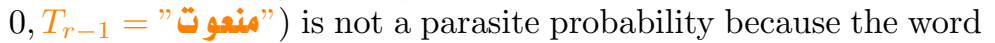
is not an ingredient and the word منعوت is النوعية is النو عيدة iven the word الجيدة is not an ingredient.|. . . . . . . . . . . . . . . 2. 24

27 situations table for $\delta_{5}(7,3)+\log \left(a_{731}\right)$ for a double agent Viterbi with external knowledge transfer after adding the sentence زيت زيتون من النوعية الجيدة to the dataset, $P\left(\Gamma_{r}=2 / \Gamma_{r-1}=\right.$ $1, T_{r-1}="$ "نsis") is a parasite probability because the word is not an ingredient in reality. . . . . . . . . . . . . . . . . 24 
28 Performances for each tag of a first order HMM , the trained dataset is used as a test dataset, and there is zero unknown words to predict . . . . . . . . . . . . . . . 26

29 Performances for each tag of a second order HMM , the trained dataset is used as a test dataset, and there is zero unknown words to predict . . . . . . . . . . . . . . . 27

30 Performance comparison using a simple double agent Viterbi with external knowledge transfer with $100 \%$ accuracy on first layer , the trained dataset is used as a test dataset to avoid unknown words prediction . . . . . . . . . . . . . . . . 28

31 Comparison of performances between a simple double agent Viterbi algorithm with external knowledge transfer and other HMM monoagent methods using the trained corpus as a testing dataset . . . 30

32 Performances of first order HMM used to predict ingredients state using 10 fold cross-validation with unknown word consideration, the test dataset have $20 \%$ sentences from the total dataset . . . 30

33 Performances of second order HMM used to predict ingredients state using 10 fold cross-validation with unknown word consideration, the test dataset have $20 \%$ sentences from the total dataset

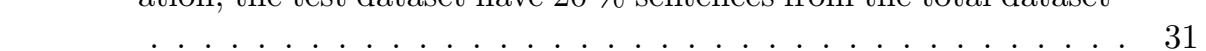

34 Average performances in predicting ingredients states with $\lambda=4$ \begin{tabular}{|l|l|} 
when accuracy is $100 \%$ on first layer with our ingredient extractor & 31
\end{tabular}

35 Average performances in predicting ingredients states with $\lambda=$ 4 when accuracy is $100 \%$ on first layer using a double layered Viterbi Algorithm . . . . . . . . . . . . 32

36 Comparison of performances between the 4 methods using $20 \%$ of the total dataset as a test dataset . . . . . . . . . . . 32

37 situations table for $\delta_{5}(12,1)+\log \left(a_{1211}\right)$ for a simple double agent Viterbi without unknown words consideration, the probability

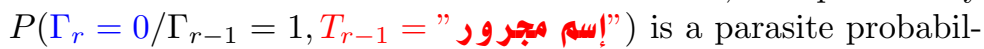
ity because the real POS tag for the word جعافو and the ingredient state of the word جافسة

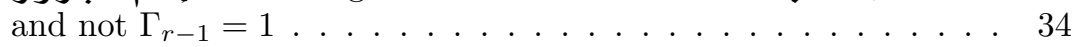

38 situations table for $\delta_{5}(12,2)+\log \left(a_{1221}\right)$ for a simple double agent Viterbi without unknown words consideration, the probability $P\left(\Gamma_{r}=0 / \Gamma_{r-1}=3, T_{r-1}="\right.$ " ity because the real POS tag for the word جعافة and the ingredient state of the word جافسهم مسجر ور

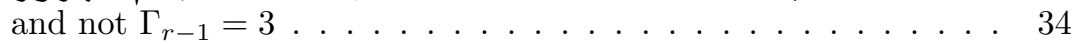

39 Situations table for $\delta_{5}(12,1)+\log \left(a_{1211}\right)$ for a simple double agent Viterbi with external knowledge transfer without unknown words consideration, the parasite probability probability $P\left(\Gamma_{r}=0 / \Gamma_{r-1}=\right.$ $1, T_{r-1}="$ "إس مجر و

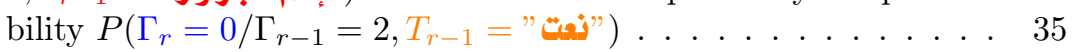


$40 \quad$ Situations table for $\delta_{5}(12,2)+\log \left(a_{1221}\right)$ for a simple double agent Viterbi with external knowledge transfer without unknown words consideration, the parasite probability probability $P\left(\Gamma_{r}=1 / \Gamma_{r-1}=\right.$ $3, T_{r-1}=$ " bility $P\left(\Gamma_{r}=1 / \Gamma_{r-1}=2, T_{r-1}="\right.$ "sis" $)$. . . . . . . . . . . 36

41 Situations table for $\delta_{5}(9,1)+\log \left(a_{911}\right)$ for a simple double agent Viterbi with unknown words consideration without external knowl-

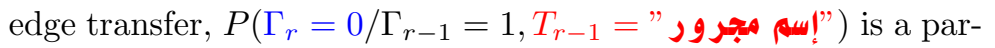
asite probability because the real ingredient state of the word جافة 37 is $\Gamma_{r-1}=2$ and the real POS tag of the word جعافت

42 Situations table for $\delta_{5}(9,2)+\log \left(a_{921}\right)$ for a simple double agent Viterbi with unknown words consideration, $P\left(\Gamma_{r}=1 / \Gamma_{r-1}=\right.$ $3, T_{r-1}="$ "إس مجرور ingredient state of the word جافة

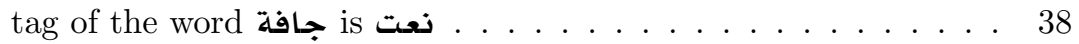

43 Situations table for $\delta_{5}(9,1)+\log \left(a_{911}\right)$ for a simple double agent Viterbi with external knowledge transfer with unknown words consideration, the parasite probability probability $P\left(\Gamma_{r}=0 / \Gamma_{r-1}=\right.$ $1, T_{r-1}="$ "اس山 مجرور bility $P\left(\Gamma_{r}=0 / \Gamma_{r-1}=2, T_{r-1}="\right.$ "ês" $)$. . . . . . . . . . . 38

44 Situations table for $\delta_{5}(9,2)+\log \left(a_{921}\right)$ for a primitive double agent Viterbi with external knowledge transfer with unknown words consideration, the parasite probability probability $P\left(\Gamma_{r}=1 / \Gamma_{r-1}=\right.$ $3, T_{r-1}="$ "إسى مجرور bility $P\left(\Gamma_{r}=1 / \Gamma_{r-1}=2, T_{r-1}="\right.$ "

\section{References}

Baklouti, Z. (2019, September 4). Hidden markov based mathematical model dedicated to extract ingredients from recipe text. https://doi.org/10.31219/osf.io/gvj45.

Bikel, D. M., Miller, S., Schwartz, R., \& Weischedel, R. (1998). Nymble: a high-performance learning name-finder. arXiv preprint cmp-lg/9803003.

Freitag, D., \& McCallum, A. (1999). Information extraction with hmms and shrinkage. In Proceedings of the aaai-99 workshop on machine learning for information extraction (pp. 31-36).

Freitag, D., \& McCallum, A. (2000). Information extraction with hmm structures learned by stochastic optimization. AAAI/IAAI, 2000, 584-589.

Leek, T. R. (1997). Information extraction using hidden markov models (Unpublished master's thesis). Citeseer.

Morwal, S., Jahan, N., \& Chopra, D. (2012). Named entity recognition using hidden markov model (hmm). International Journal on Natural Language Computing (IJNLC) Vol, 1. 
Seymore, K., McCallum, A., Rosenfeld, R., et al. (1999). Learning hidden markov model structure for information extraction. In Aaai-99 workshop on machine learning for information extraction (pp. 37-42).

Shah, L., Gaudani, H., \& Balani, P. (2016). Personalized recipe recommendation system using hybrid approach. International Journal of Advanced Research in Computer and Communication Engineering, 192-197.

Ueda, M., Asanuma, S., Miyawaki, Y., \& Nakajima, S. (2014). Recipe recommendation method by considering the users preference and ingredient quantity of target recipe. In Proceedings of the international multiconference of engineers and computer scientists (Vol. 1, pp. 12-14).

Zhu, Y., Chen, Y., Lu, Z., Pan, S. J., Xue, G.-R., Yu, Y., \& Yang, Q. (2011). Heterogeneous transfer learning for image classification. In Twenty-fifth aaai conference on artificial intelligence. 